Metals and Ceramics Division

\title{
STUDY AND ANALYSIS OF THE STRESS STATE IN A CERAMIC, BUTTON-HEAD, TENSILE SPECIMEN
}

\author{
M. G. Jenkins \\ M. K. Ferber \\ R. L. Martin \\ V. T. Jenkins \\ V. J. Tennery
}

NOTICE: This document contains information of a preliminary nature. It is subject to revision or correction and therefore does not represent a final report.

\author{
Prepared for the \\ U.S. Department of Energy \\ Assistant Secretary for Conservation and Renewable Energy \\ Office of Transportation Technologies \\ Advanced Materials Development Program \\ EE 0400000
}

Date Published - September 1991

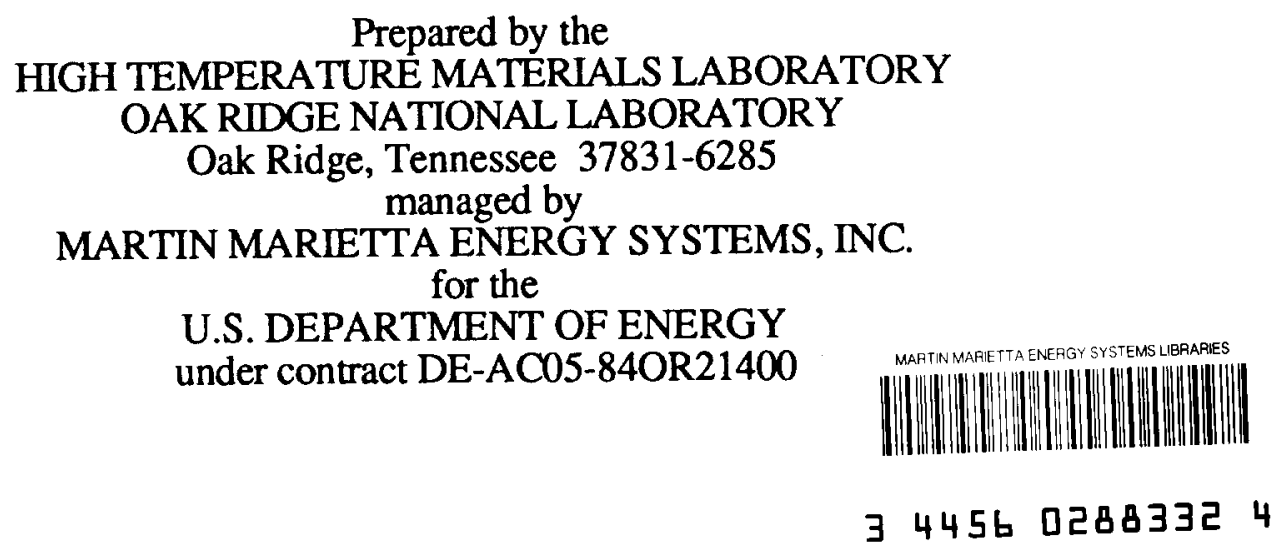


This report has been reproduced directly from the best available copy.

Available to DOE and DOE contractors from the Office of Scientific and Technical Information, P.O. Box 62, Oak Ridge, TN 37831; prices available from (615) 576-8401, FTS 626-8401.

Available to the public from the National Technical Information Service, U.S. Department of Commerce, 5285 Port Royal Rd., Springfield, VA 22161.

This report was prepared as an account of work sponsored by an agency of the United States Government. Neither the United States Government nor any agency thereof, nor any of their employees, makes any warranty, express or implied, or assumes any legal liability or responsibility for the accuracy, completeness, or usefulness of any information, apparatus, product, or process disclosed, or represents that its use would not infringe privately owned rights. Reference herein to any specific commercial product, process, or service by trade name, trademark, manufacturer, or otherwise, does not necessarily constitute or imply its endorsement, recommendation, or favoring by the United States Government or any agency thereot. The views and opinions of authors expressed herein do not necessarily state or reflect those of the United States Government or any agency thereof. 


\section{CONTENTS}

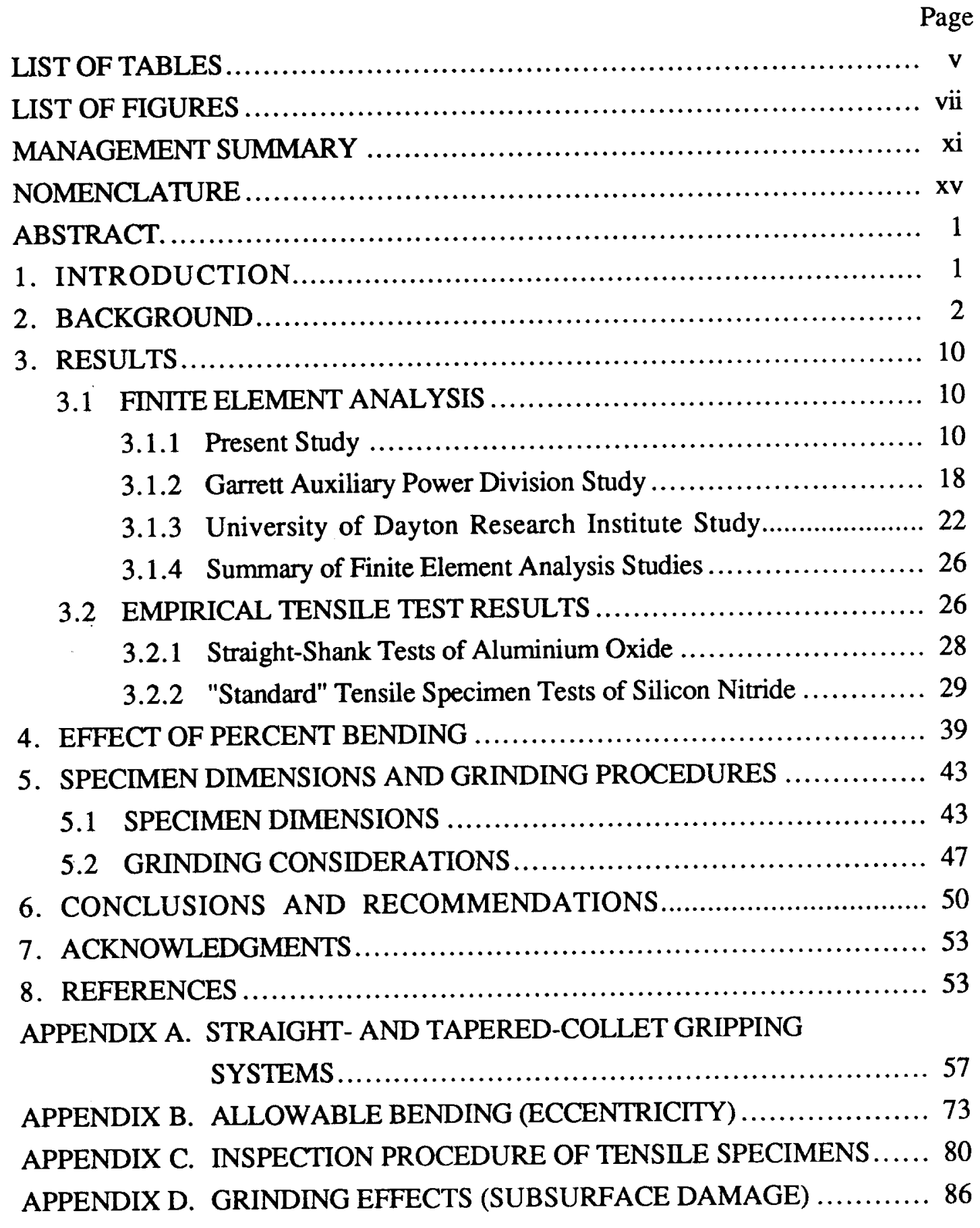




\section{BLANK PAGE}




\section{LIST OF TABLES}

Table

Page

1 Results of room-temperature tensile tests of silicon nitrides .............. 33

2 Recommended specifics of grinding procedure ........................ 49

C-1 Detailed steps for dimensional checking of complete tensile specimen in optical comparator .................................... 82

D-1 Factors influencing selection of abrasive and bond type...................... 88 


\section{BLANK PAGE}




\section{LIST OF FIGURES}

Figure

Page

1 Cylindrical button-head, tensile specimen............................. 3

2 Comparison of popular specimen geometries for testing ceramics ........... 5

3 Stress effects of bending in tensile tests ............................... 6

4 Common sources of eccentricity in tensile tests ....................... 8

5 Types of tensile specimen gripped heads.............................. 9

6 Examples of various gripping systems of button-head tensile specimens ..... 11

7 Finite element analysis models for straight- and tapered-collet

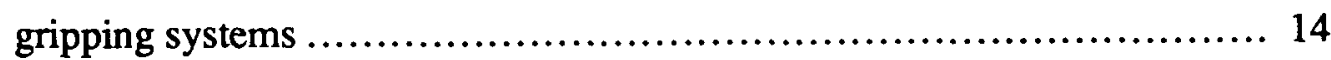

8 Normalized, maximum, tensile principal stresses versus normalized longitudinal distance for the straight-collet system in the present study ...... 15

9 Normalized, maximum, tensile principal stresses versus normalized longitudinal distance for the tapered-collet system in the present study....... 16

10 Typical normalized, maximum, tensile principal stresses versus normalized radial distance across the gage section for both gripping systems in the present study

11 Straight-collet finite element analysis model for the Garrett Auxiliary Power Division study

12 Effects of contact stress and button-head diameter on normalized stress for the Garrett Auxiliary Power Division study.............................. 20

13 Optimum shank diameters for various button-head diameters for the Garrett Auxiliary Power Division study....

14 Loading scenarios assumed in the University of Dayton Research Institute study

15 Straight-collet finite element analysis model for the University of Dayton Research Institute study.

16 Strain-gaged, straight-shank specimen .............................. 27

17 Maximum load at failure of the gripped area for tensile tests of aluminium oxide, straight-shank specimens .......................... 30

18 Percent bending at failure of the gripped area for tensile tests of aluminium oxide, straight-shank specimens 
19 Ultimate tensile strength versus percent bending for two, as-ground silicon nitrides, GTE PY6 and Norton NT 154, tested using straight-collet gripping systems with annealed copper collets.

20 Ultimate tensile strength versus percent bending for two, as-ground silicon nitrides, GTE PY6 and Norton NT154, tested using tapered-collet gripping systems.

21 Relationship between tensile strength and percent bending reported for a silicon nitride, SN220M, at room temperature .................... 38

22 Weibull tensile strength distributions for a silicon nitride, GTE PY6, at room temperature ............................................... 40

23 Weibull tensile strength distributions for a silicon nitride, Norton NT154, at room temperature ....................................... 41

24 Hypothesized effect on tensile strength distributions for various bending distributions................................................. 44

25 Normalized Weibull characteristic tensile strength versus percent bending ... 45

26 Comparison of properly and poorly machined specimens..................... 48

27 Possible modifications of tensile specimen................................. 52

A.1 Grip for straight-collet gripping system ............................. 58

A.2 Two-piece cover plate for straight-collet gripping system................. 59

A.3 Three-piece collets for straight-collet gripping system...................6 60

A.4 Two-piece short collets for straight-collet gripping system ............... 61

A.5 Procedure for using straight-collet gripping system........................6.62

A.6 Grip for tapered-collet gripping system..................................6 64

A.7 Modified grip adaptor for tapered-collet gripping system ................. 65

A.8 Collet (grip) holder and three-piece collets (grips) for tapered-collet gripping system ................................................. 66

A.9 Tapered-grip collets for preliminary machining and fabrication ............ 68

A.10 Illustration of the identification marks on each collet.......................... 69

A.11 Procedure for using tapered-collet gripping system..................... 70

B.1 Details of geometry considerations for Weibull analyses................. 74

B.2 Cumulative probability of failure versus nominal tensile strength for $5.0 \%$ bending, Weibull modus, $m=8$, Weibull characteristic tensile strength, So $=774 \mathrm{MPa}$ 
Figure

B.3 Normalized Weibull characteristic tensile strength versus percent bending ...................................................... 77

C. 1 Close-up view of inspection point on button-head radius ................ 80

C.2 Close-up view of opposite inspection point on button-head radius ......... 81

C.3 Inspection points in button-head radius and immediate shank region........ 81

D.1 Salient features that influence the grinding process ..................... 87

D.2 Measured fracture strength as a function of grit size ..................... 90

D.3 Measured residual stresses as a function of depth below surface

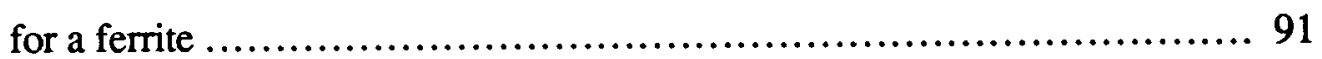

D.4 Measured fracture strength as a function of lapping depth ............... 91

D.5 Measured fracture strengths as a function of the removed, damaged material .................................................. 93

D.6 Method of tripping air flow of rotating wheel to feed coolant directly to the wheel/specimen interface 


\section{BLANK PAGE}




\section{MANAGEMENT SUMMARY}

\section{PROBLEM STATEMENT}

Unacceptably high percentages ( $>5 \%$ ) of nongage-section failures have occurred in tensile tests of ceramics using the Oak Ridge National Laboratory "standard" button-head tensile specimen. Tensile tests of ceramics in uniform stress fields are necessary to:

(1) determine strength distributions due to inherent flaws in large, stressed volumes;

(2) characterize the tensile stress-strain behavior for engineering design purposes;

(3) unambiguously quantify the effects of cyclic fatigue loading; and

(4) elucidate the tensile creep behavior at elevated temperatures.

\section{PROJECT SUMMARY}

The goals of the project were fourfold:

1. Verify incidences and circumstances of nongage-section failures, particularly in the gripped (button-head) section of the specimen.

2. Evaluate the stress state in the button-head tensile specimen to identify critical areas of concern for successful tests.

3. Evaluate the potential for reducing gripped section failures in straight- and tapered-collet gripping systems by failure testing straight-shank aluminium oxide specimens. Verify the choice of a "best" gripping system by failure testing high-strength, silicon-nitride specimens with gage sections.

4. Based on goals 2 and 3, recommend the "best" gripping system and possible modifications to the button-head, tensile specimen.

\section{CONCLUSIONS AND RECOMMENDATIONS}

1. Nongage-section failures, particularly in the gripped section of the specimen, are related to several causes: (a) mismatch at the grip/specimen interface due to improper 
dimensions, (b) improper surface finish or subsurface damage due to machining practices, and (c) localized contact stresses due to mismatches of collet dimensions or materials.

2. In both gripping systems (straight- and tapered-collet), finite element analyses showed that stress ratios in the button-head region existed that were equal to 0.75 to 1.0 of the gage-section stress. In addition, a stress ratio of $\sim 1.04$ exists at the transition area near both ends of the uniformly stressed gage section. Both of these higher stressed regions can lead to failures outside the gage section.

3. For straight-shanked specimens tested in conjunction with self-aligning, hydraulic, load-train couplers, the tapered-collet system can sustain similar loads but with lower percent bending before gripped-section failure compared to the straight-collet system with soft copper collets. An advantage of the straight-collet system is its ease and simplicity of use.

4. In the comparison of the straight- and tapered-collet gripping systems, no clear-cut "best" system exists. Similar maximum loads can be achieved with either the standard tapered-collet system or the straight-collet system with soft, deformable collets (e.g., annealed copper). The straight-collet system shows a statistically significant greater average percent bending of all the tests than shown by the tapered-collet system, although the tapered-collet system appears to produce decreasing strengths with increasing percent bending. The straight-collet system is simpler and more straightforward to use, as well as less sensitive to slight dimensional irregularities, than is the tapered-collet system.

5. The authors recommend that all specimens be strain-gaged with a minimum of four longitudinal strain gages equispaced around the circumference at the middle of the gage section. The strain gages will allow the monitoring of percent bending during testing to allow either a test to be stopped if percent bending is unacceptable $(>5.0 \%)$ or correlation of excessive percent bending with calculated strength.

6. The authors recommend that all specimens be dimensionally checked using highprecision metrology ( $\sim 1.0-\mu \mathrm{m}$ resolution) to screen unacceptable specimens before testing. Dimensional tolerances of $\pm 2.5 \mu \mathrm{m}$ are required to maintain proper 
grip/specimen interfaces and to minimize bending influences due to nonconcentricity of the gripped areas and the gage section.

7. The authors recommend that the grinding history of the tensile specimen be controlled closely to minimize subsurface machining damage that may lead to undesirable failures. Proper dimensions within the tolerances and proper arithmetic average $\left(R_{\mathbf{a}}\right)$ surface roughness of $0.4 \mu \mathrm{m}$ are still recommended but should not be the final determination of proper machining. Resinoid-bonded, diamond-abrasive wheels of at least 320 grit with maximum material removal rates (MRRs) of $\leq 645 \mathrm{~mm}^{3} /(\mathrm{mm} \cdot \mathrm{min}$ ) are recommended. In addition, water-based coolants and 1.0- $\mu$ m continuous-pass filtration are highly desirable.

8. The authors recommend that up to $5.0 \%$ bending can be consistently tolerated for fastfracture testing at room temperature without producing large variations in either the Weibull modulus or the Weibull characteristic strength.

9. The dimensions and geometry of the currently accepted button-head tensile specimen are acceptable for fast-fracture, creep, stess-relaxation, and cyclic-fatigue tensile testing at elevated temperatures. However, a possible redesign of the specimen might include a modified gripping section (conical head) with tapered collets and a straight-collet type of grip to reduce the incidences of failure of the gripped section and facilitate the installation of the collets and grips. An elliptical type of transition from the gage section would reduce the stress raiser to minimize transition area failures. 


\section{BLANK PAGE}




\section{NOMENCLATURE}

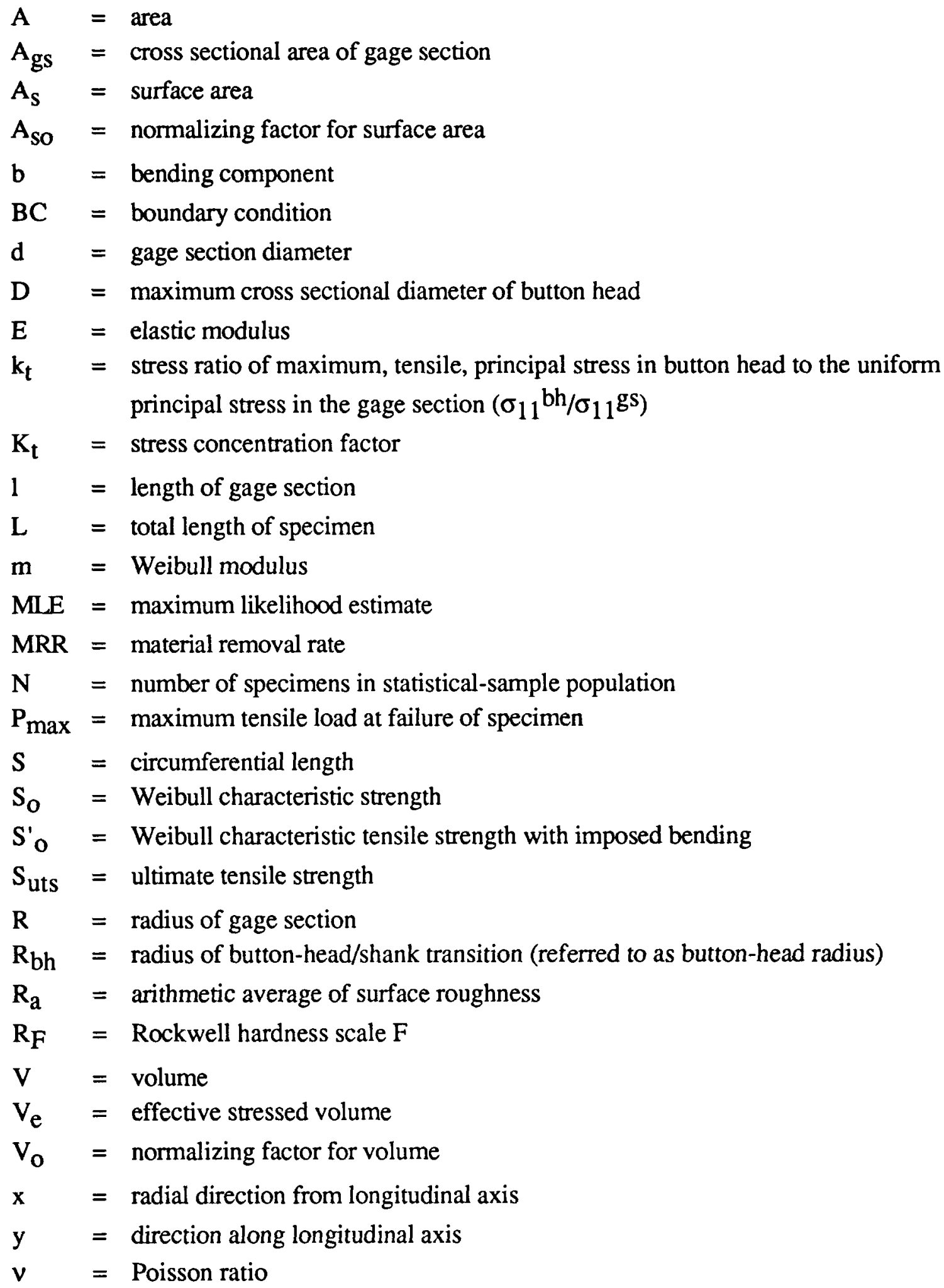




$$
\begin{array}{ll}
\sigma & =\text { actual stress } \\
\sigma_{\mathrm{a}} & =\text { applied stress } \\
\sigma_{\mathrm{r}} & =\text { residual stress } \\
\sigma_{11} \text { bh } & =\text { maximum, tensile principal stress in near button head } \\
\sigma_{11} \text { gs } & =\text { uniform principal stress in gage section } \\
\Theta & =\text { angle about the longitudinal axis in cylindrical coordinates }
\end{array}
$$




\title{
STUDY AND ANALYSIS OF THE STRESS STATE IN A CERAMIC, BUTTON-HEAD, TENSILE SPECIMEN*
}

\author{
M. G. Jenkins, M. K. Ferber, R. L. Martin, V. T. Jenkins, and V. J. Tennery
}

\begin{abstract}
The final results are reported for a study to identify and correct the causes of nongage-section failures (notably button-head failures) in ceramic tensile specimens observed in several laboratories. Numerical modeling of several candidate specimen gripping systems has shown inherent stress concentrations near the specimen button head at which the maximum stress may approach 75 to $100 \%$ of the gage-section stress for certain grip conditions. Empirical comparisons of both tapered- and straight-collet gripping systems revealed compromises in both systems. The straight-collet system, with deformable collets, is simpler to use but produces statistically significant greater average percent bending for all tests than those produced for the tapered-collet system, which is slightly more difficult to use. Empirical tensile tests of $\sim 50$ aluminium oxide and $\sim 50$ silicon nitride specimens were conducted to evaluate the loading capability of both gripping systems, the percent bending in each system, and the potential of consistently producing successful test results. These tests revealed that, due to variations in individual specimens or the individual specimen/grip interfaces, neither of the gripping systems can consistently produce bending of less than 3 to $4 \%$ at failure although occasional values of $\sim 0.5 \%$ bending were attained. Refinements of grinding procedures and dimensional measurement techniques have shown critical details in both the practices and consistency of machining necessary for achieving the dimensional tolerances while minimizing subsurface damage. Numerical integration techniques indicate that up to a consistent $5.0 \%$ bending during fast-fracture tests can be tolerated before large influences are detected in the determination of the Weibull modulus and the Weibull characteristic strength.
\end{abstract}

\section{INTRODUCTION}

Recent increases in the use of tensile tests (ultimate strength, stress rupture, cyclic fatigue, and creep) for structural ceramics, coupled with increasing ultimate strengths in these materials, have revealed a high incidence of nongage-section failures in the grinding-intensive, button-head tensile specimen. A drawing of the specimen currently in use at Oak Ridge

\footnotetext{
*Research sponsored by the U. S. Department of Energy, Assistant Secretary for Conservation and Renewable Energy, Office of Transportation Technologies, as part of the Ceramic Technology Project of the Materials Development Program, under contract DE-AC05-840R21400 with Martin Marietta Energy Systems, Inc.
} 
National Laboratory (ORNL) is shown in Fig. 1, which is a variation of a design that has been cited as having been in use several decades by many researchers. ${ }^{1}$ Tensile tests of ceramics in uniform stress fields are necessary to (1) determine strength distributions due to inherent flaws in large, stressed volumes; (2) characterize the tensile stress-strain behavior for engineering design purposes; (3) unambiguously quantify the effects of cyclic fatigue loading; and (4) elucidate the tensile creep behavior at elevated temperatures. ${ }^{1}$

The initial, critical need for successfully testing ceramics in uniform tension was to minimize the bending strains in the specimen gage section due to eccentric or off-axis loading. This need has been successfully addressed by the commercial availability of various load-train couplers reported to consistently restrict this bending to $<1 \%$ of the uniaxial tensile strain at specimen failure. ${ }^{2.3}$

However, a second critical need, which has not been adequately addressed, is the proper interface between the test machine grip and the specimen. Of particular concern are the stress concentrations at this interface due to specimen geometry changes, loading conditions, or improper fit between components. Because the nonyielding nature of ceramics does not allow for the accommodation of these stress concentrations, undesirable failures may occur at this specimen/grip interface rather than in the gage section.

This report reviews results of the study and analysis of the stress state in ceramic tensile specimens with particular emphasis on specimen-grip designs and nongage-section failures. Results are reported for numerical modeling of various gripping arrangements. The empirical measurement of percent bending for various test configurations is presented. Machining considerations are addressed, and dimensional checking procedures are outlined. Recommended steps are given for ensuring useful and successful tensile-testing results.

\section{BACKGROUND}

The primary motivation for testing materials in uniform, uniaxial stress fields is the need to control the stress-state variable to characterize the mechanical behavior of the material at given stress levels. Uniform stress fields within relatively large effective volumes of test material are important for evaluating inherent flaw distributions and the resulting statistical distributions of strengths. ${ }^{4,5}$ Common methods of controlling the stress states include the application of uniaxial and uniform compressive or tensile stresses to uniformly shaped volumes of material. ${ }^{1}$

Use of uniaxial stress tests has been limited, especially in regard to brittle, structural ceramics, because of the need for elaborate specimen preparation, the need for specialized 


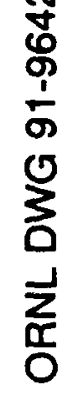

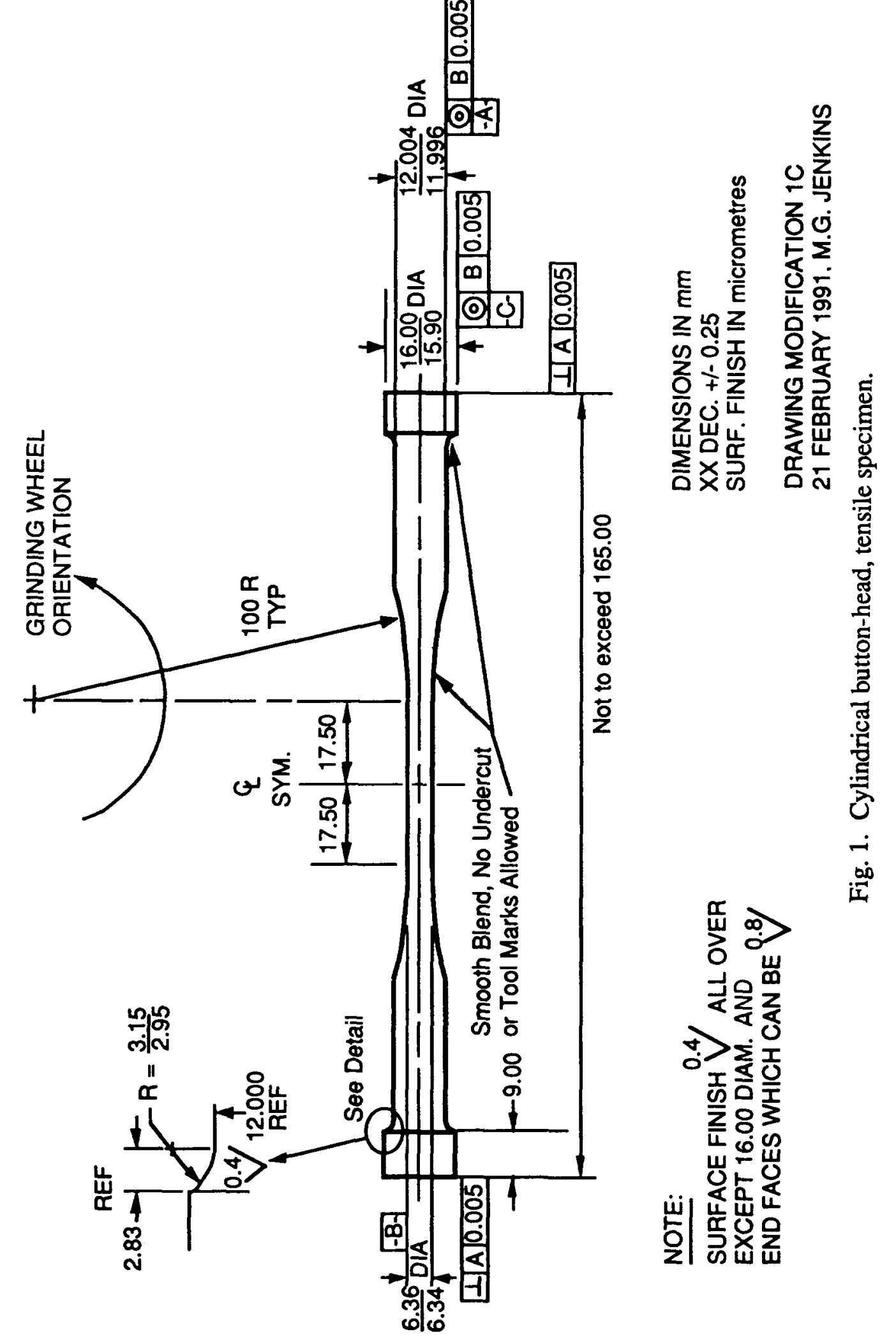


testing equipment (including specimen grips), and the difficulty of achieving the necessary uniform stress state. Therefore, the flexure bar has traditionally been the popular testing arrangement for ceramics because of the ease of fabrication of the specimen geometry, the efficient use of material, the simplicity of gripping and loading, and the seemingly straightforward analysis. However, use of the flexure bar for unequivocally characterizing a material behavior is limited, especially at elevated temperatures, because of the variation of the stress state over the cross section of the bar as well as the relatively small, equivalent stressed volume. Figure 2 illustrates the types of specimens, testing scenarios, and stress states in each condition: tension, flexure, and compression.

Because it is recognized that the limiting failure stress of brittle materials is tensile, it is necessary to test the material in a uniform tensile field to properly characterize the true, engineering, mechanical behavior. The most prominent type of tensile test is the direct "pull" method. Analytically, this test method is statically determinate, and the uniform stress state can be simply calculated as the axial load divided by the cross-sectional area of the gage section. For isotropic, homogeneous material, the two major obstacles to attaining this uniform stress in a tensile test are: 1

1. nonaxial (eccentric) loading resulting in bending stresses and 2. geometric stress concentrations in the gage section.

While obstacle 2 is a valid concern, it is also well recognized that most tensile specimens are designed with St. Venant's principle in mind. ${ }^{1}$ That is, stress concentrations decay with distance from the load application (geometrical perturbation) until the simplest, statically equivalent stress distribution is reached. Thus, the length of the uniform-diameter gage section is chosen to achieve a uniform, uniaxial stress field relatively distant from smooth reductions in the specimen cross section leading from the loading point to the gage section. Figure 3 illustrates this redistribution of stresses for both an ideal case [Fig. 3(a)] and for the case of eccentric loading [Fig. 3(b)], which was identified as obstacle 1 (Ref. 1).

Obstacle 1 is a widely recognized area of concern in tensile tests of materials. ${ }^{1-3,6-27}$ As shown in Fig. 3(b,) moments due to an eccentricity applied at the end of the specimen will not decay with distance from the ends. Although the stress distributions at each location in Figs. 3( $a)$ and $(b)$ are statically equivalent, the bending remains a part of all stress distributions in Fig. 3(b). It should be noted that eccentric loading at the ends of the specimen can exacerbate nongage-section failures because of the nonuniformity of the stress 

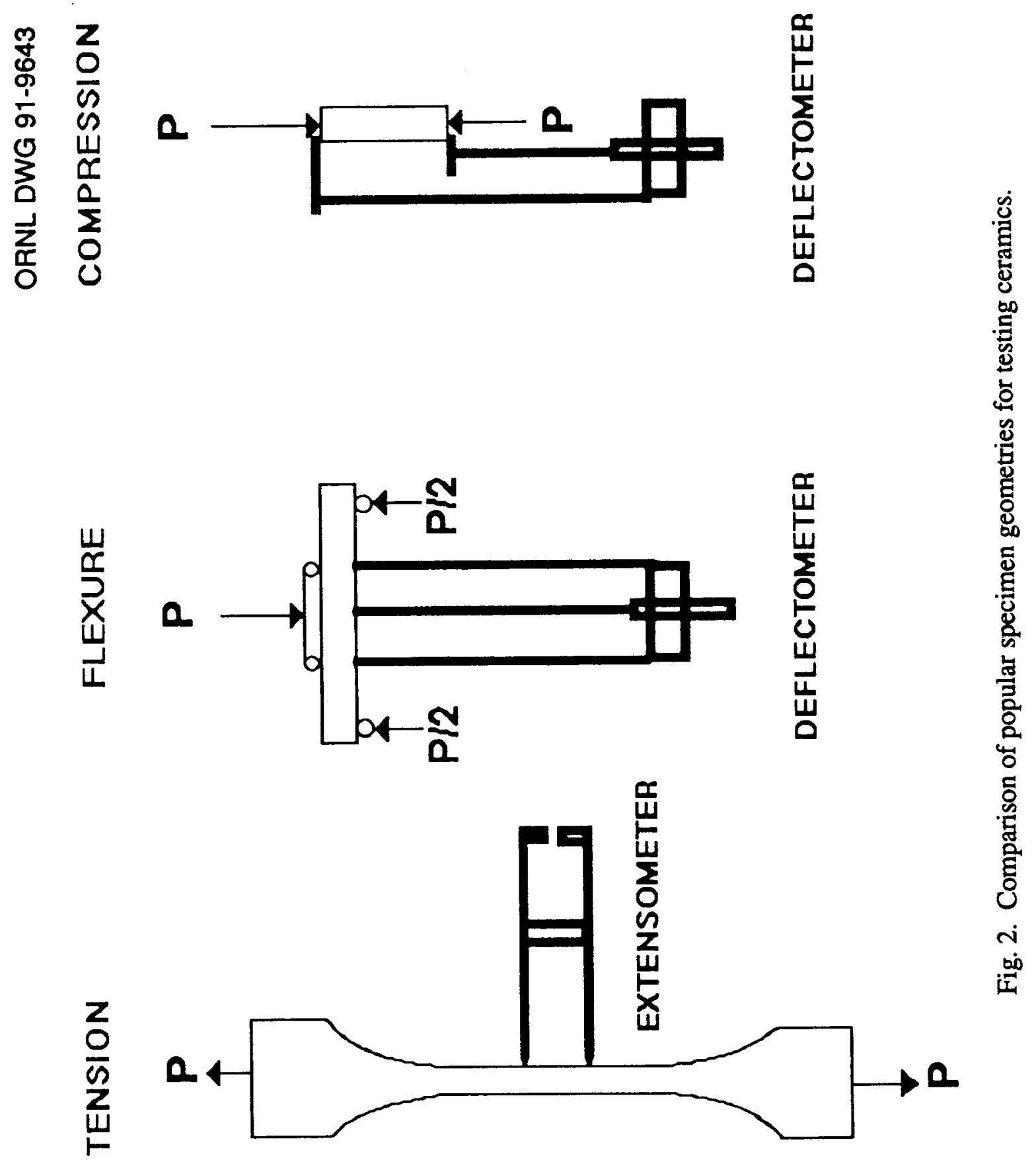
ORNL DWG 91-9644

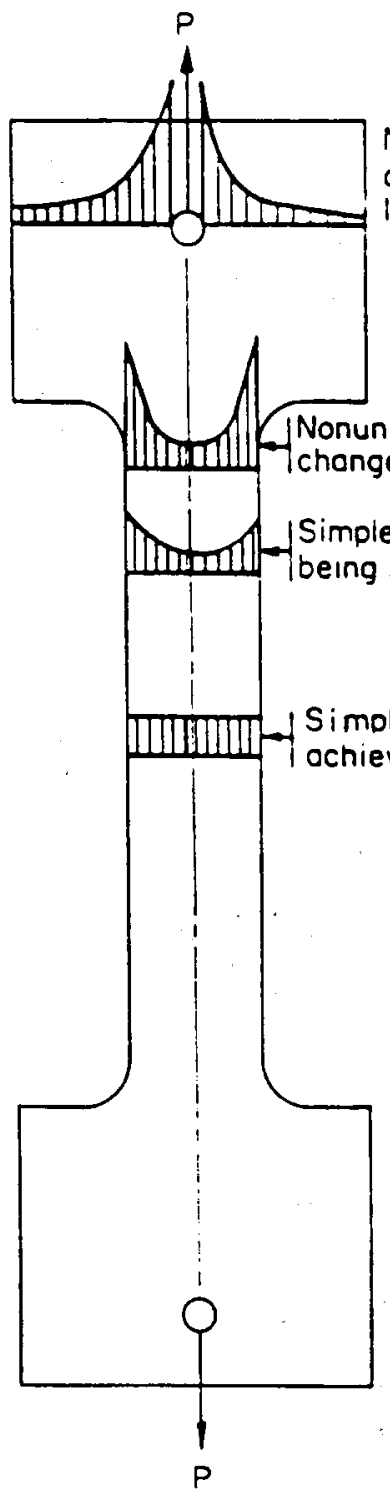

a. Axial Loading

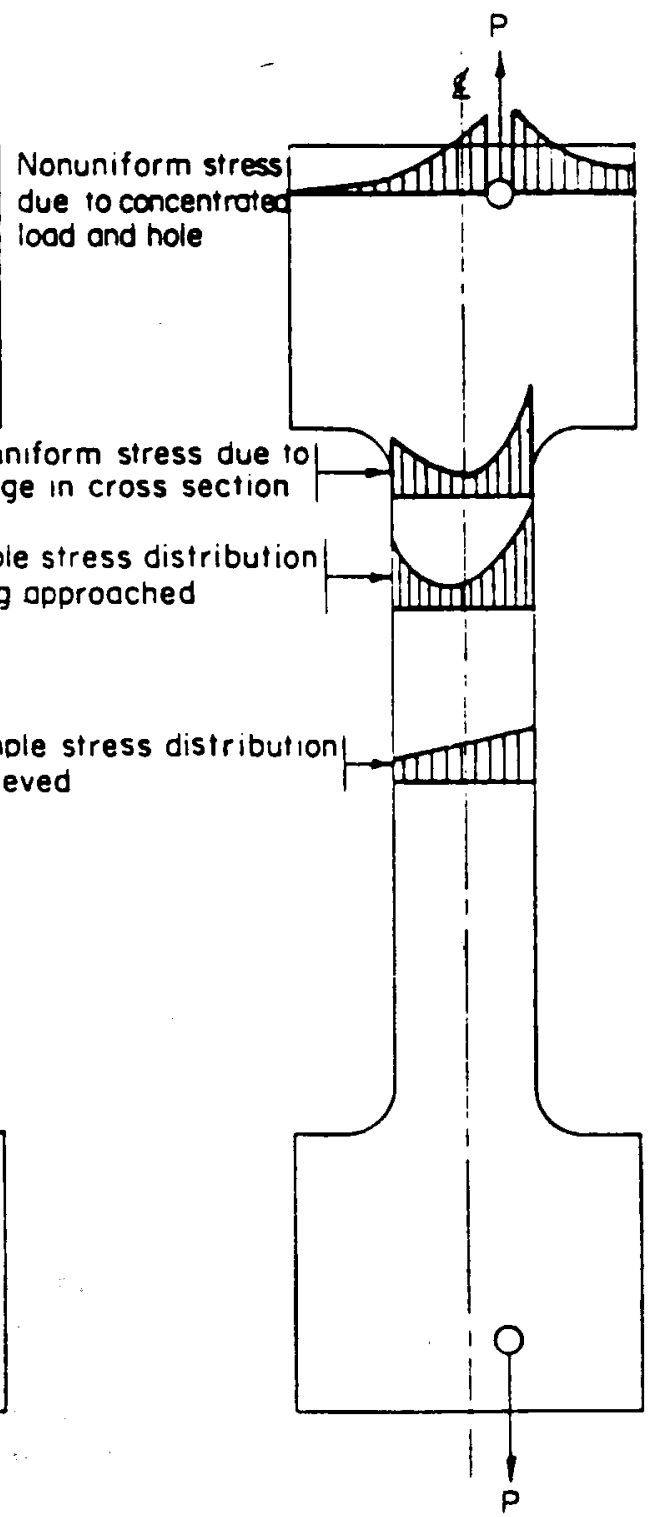

b. Eccentric Looding

Fig. 3. Stress effects of bending in tensile tests. Source: A. Rudnick, C. W. Marschall, W. H. Duckworth, and B. R. Emrich, The Evaluation and Interpretation of Mechanical Properties of Brittle Materials, AFML-TR-67316, Air Force Materials Laboratory, Wright Patterson Air Force Base, Ohio, 1968. 
distributions, particularly near changes in specimen geometry such as transition regions or button heads.

Figure 4 shows common sources of eccentricity in general. Off-center loading [Figs. $4(a)$ and $(b)$ ] is the most commonly recognized source of eccentricity. Constant eccentricity [Fig. 4(a)] is a first approximation but will most likely reflect an improperly aligned load train. Variable eccentricity [Fig. $4(b)]$ is more realistic and reflects the effects of variations in the specimen geometry and the specimen/grip interface. This condition tends to result in failures near the end with the greatest eccentricity, thus serving to skew failure origins toward changes in specimen geometry or even gripped regions. End moments [Fig. $4(c)$ ], which are reduced with increasing load, usually result from "kinks" in the load train although improper specimen/grip interfaces are also particular areas of concern. Imperfect specimen geometry [Fig. $4(d)$ ] is a troublesome area of concern and requires diligent machining practices and careful dimensional checking to eliminate any sources of error because once the eccentricity exists, there is no way to attain uniform stresses in the specimen. Finally, a less obvious potential source of eccentricity is twisting about the longitudinal axis [Fig. 4(e)], which may result from nonsymmetrical variations of elastic properties in the test material or the tendency for screw-thread joints in the load train to unwind. The question of what is acceptable eccentricity (bending) is discussed in Appendix A and Ref. 1.

Various systems have been developed to eliminate the sources of eccentricity just discussed. These systems have concentrated on removing the sources of eccentricity from the load train [Figs. 4(a), $(c)$, and $(e)$ ], and for the most part, these load-train couplers have proved successful. These couplers are generally passive devices (self-aligning and selfactuating) utilizing gas- or hydraulic-bearing supports. $2,3,7,9,20,25,28$

Accepting the efficacy of these couplers for eliminating the sources of eccentricity in the load train, the interface between the specimen and the grip, and the specimen itself becomes the object of attention. Gripping the specimen is a particularly important concern because an improper interface can lead to the introduction of eccentricity or, in the extreme case, failure of the specimen at the interface. In an earlier study, ${ }^{15}$ it was noted that in decreasing order of stability (in regard to eccentricity) were interfaces using specimens with taper heads, button heads, and finally threaded heads as shown in Fig. 5.

For ceramics, threaded heads were never really a viable option because of the difficulty of fabricating the threads; hence, the question of eccentricity was never a major concern. The taper head is attractive from a material/mechanics standpoint because the load transfer into the specimen is compressive, thus taking advantage of the superior compressive strengths of 
ORNL DWG 91-9645

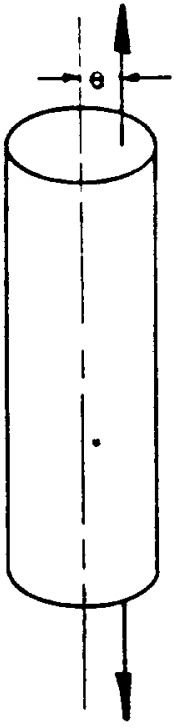

a. Off-Center Looding (Constont eccentricity)

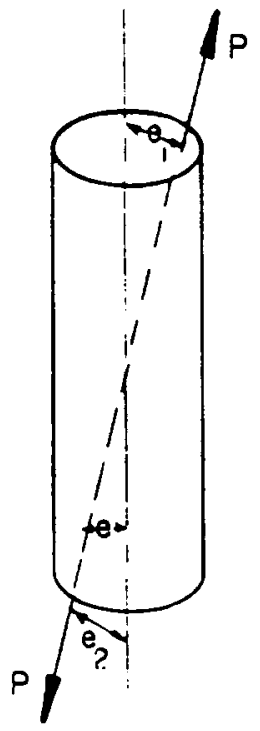

b. Off-Center Loading (Variable eccentricity)

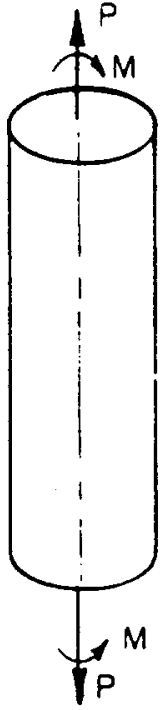

c. Moment Applied at End

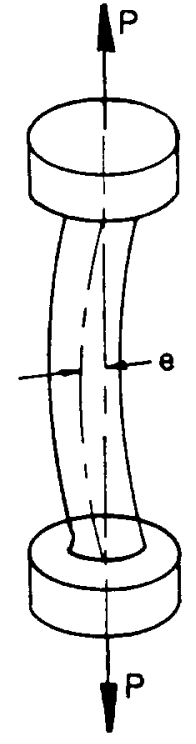

d. Curved Specimen

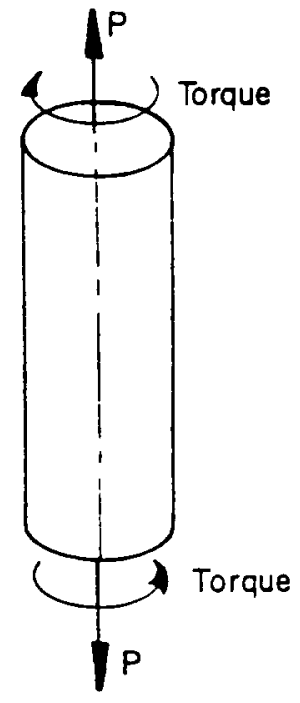

e. Twisting

Fig. 4. Common sources of eccentricity in tensile tests.

Source: A. Rudnick, C. W. Marschall, W. H. Duckworth, and B. R. Emrich, The Evaluation and Interpretation of Mechanical Properties of Brittle Materials, AFML-TR-67-316, Air Force Materials Laboratory, Wright Patterson Air Force Base, Ohio, 1968. 
ORNL DWG 91-9646

TAPERED

HEAD

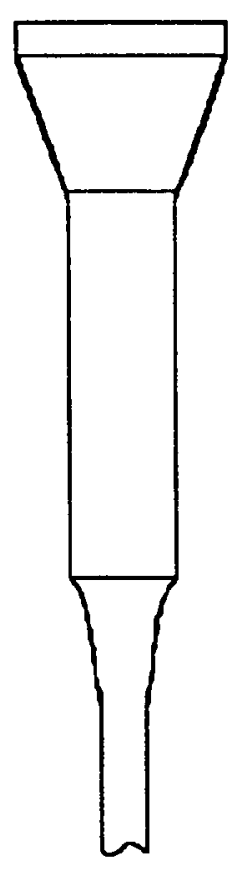

GREATEST

STABILITY
BUTTON

HEAD

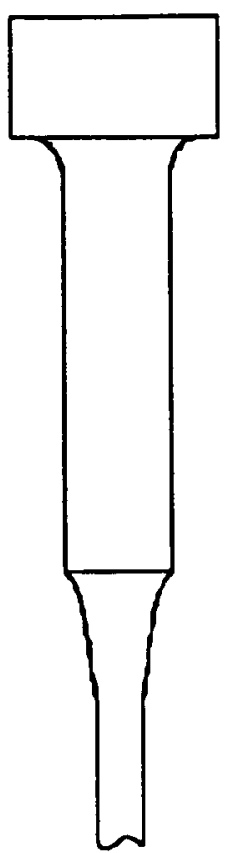

THREADED

HEAD

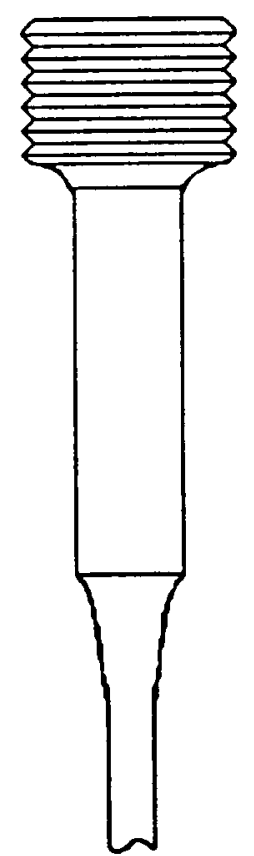

LEAST

STABILITY

Fig. 5. Types of tensile specimen gripped heads. 
most ceramics. However, fabrication problems with producing consistent and symmetrical taper angles, as well as the need for a large amount of closely toleranced machining along the interface surface, caused a decrease in interest in this geometry. ${ }^{15}$ Therefore, the button-head specimen has subsequently been the object of considerable variations in grip designs as illustrated in Fig. 6.

This study investigates the stress state in a ceramic, button-head, tensile specimen and evaluates several gripping systems to determine the proper arrangement to minimize both the eccentricity (bending) in the gage section and the incidence of nongage-section failures (button-head failures). Particular emphasis was placed on straight- and tapered-collet gripping systems [Figs. 6(a) through $(d)$ ]; these appeared to have the greatest potential for testing applications because of their "popularity." $2,20,25,28,29$

\section{RESULTS}

Results are reported for numerical modeling of various gripping arrangements. The empirical measurement of percent bending, ultimate strength, and load carrying ability for various test configurations is presented. Machining considerations are addressed, and dimensional checking procedures are outlined. Recommended steps are given for ensuring useful and successful tensile-testing results.

\subsection{FINITE ELEMENT ANALYSIS}

Recently, several finite element studies have been undertaken to understand the stress state in the button-head region of the specimen design illustrated in Fig. 1. Work conducted in this study is discussed, followed by discussions of efforts conducted at Garrett Auxiliary Power Division (GAPD)* and the University of Dayton Research Institute (UDRI). ${ }^{29}$

\subsubsection{Present Study}

Finite element analysis (FEA) techniques were applied to ascertain the stress distributions in the specimen as influenced by the straight- and tapered-collet gripping systems. The objective of the study was to investigate the interaction between the collets and the specimen as well as to identify key parameters, such as friction at the collet/specimen interfaces, that might influence the stress distributions in the button-head area.

"D. Carruthers and J. Cuccio, "Button-head Failures Necessitate Tensile Specimen Redesign," unpublished presentation at Bi-annual Advanced Turbine Technology Applications Project Meeting, Garrett Auxiliary Power Division, Phoenix, Ariz., March 29, 1989. 
ORNL DWG 91-9647
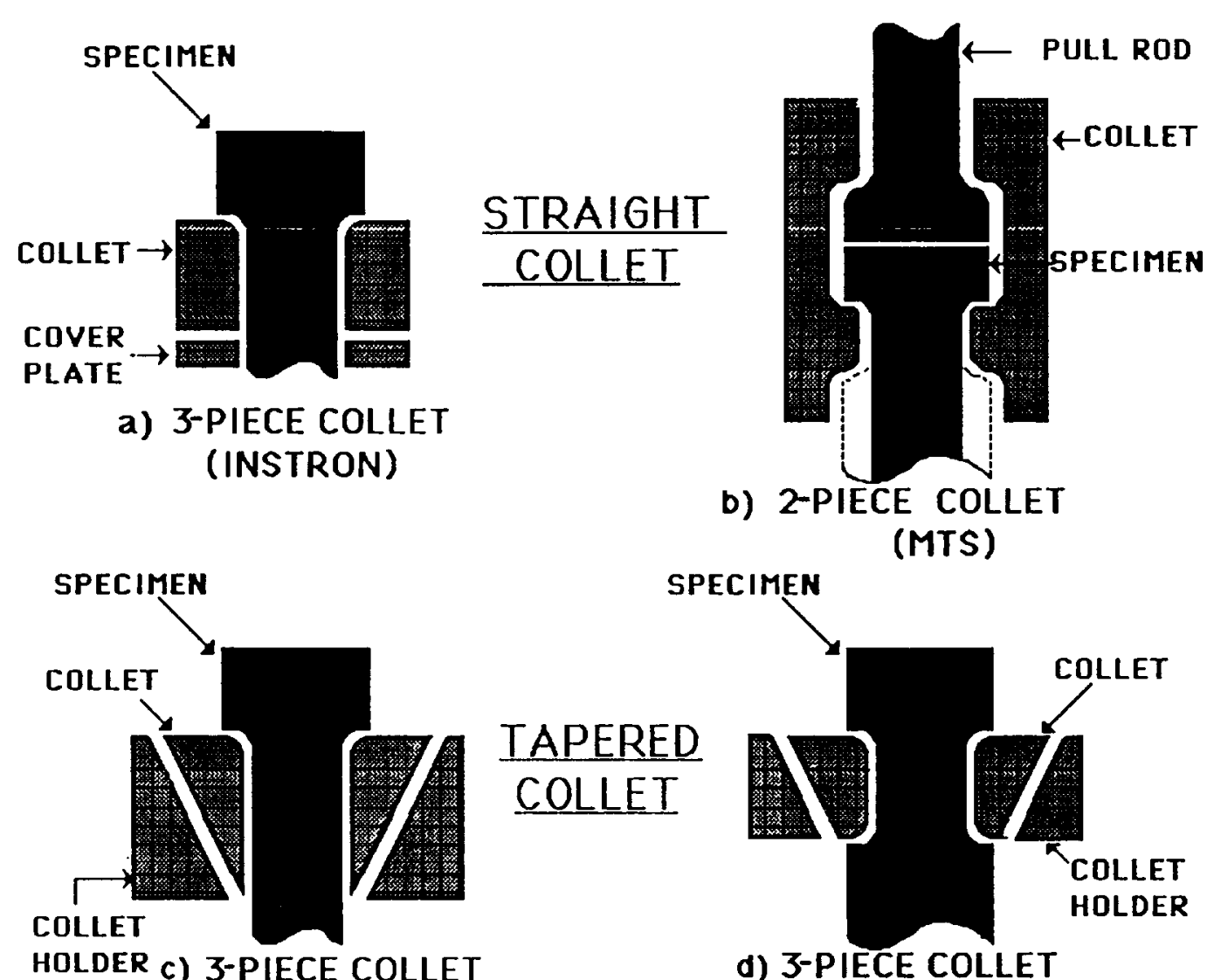

a) 3-PIECE COLLET
(INSTRON)

b) 2-PIECE COLLET (MTS) (K. LIU, ORNL)

d) 3-PIECE COLLET (So RI)

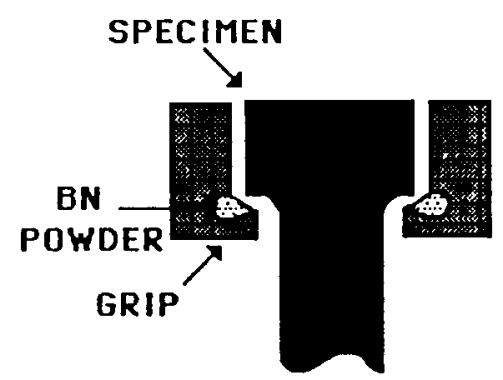

e) 2-PIECE GRIP

(F.F. LANGE, ROCKWELL)

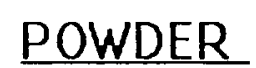
GRIP

Fig. 6. Examples of various gripping systems of button-head tensile specimens. 
COSMOS $/ \mathrm{M}^{*}$, a commercial personal computer (PC)-based finite element code running in the protected mode of the Intel 80386 processor, was used in conjunction with the sophisticated geometric modeler, GEOSTAR, to perform analyses of the specimen and the gripping systems. ${ }^{31}$

The axisymmetric ( $y$-axis along the longitudinal axis of the specimen), quartersymmetry models were composed of $\sim 7,500$ to 9,500 degrees of freedom (DOFs). Twodimensional, four-noded plane elements were used to model the structure of the specimen and collets. Nonlinear, frictional, "gap" elements* were used to model the interfaces between the specimen and collet at both the button-head radius and the shank. Because these particular "gap" elements did not contribute to the overall stiffness matrix of the specimen/collet system, ultra-low stiffness, two-dimensional truss elements were used to provide remote mathematical constraints to the collet in the necessary directions. It should be noted that the "gap" elements used in this case were not true surface contact elements and, therefore, the resulting stress values should be interpreted on only a relative basis. Specimen dimensions were those as shown in Fig. 1 except for the button-head radius, which was changed to match the particular gripping system as previously discussed. Applicable grip dimensions were taken from the drawings contained in Appendix A.

For the specimen, material-symmetry boundary conditions (BCs) were applied along the longitudinal axis and at the "free" end of the gage section. These BCs were modeled as rollers where free, nodal displacements were allowed parallel to the surface, but the nodal displacements were constrained normal to the surface. Similar BCs were applied to the collet systems to simulate the constraints of the gripping arrangement.

The linear-elastic material properties of the specimen were those of an isotropic polycrystalline silicon nitride at room temperature with an elastic modulus of $E=310 \mathrm{GPa}$ and a Poisson ratio, $v=0.27$ (Ref. 30). The properties of the collets were those of steel in which $E=200 \mathrm{GPa}$ and $v=0.3$ (Ref. 30 ). As noted, the truss elements were used only for mathematical constraint; thus, $\mathrm{E}=1 \times 10^{-6} \mathrm{GPa}$ and $\mathrm{v}=0.3$.

Because of the nonlinear behavior of the gap elements, the element pressure loading on the collets was applied in incremental steps allowing structural equilibrium to be reached at each step by an iterative process. The size and number of time steps, as well as the refinement of the element mesh, were determined manually through a trial-and-error method of examining the convergence of the nodal displacements. 1989.

${ }^{*}$ COSMOS/m 1.52A, Structural Research \& Analysis Corp., Santa Monica, Calif., 
The two models, which include the specimen and gripping systems, are shown in Fig. 7. Figures 8 and 9 illustrate the variation of the normalized, maximum, tensile principal stresses $\left(\sigma_{11} / \sigma_{11} \mathrm{gs}\right)$ as a function of normalized longitudinal distance $[\mathrm{y} /(\mathrm{L} / 2)]$ from the center of the specimen.

Two anomalies in the stress distributions should be noted in Figs. 8 and 9. The first is that, for both gripping systems, the uniform, uniaxial, stress state in the gage section $[0<y /(L / 2)<0.212]$ is perturbed as the gage section begins the transition into the large radius leading to the shank. This perturbation, illustrated in Fig. 10, results in a surface stress raiser $\sim 4 \%$ greater than the uniaxial, gage-section stress. Thus, for a uniaxially aligned testing system and a defect-free material, the distribution of the locations of gage-section failures may tend to skew toward the surface of this transition. This stress raiser could be reduced $<0.5 \%$ if an elliptical or streamline transition were used in place of the large radius, circular transition. ${ }^{31}$ Investigation of this type of transition would be appropriate for the redesign of the existing tensile specimen.

The second stress anomaly is in the area of the button-head radius. As shown in Fig. 8 for the straight-collet system, the stress ratio, $\mathrm{k}_{\mathrm{t}}$ (i.e., the ratio of the maximum tensile principal stresses where $\mathrm{k}_{\mathrm{t}}=\sigma_{11} \mathrm{bh} / \sigma_{11} \mathrm{gs}$ ), between the button head and the gage section is $\sim 0.72$ when a coefficient of friction, $\mu=0.5,{ }^{*}$ is used for the collet/specimen (steel/silicon nitride) interface. For the case of $\mu=0.0$ (frictionless), $\mathrm{k}_{\mathrm{t}}=0.69$, thus indicating that friction may not be as critical a contribution to the stress state as the inherent stress concentration of both the button-head geometry and the loading condition of the straightcollet system. In Fig. 9 for the tapered-collet system, $k_{t}=0.75$ when the collets contact the button head from the beginning of the loading sequence. This situation simulates the installation of the collets with no regard to preloading the collet against the specimen shank. However, if a slight preload is simulated at the collet/specimen interface, $k_{t}=0.35$ because a greater portion of the load is transferred directly into the shank.

The following conclusions were made from this FEA study:

1. The stress distribution in the gage section is, for the most part, uniform and uniaxial except for a small $(\sim 4 \%)$ stress raiser near the transition into the shank.

2. The stress concentration in the button-head radius of the contacting straight-collet system may cause the stresses in the button-head region and the gage section to

${ }^{\text {*} P . ~ J . ~ B l a u, ~ p e r s o n a l ~ c o m m u n i c a t i o n ~ t o ~ M . ~ G . ~ J e n k i n s, ~ O a k ~ R i d g e ~ N a t l . ~ L a b ., ~}$ Oak Ridge, Tenn., July 15, 1989. 
ORNL DWG 91-9648

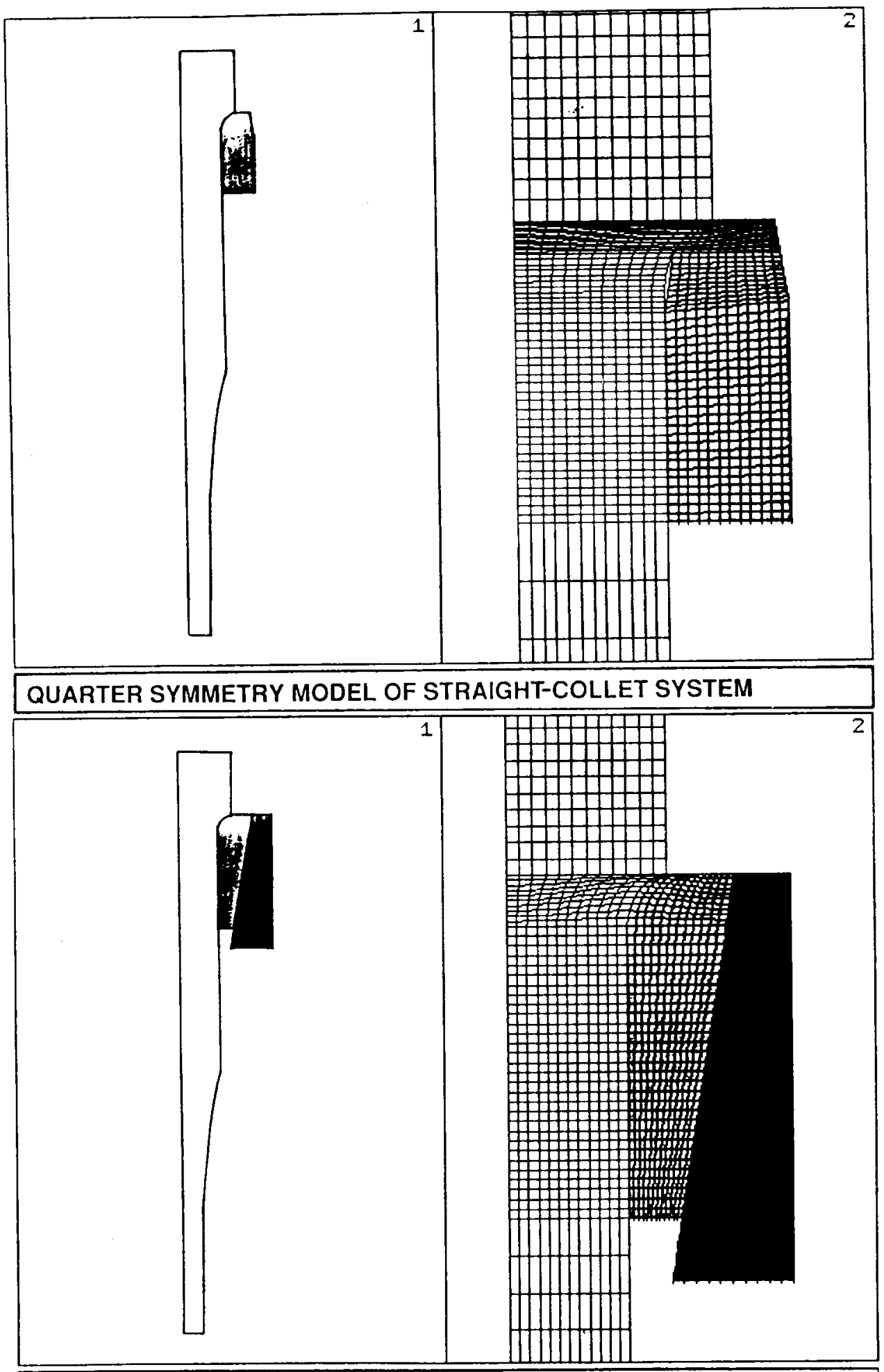

QUARTER SYMMETRY MODEL OF TAPERED-COLLET SYSTEM

Fig. 7. Finite element analysis models for straight- and tapered-collet gripping systems. 

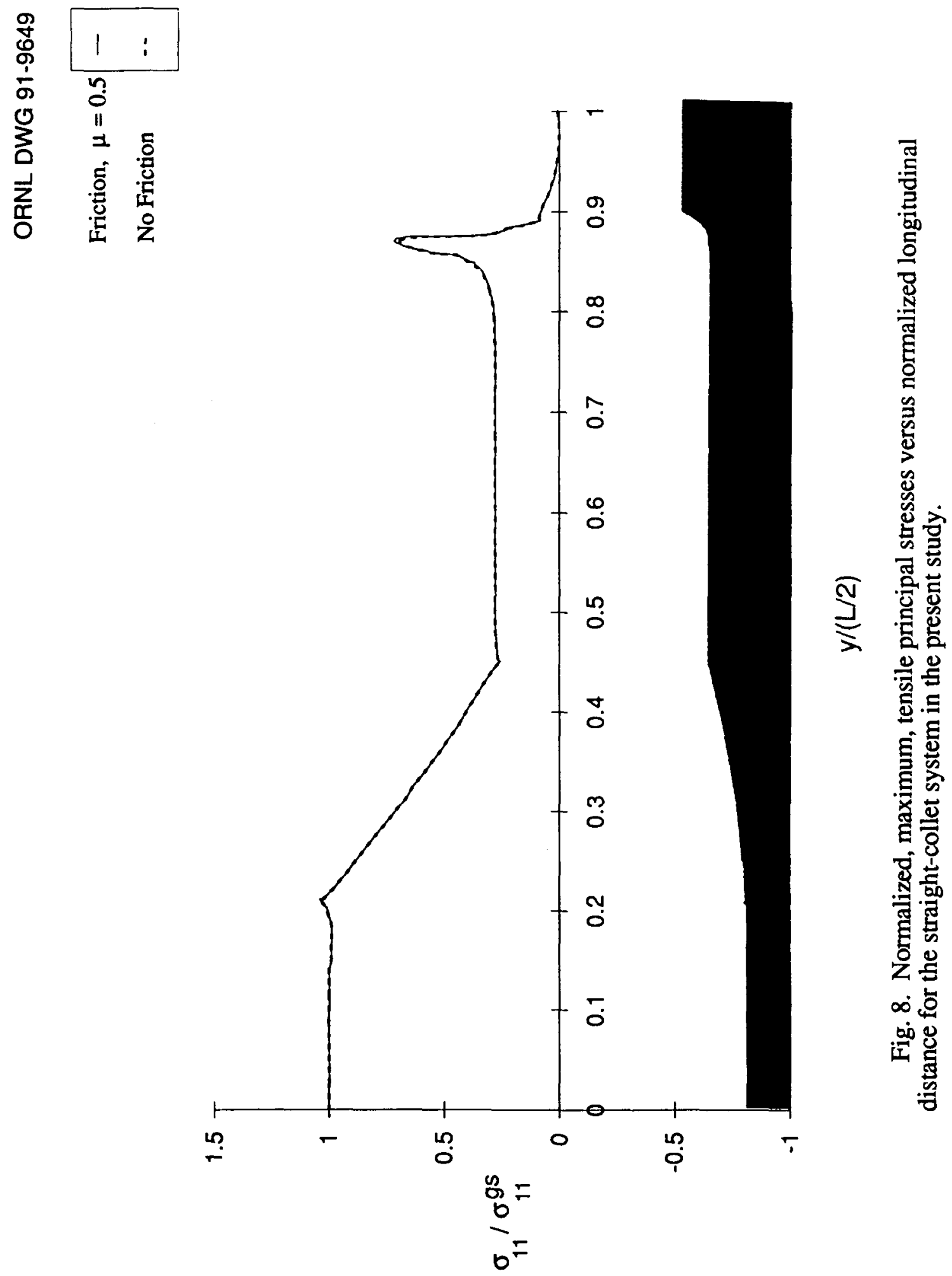


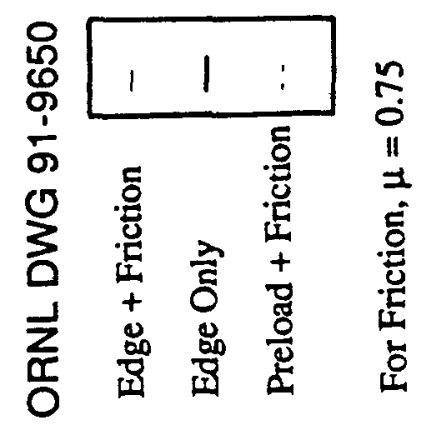

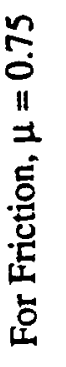
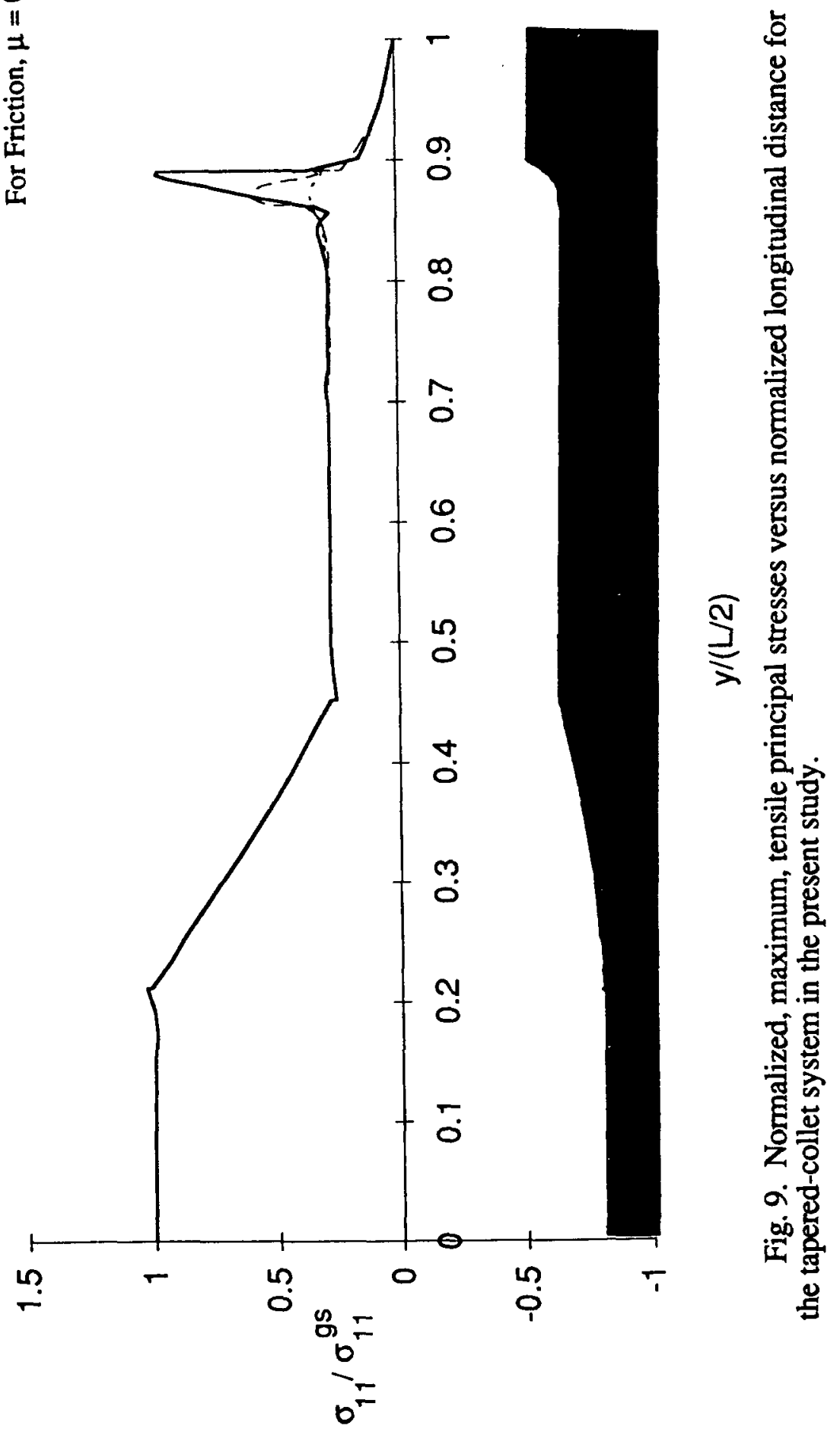


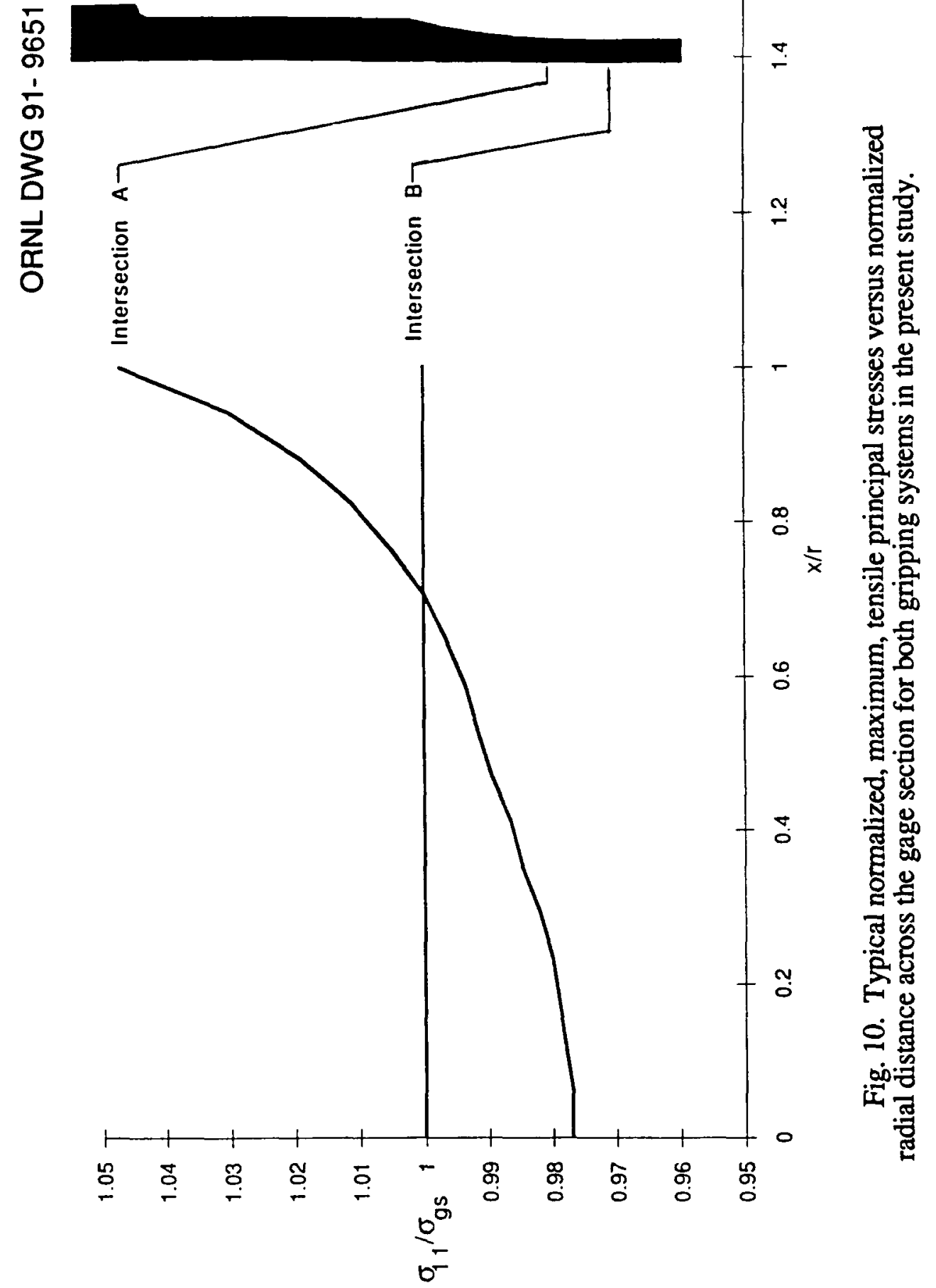


simultaneously fall within the Weibull strength distribution of the material, thus leading to the increasing probabilities of nongage-section failures.

3. The tapered-collet system can significantly reduce the stress concentration in the buttonhead region if a sufficient preload is applied before testing to prevent movement of the collets in relation to the specimen.

\subsubsection{Garrett Auxiliary Power Division Study}

The FEA modeling at GAPD was used to ascertain the parameters influencing the stress state in the button-head region to accommodate a redesign of the gripping system and the specimen button head.* A hybrid approach was used in which a linear FEA solution was first obtained for the collet/specimen model. Where contact stresses were of concern, an analytically derived solution for the Hertzian-type contact stresses between two cylinders was then superposed on the FEA linear-elastic solutions to obtain the solution for the final stress state. $^{32}$ A Control Data Corporation Cyber mainframe computer was used in conjunction with the commercial finite element code ANSYS. ${ }^{\dagger}$

Approximately 3,000 DOFs were used in the axisymmetric, quarter-symmetry model of the gripping system and the specimen as shown in Fig. 11. Two-dimensional, isoparametric solid elements were used to form the structure. Essentially, a parametric study was conducted to identify key dimensions or loading configurations that would minimize potential button-head failures. Maintaining the current $3.0-\mathrm{mm}$ button-head radius $\left(\mathrm{R}_{\mathrm{bh}}\right)$ and 6.35-mm-diam gage section (d), the following specific areas were investigated:

1. determination of the effect of contact stresses on the button-head stress state for a straight-collet system (Fig. 12);

2. development of a relationship between the stress ratio $\left(\mathrm{k}_{\mathrm{t}}\right)$ and the button-head diameter (Fig. 12);

3. determination of optimum shank diameters for various button-head diameters (Fig. 13); and

4. determination of the effects of dimensional changes for the button-head length, the shank length, and a double radius at the button head.

${ }^{*}$ D. Caruthers and J. Cuccio, "Button-head Failures Necessitate Tensile Specimen Redesign," unpublished presentation at Bi-annual Advanced Turbine Technology Applications Project Meeting, Garrett Auxiliary Power Division, Phoenix, Ariz., March 29, 1989.

†ANSYS Engineering System, Revision 4.5, Swanson Analysis Systems, Inc., Houston, Pa., 1989. 


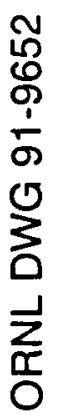

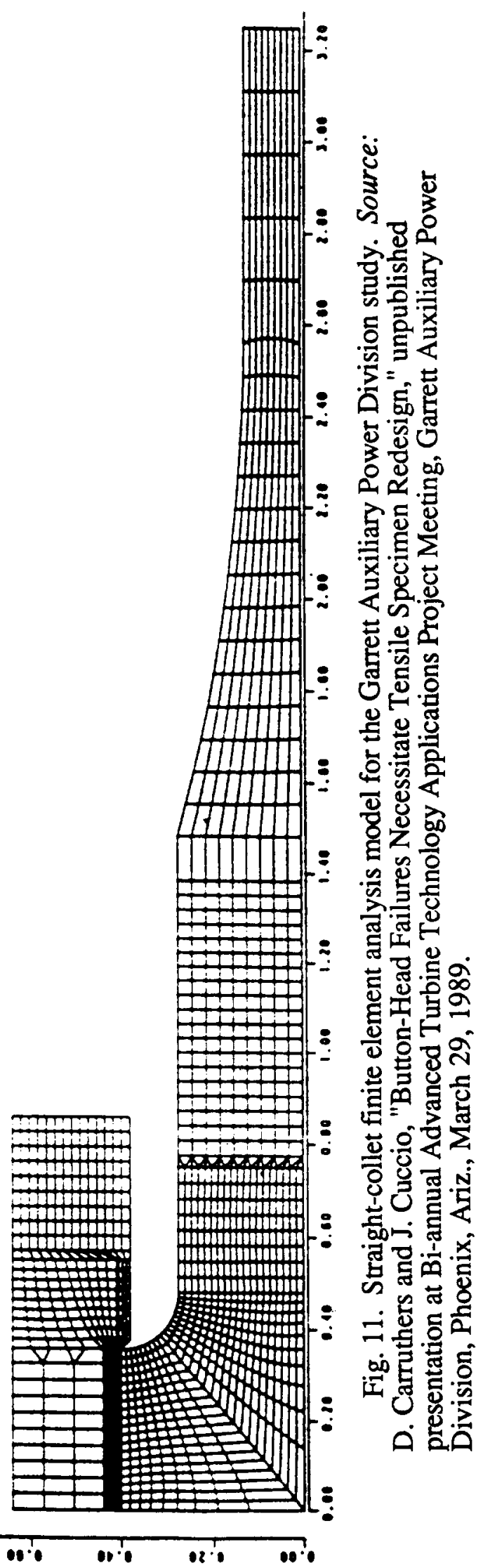


0
0
0
1
0
0
$\vdots$
$\vdots$
$\vdots$
$\vdots$
0
0

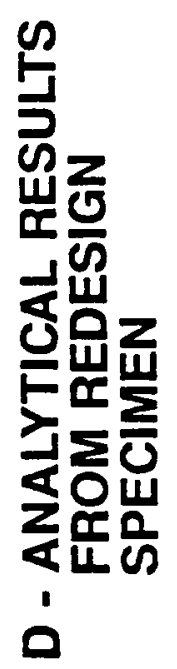

ఫ్ర్ర 承焉 空文 ㅎㅇㅇㅁㅕ

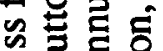
的元. 品= $\frac{1}{3}$ 马윰 겅 농 ฮึ已.응 돌 可 ธิ สิ 氖它 害乐

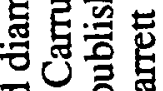

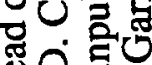
Q

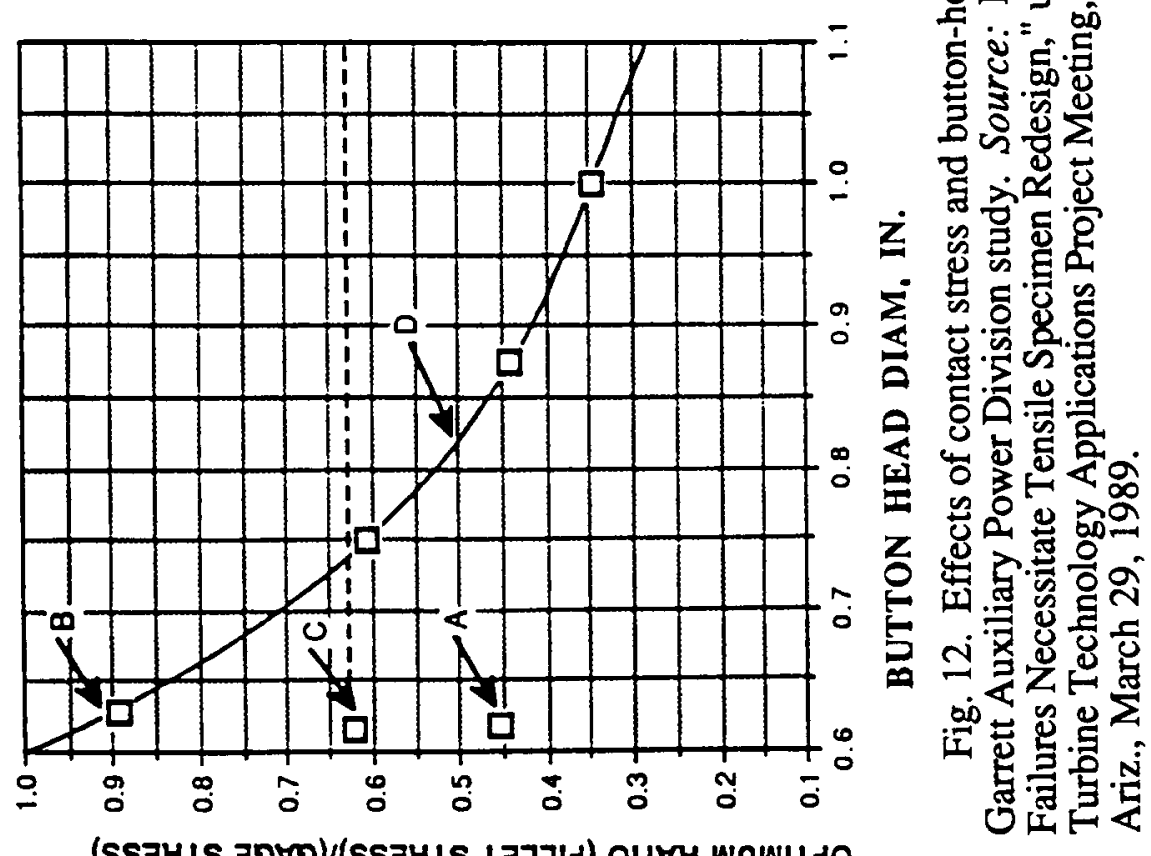




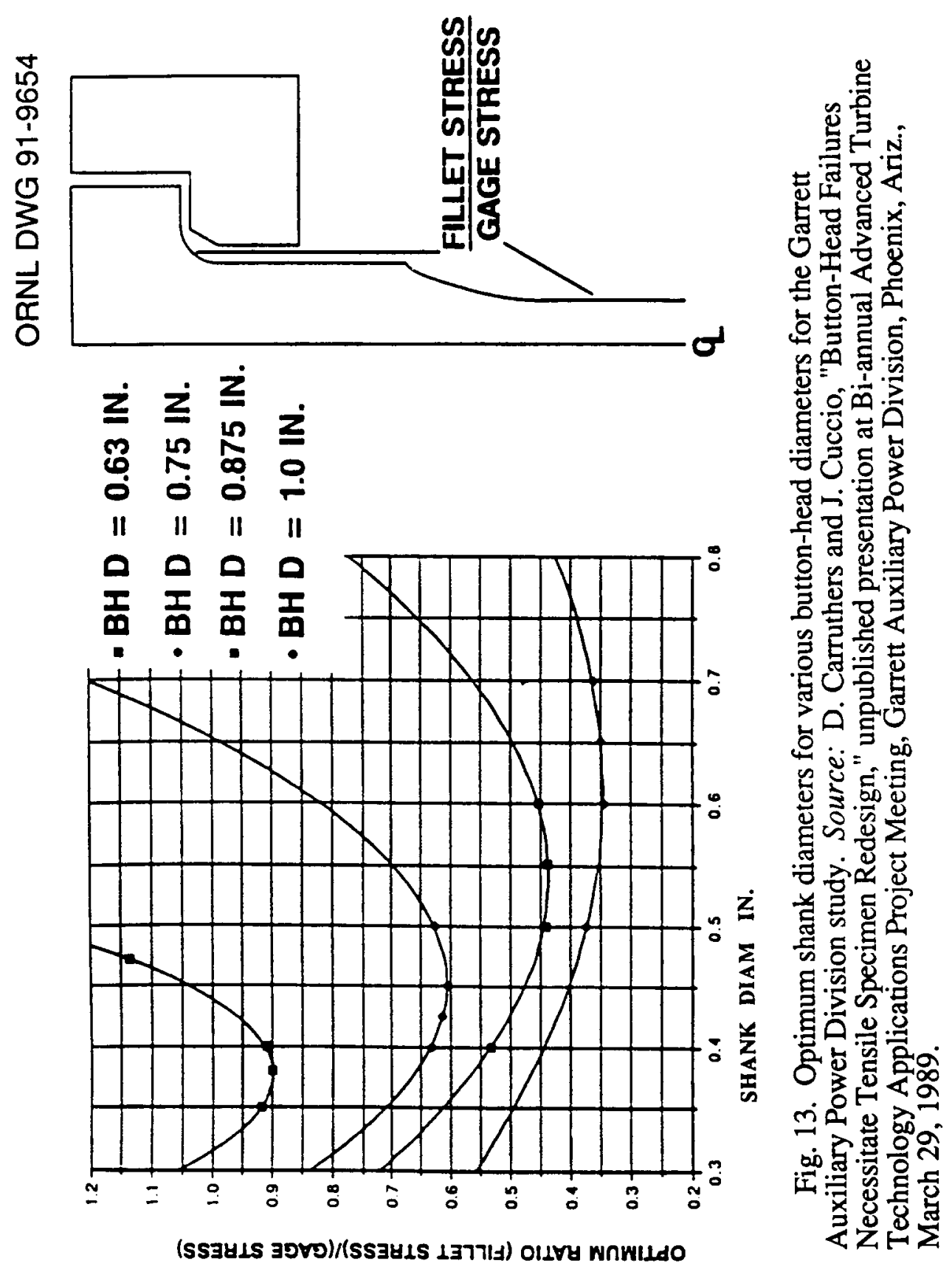


As shown in Fig. 12, assumed contact stresses in the currently used straight-collet system may cause $\mathrm{k}_{\mathrm{t}}$ to approach 0.9 if the current button-head diameter is maintained. However, for increasing button-head diameters and/or the elimination of contact stresses, $\mathrm{k}_{\mathrm{t}}$ can be decreased into the range of 0.35 to 0.60 .

For various button-head diameters, "optimum" shank diameters can be found as shown in Fig. 13. The current button-head diameter of $16 \mathrm{~mm}(0.63 \mathrm{in}$.) sharply limits the choice of the shank diameter even for a relatively high $\mathrm{k}_{\mathrm{t}}(0.9)$, while a button-head diameter (D) of $25.4 \mathrm{~mm}$ ( $1.0 \mathrm{in}$.) allows a wider choice of shank diameters for an acceptable $\mathrm{k}_{\mathrm{t}}(0.35$ to $0.40)$.

For the range of specimen dimensions examined, small effects on $\mathrm{k}_{\mathrm{t}}$ were found for dimensional changes in the button-head length, shank length, and a double radius at the button head. The conclusions of the GAPD study can be summarized as follows:

1. Contact stresses combined with the inherent stress concentration in the button-head region may cause unacceptably large $k_{t}$ values.

2. The gripping system should be redesigned to eliminate contact stresses in the critical button-head region.

3. Acceptably low $\mathrm{k}_{\mathrm{t}}$ values can be achieved with a nonfrictional gripping system in combination with a button-head diameter of $\sim 22.0 \mathrm{~mm}$, a shank diameter of $\sim 14.0 \mathrm{~mm}$, and a button-head radius of $\sim 3.0 \mathrm{~mm}$.

\subsubsection{University of Dayton Research Institute Study}

Concurrent FEA modeling at UDRI was aimed at determining the $\mathrm{k}_{\mathrm{t}}$ effects over a range of loading situations in the button-head region. ${ }^{29}$ Various loading scenarios, as shown in Fig. 14, were simulated by using appropriate element pressures and a simple linear-elastic model of the button-head/shank portion of the specimen.

An axisymmetric, quarter-symmetry model was used with $\sim 12,000$ to $13,000 \mathrm{DOF}$ as partially illustrated in Fig. 15. Four-noded, bilinear elements were used in the analysis, which was conducted on the PC-based commercial code, SUPERSAP.* The specimen material properties were those of silicon carbide ( $E=427 \mathrm{GPa}, v=0.14$ ), which was deemed a representative, brittle material with the specimen dimensions ${ }^{29}$ as shown in Fig. 1.

The tension case shown in Fig. 14 was used to represent the ideal case of a unidirectional stress case and also served to validate the mesh geometry through comparison

${ }^{*}$ SUPERSAP PC FEA, Algor, Pittsburgh, Pa., 1989. 
ORNL DWG 91-9655

Tension

Hydrostatic
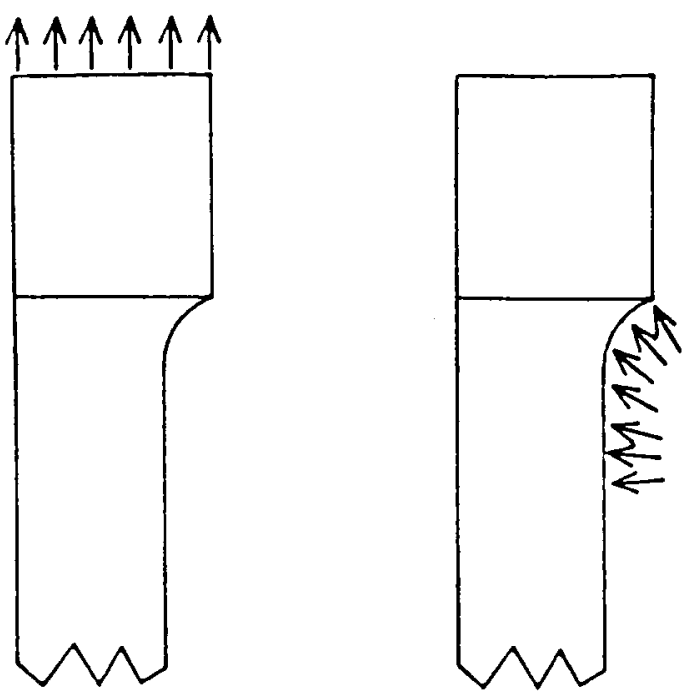

Ring

Ideal

Instron
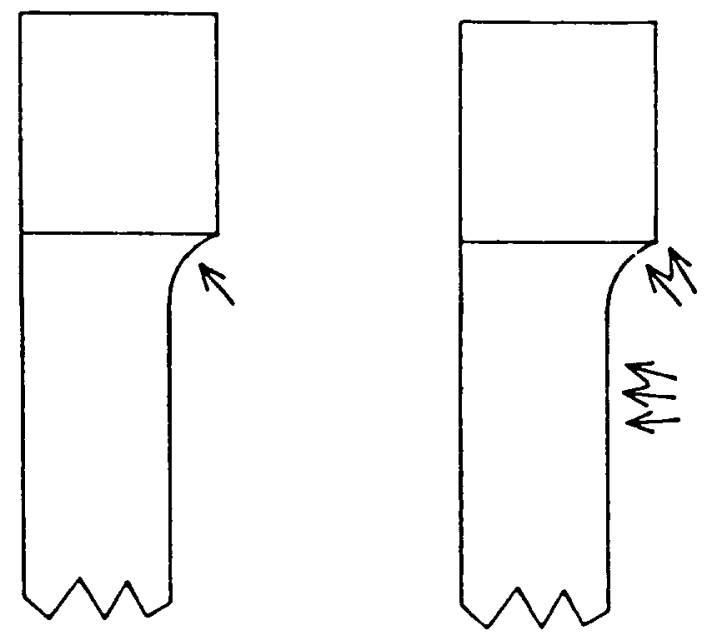

Fig.14. Loading scenarios assumed in the University of Dayton Research Institute study. Source: N. L. Hecht, "Environmental Effects in Toughened Ceramics," W.B.S. Element 3.3.1.4, pp. 379-422 in Ceramic Technology for Advanced Heat Engines Project Semiannual Progress Report for April 1989 through September 1989, ORNL/TM-11489, Martin Marietta Energy Systems, Inc., Oak Ridge Natl. Lab., 1990. 
ORNL DWG 91-9656
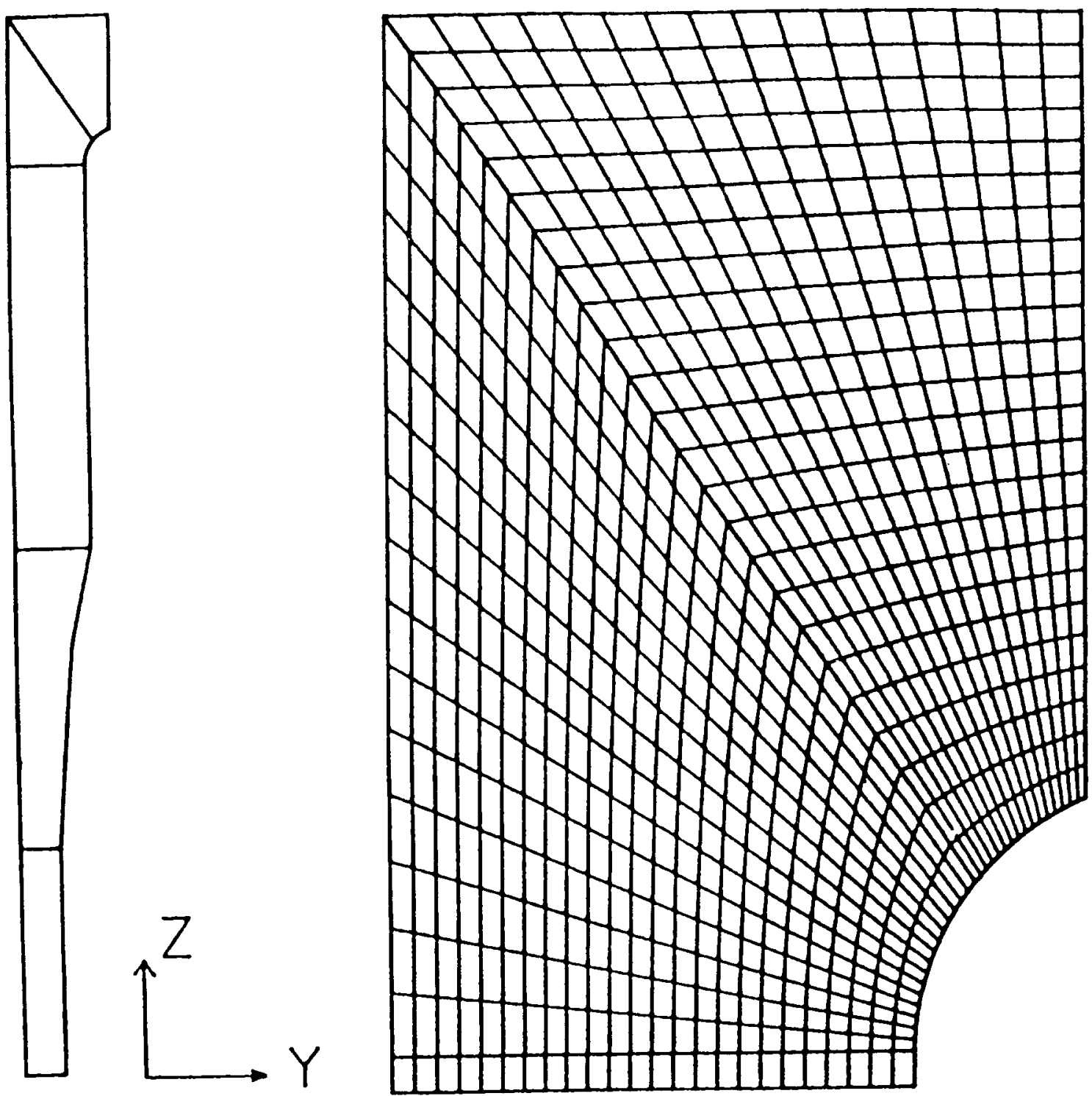

Fig. 15. Straight-collet, finite element analysis model for the University of Dayton Research Institute study. Source: N. L. Hecht, "Environmental Effects in Toughened Ceramics," W.B.S. Element 3.3.1.4, pp. 379-422 in Ceramic Technology for Advanced Heat Engines Project Semiannual Progress Report for April 1989 through September 1989, ORNL/TM-11489, Martin Marietta Energy Systems, Inc., Oak Ridge Natl. Lab., 1990. 
of the stress results with readily available analytical solutions. The $\mathrm{k}_{\mathrm{t}}$ for the tension case was found to be $\mathbf{0 . 4 4}$. The general stress concentration factor at the button-head/shank transition as determined from the FEA model in which $\mathrm{K}_{\mathrm{t}}=1.5$ compares reasonably well to the analytical case 29,31 where $\mathrm{K}_{\mathrm{t}}=1.4$.

The hydrostatic pressure case of Fig. 14 was intended to represent the case of perfect contact between a straight collet and the specimen. This situation may exist because of plastic deformation of some collet configurations [such as annealed copper, straight collets, or boron nitride $(B N)$ powder cushions] $]^{14,16,21,29}$ For this case, $k_{t}=0.53$, which is sufficiently low to explain successful (no button-head failures) tensile tests using "soft" collet systems. ${ }^{14,16,21,29}$

The ring-loading and "ideal-Instron" cases shown in Fig. 14 were investigated to determine the effects of various scenarios for "hard" straight collets illustrated in Fig. 6 (Ref. 2). The ring loading would occur if there was a mismatch between the button head and the collet radii. The "ideal-Instron" case was the research interpretation of the collet/specimen interaction for the as-designed, straight-collet gripping supplied by Instron Corporation. ${ }^{2}$ The $\mathrm{k}_{\mathrm{t}}$ in this case is $\sim 0.75$ for mismatches of 1 to $10 \%$ (collet radius less than the buttonhead radius). For the ideal-Instron case, $\mathrm{k}_{\mathrm{t}}=0.85$, which is in the range of the Weibull strength of the material as mentioned earlier. It should be noted that the assumed loading for the UDRI ideal-Instron case did not exactly agree with the loading observed in the FEA of the present study, where it was attempted to actually model the interactions between the collet and the specimen. Nevertheless, the $\mathrm{k}_{\mathrm{t}}$ values for these idealized, linear-elastic cases are sufficiently high that button-head failures might be expected if even minor Hertzian-type stresses were present in the contact areas.

The results of the UDRI study can be summarized as follows:

1. Hydrostatic loading promotes acceptable stress states in the button-head region and can be realistically approached in the laboratory.

2. Increased contact area between the collet and the button head can substantially reduce button-head failures.

3. Alternative geometries should be investigated to reduce the criticality of the inherent stress concentration at the button-head radius. 


\subsubsection{Summary of Finite Element Analysis Studies}

All three FEA studies described here took different approaches; yet, the results are in reasonable agreement. However, it is interesting to note the directions of the conclusions.

GAPD recommends the elimination of direct or frictional contact between the specimen and the collet and advises enlarging the specimen dimensions substantially to accommodate this change. However, both the UDRI and the present studies indicate the efficacy of direct but conformable contact between the collet and the button head (deformable collet) or direct frictional contact between the collet and the shank (tapered collet), which minimize the loadbearing role of the button head.

Unfortunately, none of the FEA studies addressed the equally important issue of the gripping system - the minimization of bending stresses. Ideally, the gripping system, which ultimately eliminates nongage-section failures, must also help to minimize the bending stresses in the gage section. The effects of bending are discussed generally in a following section and in detail in Appendix B.

\subsection{EMPIRICAL TENSILE TEST RESULTS}

As mentioned, the "popularity" of two types of gripping systems, the straight(Instron-type) and the tapered-collet system, was used in a test program to determine which system could sustain the highest ultimate load in the button-head region while simultaneously minimizing the bending stresses in the specimen.2,20,25,29 Because few attempts have been made to modify the tapered-collet system as originally designed, that system was used only in the "as-designed" configuration. ${ }^{25,28}$ However, several modifications have been applied to the straight-collet system including the use of (1) single or two-piece cover plates, (2) twoor three-piece collets, (3) as-received or freshly annealed (Rockwell hardness, $R_{F} \approx 40$ ) copper collets, and (4) long (11-mm) or short (7-mm) copper collets. The effects of these modifications were studied in these empirical tests.

A series of empirical tests were conducted, first with straight-shank (no gage section as shown in Fig. 16) specimens of aluminium oxide and finally with "standard" (as shown in Fig. 1) tensile specimens of two high-performance silicon nitrides. The tests of the straightshank specimens were intended to force the failure of the specimen into the gripped area to ascertain the ultimate load-carrying capability before button-head failure of the two gripping systems while using a typical model ceramic. The tests of "standard" tensile specimens were intended to verify the load-carrying capabilities of the two gripping systems where $100 \%$ gage-section failures were desired. Details and results of the two types of empirical tests are described in the following subsections. 


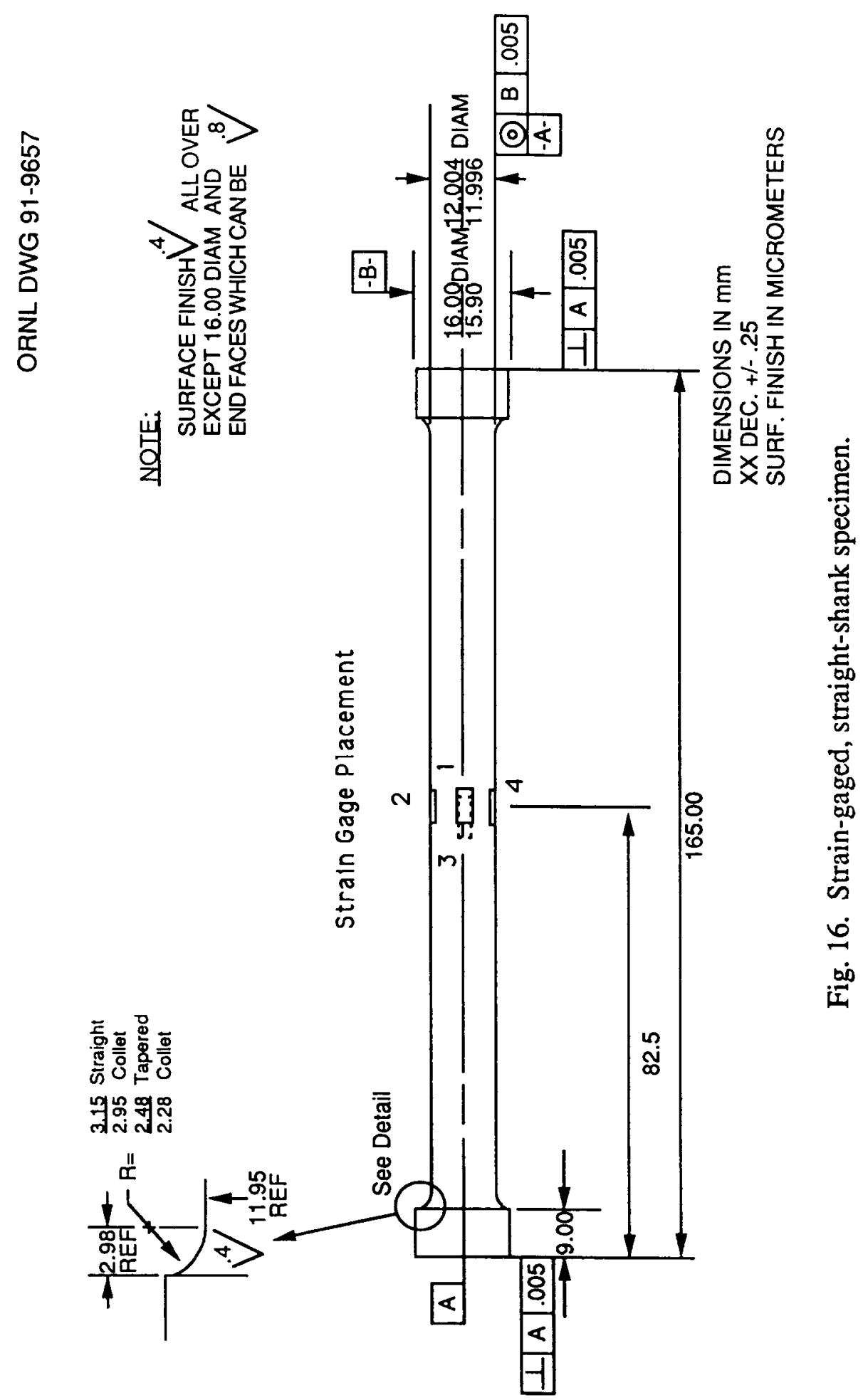




\subsubsection{Straight-Shank Tests of Aluminium Oxide}

A series of strain-gaged tensile tests was conducted with $99 \%$ pure aluminium oxide* specimens that did not have gage sections (straight-shank specimens). The primary purpose of these tests was to determine the maximum load each gripping system could sustain before specimen failure occurred in the gripped section (i.e., button head or shank). All testing was conducted under ambient conditions [ 20 to $25^{\circ} \mathrm{C}, 35$ to $55 \% \mathrm{RH}$ (relative humidity)] on screw-driven, electro-mechanical test machines operating under electronic load control. ${ }^{\dagger}$ Two stressing rates were used: (1) $\sim 11 \mathrm{MPa} / \mathrm{s}$ for the tapered- and "hard" straight-collet systems and (2) a two-step process for the "soft" collets whereby the stress rate was $\sim 0.2 \mathrm{MPa} / \mathrm{s}$ from 0 to $6,500 \mathrm{~N}$ and $\sim 30 \mathrm{MPa} / \mathrm{s}$ from $6,500 \mathrm{~N}$ to failure. ${ }^{29}$ Details of the procedures for using the grips and specific details of the components of the gripping systems are contained in Appendix A.

In addition to determining the potential for maximum load before failure of the gripped section, it was also desired to determine which system would introduce the least bending into the tensile specimen. All tests were performed with hydraulic couplers in the load trains to minimize the bending moment contribution of the load trains themselves. ${ }^{2}$ Subsequent bending contributions were assumed to be related only to either eccentricity of the gripping system or nonconcentricity of the shanks and gage sections. As shown in Fig. 16, four equally spaced, uniaxially aligned strain gages $\ddagger$ (1.0-mm-long by 1.3 -mm-wide sensing area) were applied at the specimen midpoint to measure the percent bending for the various grip configurations. ${ }^{6,33}$ The percent bending was calculated continuously during the tests by using a front-end processor/conditioning system, ${ }^{* *}$ which displayed and recorded the load, strain, and percent bending at $0.1-\mathrm{s}$ intervals. Percent bending at the midpart of the gage section is calculated such that

$$
\% \text { bending }=\frac{\left.\left[\left(\Delta \mathrm{g}_{1,3}\right)^{2}+\left(\Delta \mathrm{g}_{2,4}\right)^{2}\right)\right]^{1 / 2}}{\mathrm{~g}_{0}} \times 100
$$

\footnotetext{
*AD-995, Coors Porcelain Company, Golden, Colo.

tInstron 1380 Creep Fatigue Machine, Instron Corporation, Canton, Mass., 1988.

‡TML Type FLE-1-5-LT, Tokyo Sokki Kenkyujo Co., Ltd., Tokyo, 1989.

** Daytronic System 10 DataPAC 10K4T-D with 10A73-4 Quad 1/4 and 1/2 bridge strain conditioner card, 10CJB-5 bridge completion card, 10A60-4 quad voltage conditioner card, and serial interface to IBM-compatible PC, Daytronic Corporation, Miamisburg, Ohio,
} 1989. 
where

$$
\begin{aligned}
& \Delta g_{1,3}= \frac{\left(g_{1}-g_{0}\right)-\left(g_{3}-g_{0}\right)}{2}=\frac{\left(g_{1}-g_{3}\right)}{2} \\
& \Delta g_{2,4}=\frac{\left(g_{2}-g_{0}\right)-\left(g_{4}-g_{0}\right)}{2}=\frac{\left(g_{2}-g_{4}\right)}{2}
\end{aligned}
$$

and

$$
g_{0}=\frac{\left(g_{1}+g_{2}+g_{3}+g_{4}\right)}{4}
$$

where $g_{1}, g_{2}, g_{3}$, and $g_{4}$ are the strain gage readings in units of strain, and compressive strains are considered to be negative. ${ }^{6,33}$

Results for the maximum load and percent bending error at specimen failure are shown in Figs. 17 and 18, respectively. The tapered-collet system was able to sustain a higher load while still maintaining a lower percent bending error as compared with the straight-collet system. Similar high loads were sustained by the straight-collet system with soft, freshly annealed copper collets but with higher percent bending at failure than for the tapered-collet system. These empirical results compare well with the low $k_{t}$ values predicted for these configurations by the FEA modeling.

\subsection{2 "Standard" Tensile Specimen Tests of Silicon Nitride}

Confirmatory tensile tests were conducted on tensile specimens of high-strength, polycrystalline silicon nitrides (designated PY $6^{*}$ and NT154†). Two gripping arrangements were compared (tapered- and straight-collet systems with annealed-copper collets) because these two systems appeared to be able to sustain similar ultimate loads in the button-head area as shown in Fig. 17. One modification to the straight-collet systems was to use two-piece copper collets shorter in length than those used in the tests of the aluminium oxide $(7 \mathrm{~mm}$ vs $11 \mathrm{~mm}$ ). The shorter collets were originally used to accommodate specimens which lacked the sufficient total length as specified. However, subsequent experience with the shorter collets showed that they were easier to use and appeared to provide more consistent percent bending than did the longer collets. As in the tests of the straight-shank aluminium oxide specimens, hydraulic couplers were used in the load trains to restrict the contributions of bending to the gripping system or specimen. Stressing rates for the respective systems were

\footnotetext{
"PY6, GTE Laboratories, Inc., Waltham, Mass., 1990.

†NT154, Norton Company, Worcester, Mass., 1990.
} 


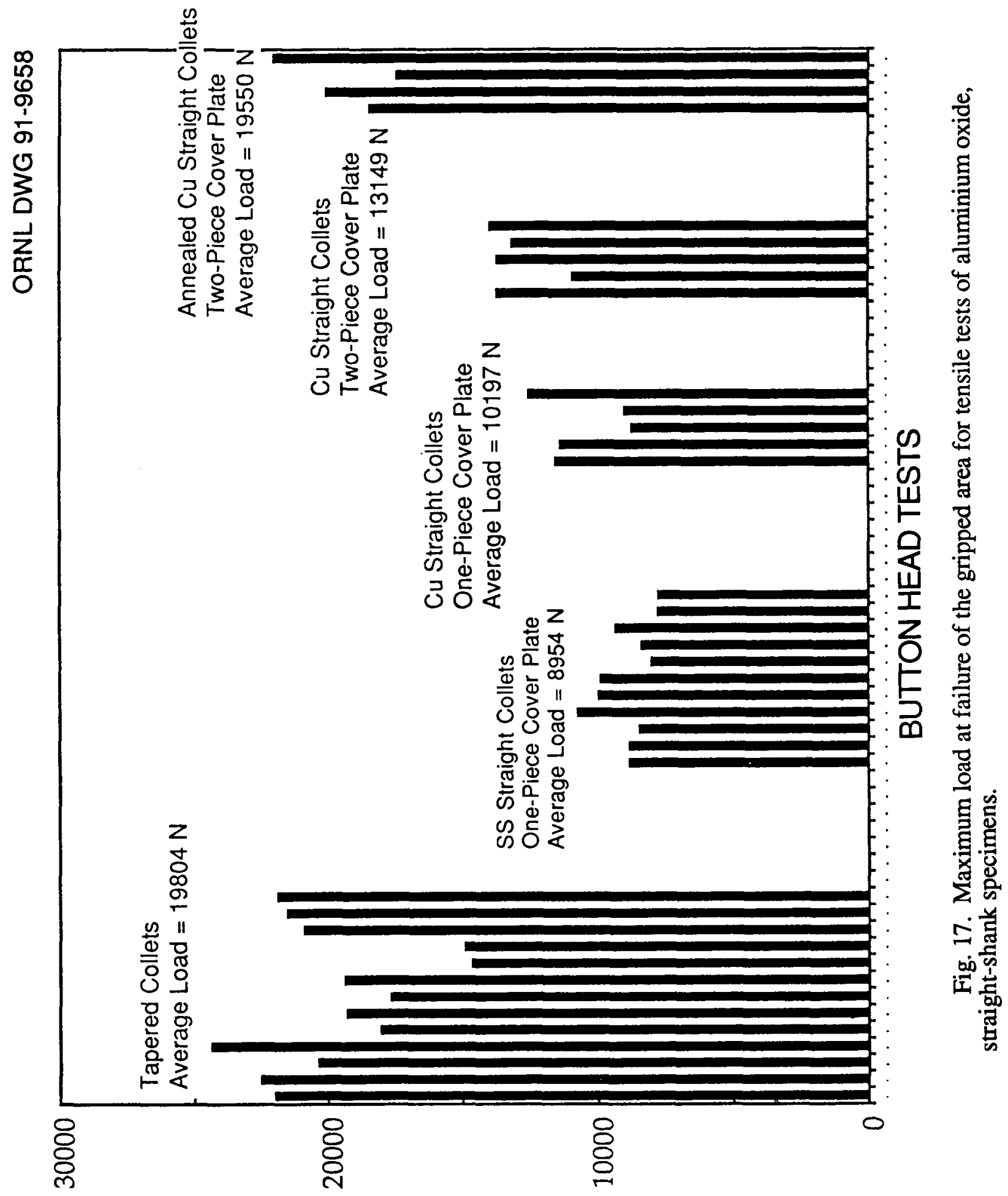

(N) $\exists y \cap 7 I \forall \unlhd \perp \forall$ Q $\forall 07$ WกWIX $\forall W$ 


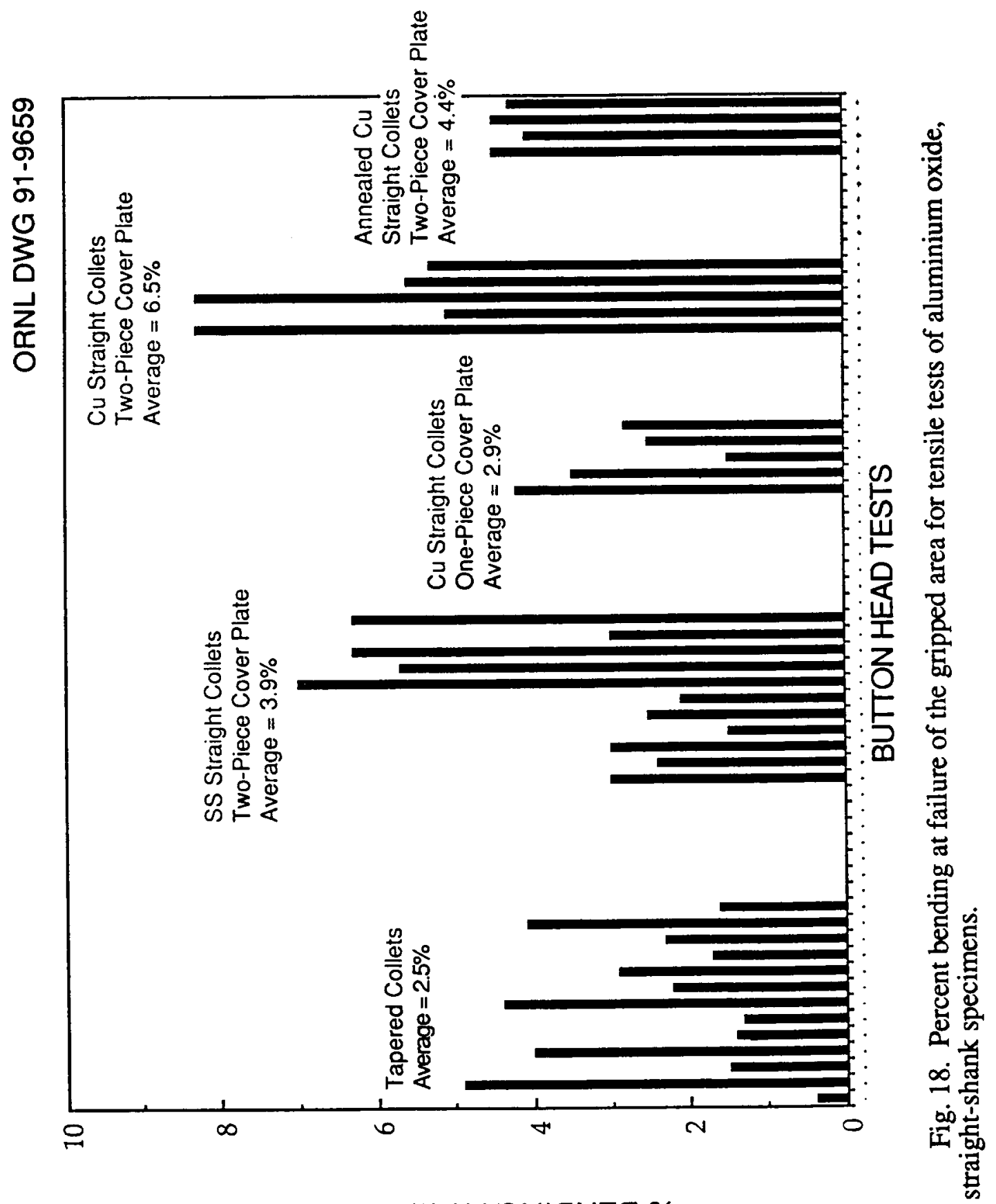

a $\forall 07$ WחWIX $\forall W \perp \forall$ ONION $\exists g \%$ 
as described for the tests of the straight-shank specimens. All testing was conducted under ambient laboratory conditions $\left(20\right.$ to $25^{\circ} \mathrm{C}, 35$ to $\left.55 \% \mathrm{RH}\right)$ with the same fixturing and test machines used in the tests of the straight-shank specimens.

To minimize skewing of test results due to variations in the material, all specimens were fabricated from the same shipments of material with individual, unmachined rod blanks randomly selected for fabrication to the specifications for each gripping system. A "fouraxis" grinding machine* operated via computer numerical control (CNC) was used to fabricate the specimens to the dimensions shown in Fig. 1. Formed, $\sim 200$-mm-diam grinding wheels ${ }^{\dagger}$ with either resinoid-bonded, 320-grit or metal-bonded, 400-grit diamond abrasive were used for both the shaping and finishing operations. The cutting edges of the wheel had radii to match the desired radius in the button heads of the specimen. The button heads and shanks of the specimen were ground circumferentially at MRRs of $<100 \mathrm{~mm}^{3} /(\mathrm{mm} \cdot \mathrm{min})$. The final grinds of the gage-section transitions and the actual gage sections were done longitudinally at MRRs of $<10 \mathrm{~mm}^{3} /(\mathrm{mm} \cdot \mathrm{min})$. All specimens were dimensionally checked with an optical comparator $¥$ having a resolution of $1.0 \mu \mathrm{m}$.

Specimens with dimensions outside the specified tolerances were rejected for testing in this study. Surface finishes were verified by using a diamond-tipped profilometer ${ }^{* *}$ with a resolution of $\sim 0.012 \mu \mathrm{m}$. All specimens were tested in the "as-ground" condition. No postmachining heat treatment was used to either "heal" surface damage due to machining or relieve surface residual stresses due to machining.

Table 1 summarizes the testing results. Figures 19 and 20 show the calculated ultimate tensile strengths, $S_{\mathrm{uts}}\left(\mathrm{S}_{\mathrm{uts}}=\mathrm{P}_{\mathrm{max}} / \mathrm{A}_{\mathrm{gs}}\right)$, plotted versus percent bending at failure. Percent bending was determined as described for the straight-shank specimens where four, uniaxial strain gages were applied equispaced circumferentially around the gage section of each specimen.

Since bending is considered a parasitic component of tensile tests, the $S_{\text {uts }}$ would be expected to decrease with increasing percent bending. However, this decreasing trend is not seen in the results for the straight-collet system. A more obvious decrease in $S_{u t s}$ with increasing percent bending can be seen for the results for the tapered-collet system.

\footnotetext{
*Jungner PSA 600, Grinding Technology, Inc., Hartford, Conn., 1986.

†Norton Diamond Wheel, SD320-R150BXL6145-7/32(1/4), Norton Company, Worcester, Mass., 1990.

¥Nikon V-12 Profile Projector with O2L Linear Encoded Stage and DP-201 Data Processor, Nikon, Inc., Instrument Group, Garden City, New York, 1988.

${ }^{* *}$ Talysurf 10 Surface Texture Measuring Instrument, Rank Taylor Hobson, Ltd., Leicester, England, U.K., 1989.
} 
Table 1. Results of room-temperature tensile tests of silicon nitrides

\begin{tabular}{|c|c|c|c|c|}
\hline $\begin{array}{l}\text { Specimen I.D./ } \\
\text { material }\end{array}$ & $\begin{array}{l}P_{\max } \\
(\mathrm{N})\end{array}$ & $\begin{array}{l}\mathrm{S}_{\mathrm{uts}}{ }^{a} \\
(\mathrm{MPa})\end{array}$ & $\begin{array}{l}\% \text { Bending } \\
\text { at } P_{\max }\end{array}$ & $\begin{array}{l}\text { Remarks/ } \\
\text { failure point } b\end{array}$ \\
\hline \multicolumn{5}{|l|}{ Straight collet } \\
\hline D7 (PY6) & 26,730 & 841 & 3.4 & $-12 \mathrm{~mm} \mathrm{~S}$ \\
\hline A11 (PY6) & 23,190 & 734 & 3.3 & $-8 \mathrm{~mm} \mathrm{~S}$ or $\mathrm{V}$ \\
\hline D14 (PY6) & 22,810 & 718 & 3.1 & $-10 \mathrm{~mm} \mathrm{~S}$ \\
\hline N13 (PY6) & 22,680 & 712 & 3.5 & $+10 \mathrm{~mm} \mathrm{~V}$ \\
\hline P10 (PY6) & 22,010 & 694 & 2.8 & $-12 \mathrm{~mm} \mathrm{~S}$ \\
\hline P2 (PY6) & 21,620 & 689 & 2.5 & $-14 \mathrm{~mm} \mathrm{~S}$ or $\mathrm{V}$ \\
\hline P19 (PY6) & 21,350 & 673 & 0.4 & $-5 \mathrm{~mm} \mathrm{~S}$ \\
\hline A4 (PY6) & 21,010 & 660 & 4.3 & $+6 \mathrm{~mm} \mathrm{~S}$ \\
\hline A22 (PY6) & 20,980 & 660 & 2.2 & $+3 \mathrm{~mm} \mathrm{~V}$ \\
\hline A15 (PY6) & 20,610 & 648 & 1.3 & $+5 \mathrm{~mm} \mathrm{~S}$ \\
\hline A3 (PY6) & 19,320 & 607 & 3.8 & $-3 \mathrm{~mm} \mathrm{~V}$ \\
\hline A6 (PY6) & 19,210 & 604 & 4.1 & $+10 \mathrm{~mm} \mathrm{~S}$ \\
\hline P1 (PY6) & 19,090 & 601 & 3.7 & $+18 \mathrm{~mm} \mathrm{~S}$ \\
\hline A12 (PY6) & 18,670 & 587 & 1.4 & $+1 \mathrm{~mm} \mathrm{~S}$ \\
\hline $\mathrm{A} 2$ (PY6) & 18,580 & $584^{\circ} \mathrm{C}$ & 2.9 & $+26 \mathrm{~mm} \mathrm{~S}$ \\
\hline K4 (PY6) & 7,720 & $243^{\circ} \mathrm{C}$ & 1.0 & $+22 \mathrm{~mm} \mathrm{~V}$ \\
\hline Average PY6 & & $673 \pm 67$ & $2.7 \pm 1.2$ & \\
\hline 1910 (NT154) & 25,950 & 820 & 3.5 & $-17 \mathrm{~mm} \mathrm{~S}$ or $\mathrm{V}$ \\
\hline 1911 (NT154) & 23,990 & 756 & 2.8 & $-5 \mathrm{~mm} \mathrm{~S}$ \\
\hline 1919 (NT154) & 23,210 & 728 & 2.8 & $+2 \mathrm{~mm} \mathrm{~S}$ \\
\hline 1920 (NT154) & 23,000 & 722 & 1.6 & $+5 \mathrm{~mm} \mathrm{~S}$ \\
\hline 1953 (NT154) & 22,740 & 719 & 3.3 & $+7 \mathrm{~mm} \mathrm{~S}$ \\
\hline 1955 (NT154) & 21,500 & 673 & 0.4 & $+8 \mathrm{~mm} \mathrm{~S}$ \\
\hline 1926 (NT154) & 21,100 & 669 & 4.0 & $-17 \mathrm{~mm} \mathrm{~S}$ \\
\hline 1956 (NT154) & 20,390 & 643 & 3.1 & $-22 \mathrm{~mm} \mathrm{~S}$ \\
\hline 1918 (NT154) & 19,910 & 630 & 5.5 & $+14 \mathrm{~mm} \mathrm{~S}$ \\
\hline $19-2$ (NT154) & 19,870 & $627^{\circ} \mathrm{C}$ & 5.9 & $-23 \mathrm{~mm} \mathrm{~S}$ \\
\hline 1922 (NT154) & 17,980 & 566 & 4.7 & $-3 \mathrm{~mm} \mathrm{~S}$ or $\mathrm{V}$ \\
\hline Average NT154 & & $693 \pm 72$ & $3.4 \pm 1.6$ & \\
\hline $\begin{array}{l}\text { Average straight } \\
\text { collet }\end{array}$ & & & $3.0 \pm 1.4$ & \\
\hline
\end{tabular}


Table 1 (continued)

\begin{tabular}{|c|c|c|c|c|}
\hline $\begin{array}{l}\text { Specimen I.D.I } \\
\text { material }\end{array}$ & $\begin{array}{l}P_{\max } \\
(\mathrm{N}) \\
\end{array}$ & $\begin{array}{l}\mathrm{S}_{\mathrm{uts}}{ }^{a} \\
(\mathrm{MPa}) \\
\end{array}$ & $\begin{array}{l}\text { \% Bending } \\
\text { at } P_{\max }\end{array}$ & $\begin{array}{l}\text { Remarks/ } \\
\text { failure point } b\end{array}$ \\
\hline \multicolumn{5}{|l|}{ Tapered collet } \\
\hline N23 (PY6) & 23,970 & 757 & 0.8 & $+12 \mathrm{~mm} \mathrm{~S}$ \\
\hline B13 (PY6) & 23,880 & 752 & 1.5 & $-15 \mathrm{~mm} \mathrm{~V}$ or $S$ \\
\hline P3 (PY6) & 22,380 & 707 & 1.5 & $-13 \mathrm{~mm} \mathrm{~S}$ \\
\hline B14 (PY6) & 22,360 & 704 & 2.6 & $-10 \mathrm{~mm} \mathrm{~V}$ \\
\hline $\mathrm{O}$ (PY6) & 21,950 & $691^{\circ} \mathrm{C}$ & 1.3 & $+21 \mathrm{~mm} \mathrm{~V}$ \\
\hline K1A (PY6) & 21,440 & 675 & 1.5 & $-11 \mathrm{~mm} \mathrm{~S}$ \\
\hline B15 (PY6) & 18,150 & 571 & 2.8 & $-4 \mathrm{~mm} \mathrm{~V}$ \\
\hline B10 (PY6) & 16,600 & 524 & 2.7 & $+12 \mathrm{~mm} \mathrm{~V}$ \\
\hline B11 (PY6) & 16,540 & 521 & 2.1 & $+11 \mathrm{~mm} \mathrm{~V}$ \\
\hline P7 (PY6) & 15,430 & 497 & 2.3 & $+16 \mathrm{~mm} \mathrm{~V}$ \\
\hline Average PY6 & & $634 \pm 105$ & $1.9 \pm 0.7$ & \\
\hline 1963 (NT154) & 25,610 & 804 & 0.9 & $-10 \mathrm{~mm} \mathrm{~S}$ \\
\hline 1977 (NT154) & 24,380 & 770 & 0.8 & $-9 \mathrm{~mm} \mathrm{~S}$ \\
\hline 1913 (NT154) & 24,290 & 765 & 2.6 & $-10(+20) \mathrm{mm} \mathrm{S}$ \\
\hline 1976 (NT154) & 22,530 & 711 & 2.3 & $-8 \mathrm{~mm} \mathrm{~S}$ \\
\hline 1980 (NT154) & 21,610 & 680 & 4.6 & $-16 \mathrm{~mm} \mathrm{~S}$ \\
\hline 1917 (NT154) & 21,560 & 677 & 1.2 & $-1 \mathrm{~mm} \mathrm{~S}$ \\
\hline 1979 (NT154) & 20,880 & 658 & 2.8 & $-6 \mathrm{~mm} \mathrm{~S}$ \\
\hline 1912 (NT154) & 19,490 & 615 & 2.7 & $+12 \mathrm{~mm} \mathrm{~S}$ \\
\hline 1948 (NT154) & 18,700 & 586 & 1.8 & $-13 \mathrm{~mm} \mathrm{~S}$ \\
\hline 1951 (NT154) & 16,610 & 522 & 3.3 & $-9(+25) \mathrm{mm} \mathrm{S}$ \\
\hline 1923 (NT154) & 15,570 & 489 & 3.7 & $-12 \mathrm{~mm} \mathrm{~S}$ \\
\hline $19-5$ (NT154) & 13,210 & $419^{\circ} \mathrm{C}$ & 3.6 & $+25 \mathrm{~mm} \mathrm{~S}$ \\
\hline Average NT154 & & $662 \pm 101$ & $2.5 \pm 1.2$ & \\
\hline $\begin{array}{l}\text { Average tapered } \\
\text { collet }\end{array}$ & & & $2.2 \pm 1.0$ & \\
\hline
\end{tabular}

$a$ Suts = ultimate tensile strength.

$b$ Failure point references the longitudinal midpoint of the gage section such that the uniform gage section is between $+17.5 \mathrm{~mm}$ (toward the upper end of the specimen as tested) and -17.5 (toward the lower end of the specimen as tested).

$\mathrm{S}=$ Surface failure origin, $\mathrm{V}=$ Volume failure origin. Effective volume $\left(\mathrm{V}_{\mathrm{e}}\right) \approx 1108 \mathrm{~mm}^{3}$.

$\mathrm{C}=$ Censored $=$ test, used as a suspended item in the statistical analyses. 


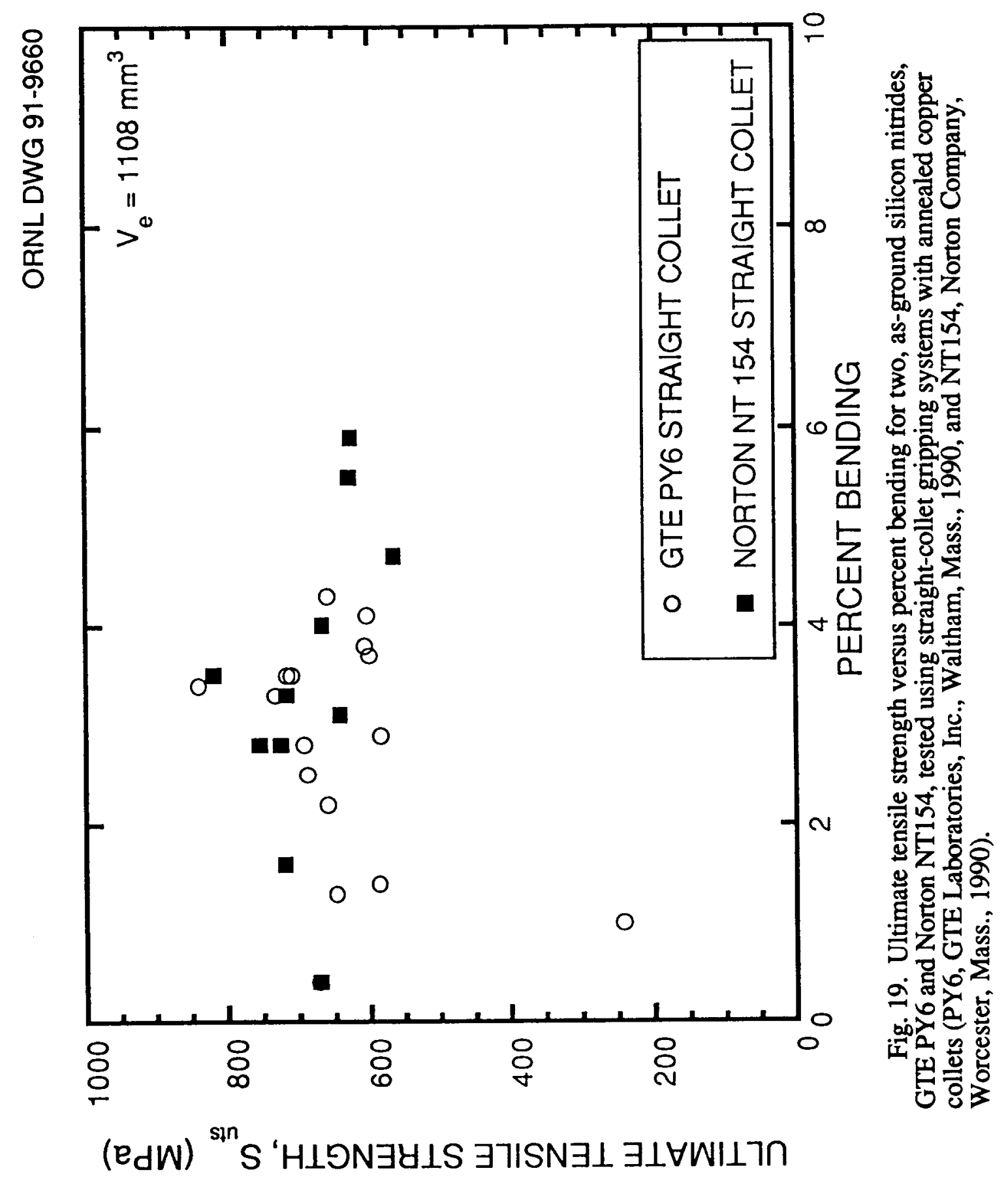




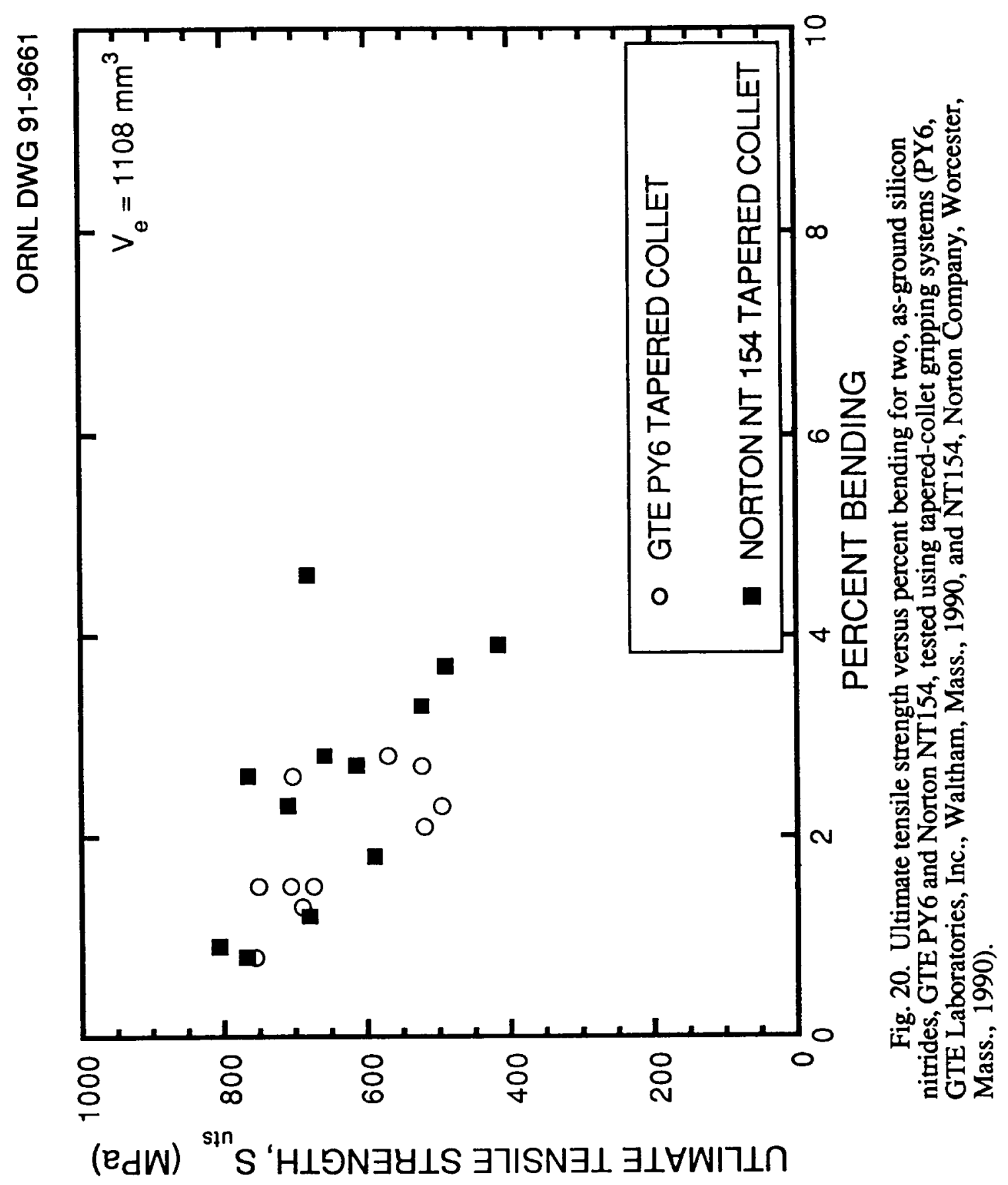


Speculation is that the softer material in the straight-collet system allows a certain accommodation of bending, and the rigid material of the tapered-collet system will not produce this accommodation but, instead, transfers a higher bending (and ultimately the failure location) into the ends of the gage section. This hypothesis is somewhat supported in two ways. First, in occasional tests using the tapered-collet system, multiple failure locations occurred, usually at either end of the gage section, thus indicating somewhat higher stresses at those locations. Second, tensile test results* by Kyocera (see Fig. 21) from tests using a straight-collet system with soft inserts do not readily show the expected trend of decreasing $S_{u t s}$ with increasing percent bending. A definite conclusion cannot be made on the direct influence of the gripping system on the relationship of $S_{\text {uts }}$ and percent bending because of the limited number of tensile tests presented here. However, the effect of percent bending on the distribution of material tensile strengths is discussed in the following section and in detail in Appendix B.

A t-test ${ }^{34}$ was applied to determine whether a statistically significant difference existed between the averages of the percent bending for the straight- and the tapered-collet gripping systems. The $t$-test was used to evaluate the null hypothesis of the equality of two averages at the $5 \%$ significance level. No statistically significant differences were found between the averages of the percent bending and the averages of the $S_{\text {uts }}$ for the tests of the PY6 with the straight- and the tapered-collet systems, or the averages of percent bending and the averages of the $S_{\mathrm{uts}}$ for the tests of the NT154 with the straight- and the tapered-collet systems.

However, a statistically significant difference was found between the averages of the percent bending for all the tests (percent bending for PY6 and NT154 combined) with the straightand the tapered-collet systems. It is not clear why this difference is found for averages of all the tests and not for the averages of the tests for each material.

"M. Kaji, "Evaluation of Techniques of Mechanical Properties," unpublished presentation given at Kyocera Central Research Laboratory, Kokubu, Japan, July 19, 1989. 
ORNL DWG 91-9662

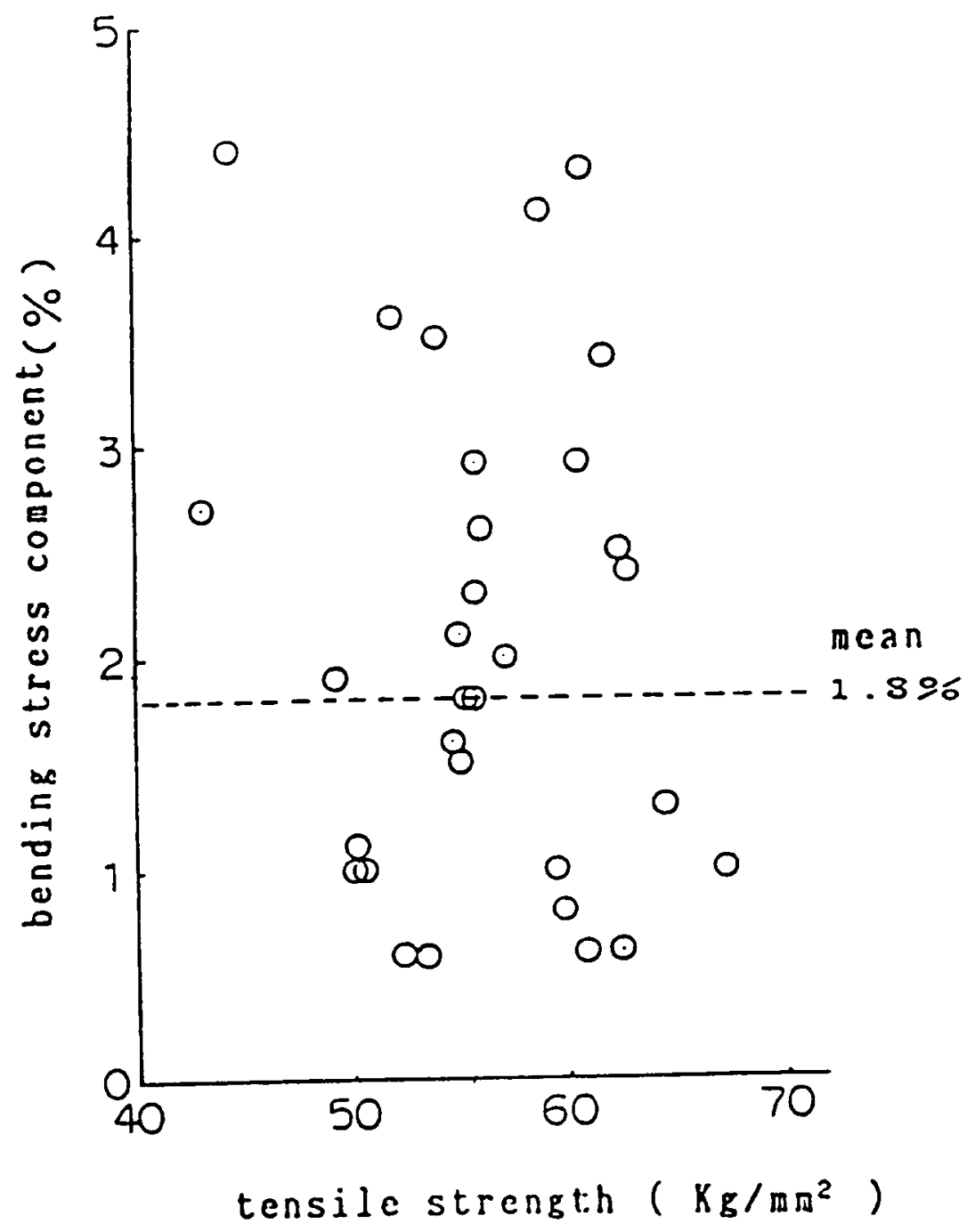

Fig. 21. Relationship between tensile strength and percent bending reported for a silicon nitride, SN220M, at room temperature (SN220M, Kyocera, Inc., Kyoto, Japan, 1989). Source: M. Kaji, "Evaluation of Techniques of Mechanical Properties," unpublished presentation given at Kyocera Central Research Laboratory, Kokubu, Japan, July 19, 1989. 
The Weibull tensile strength distributions of the PY6 and NT154 for both gripping systems are shown in Figs. 22 and 23 in which the Weibull modulus (m) and the Weibull characteristic tensile strength $\left(S_{\mathrm{o}}\right)$ were determined from the maximum likelihood estimate (MLE) method for a censored sample population. 35 In the application of this technique to the present case, all tests in which the tensile specimen failed outside the gage section, as shown in Table 1 (or from Ref. 29), were considered suspended tests, and the stress in the gage section at the time of the failure was used for purposes of statistical ranking only. The designation and use of the results from tests failing outside the gage section as suspended tests, rather than eliminating them as invalid tests, recognize the fact that the material in the uniformly stressed gage section could sustain at least the level of stress at the maximum recorded load before the test was halted by a failure outside the gage section.

The results of the present study are compared to similar tensile tests conducted at UDRI in which only a straight-collet system with annealed-copper collets was used. ${ }^{29}$ Given the limited sample sizes and different material batches, the strength distributions show reasonable agreement regardless of the gripping system used, thus indicating that the gripping system may not directly affect the failure stresses in the gage section for statistical populations. The results of the empirical tests show that both the tapered- and the straight-collet systems with deformable collets can sustain similar loads in the gripped section of the specimen before failure in the gage section. However, the tapered-collet system does seem to indicate a decreasing trend of $S_{\text {uts }}$ with increasing percent bending. Although this decreasing trend is not readily apparent for the straight-collet gripping system, a statistically significant difference is not apparent between the averages of the percent bending for the two gripping systems for the same material. While both gripping systems appear to perform the function of holding a specimen during tensile tests without failing the gripped section of the specimen, the straight-collet system is more straightforward and simpler to use as well as more accommodating to slight variations in specimen dimensions. At the levels of bending incurred in these tests, the Weibull tensile strength distributions of the two materials tested are not adversely affected as compared to results obtained by previous researchers. ${ }^{29}$

\section{EFFECT OF PERCENT BENDING}

Currently, no quantitative guideline has been established for determining the maximum bending allowable in a tensile test. There is general agreement that the cause of most of the 


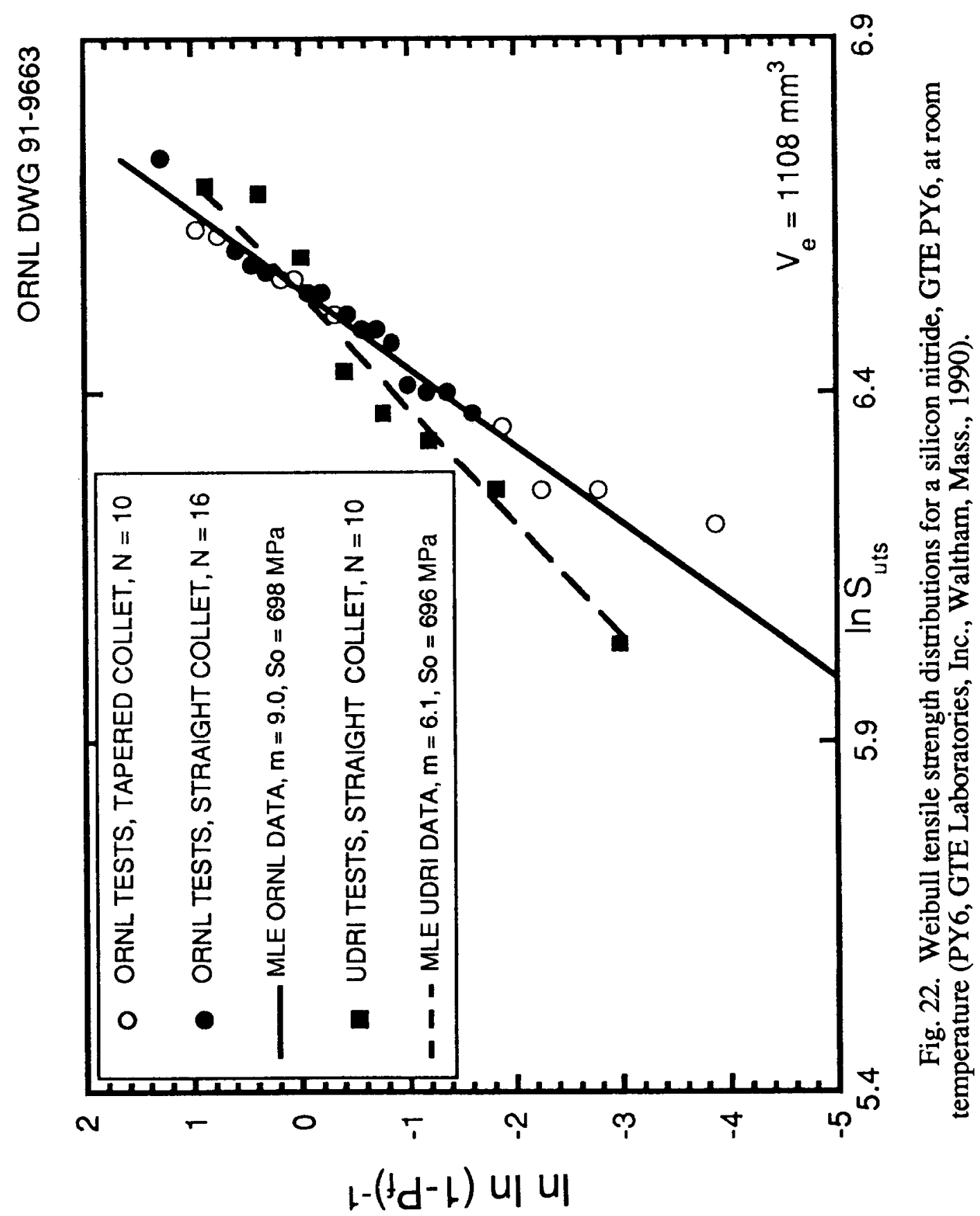




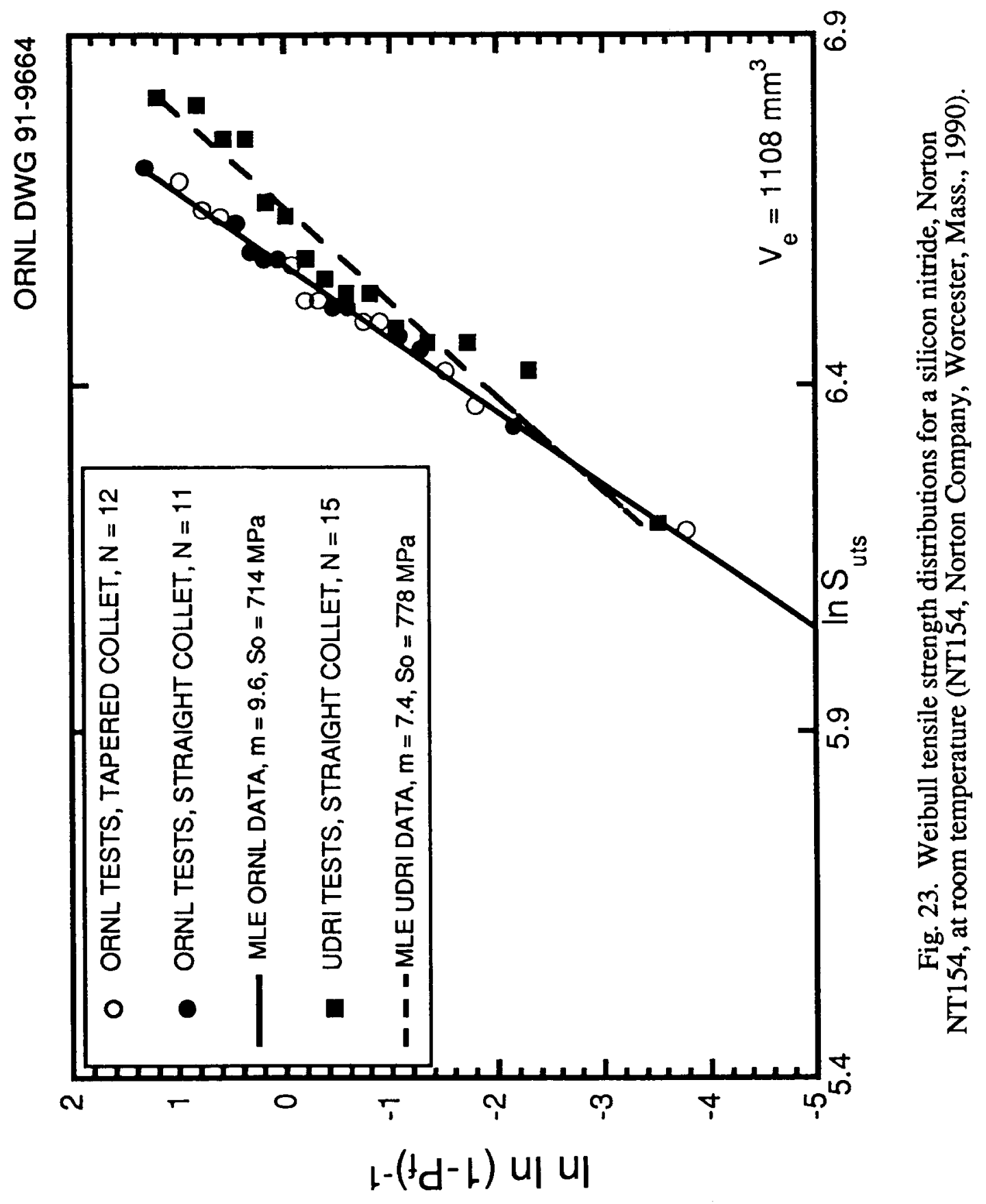


"scatter" in tensile test results may be atributed to nonuniform stress states due primarily to the presence of this unwanted bending. $1,8,11,15$

However, confirmation of this assertion has been lacking. Figure 21 shows recent tensile-strength test results* by Kyocera on 31 tensile specimens (gage section $6.0-\mathrm{mm}$ diam and 30.0-mm length) of an advanced ceramic (SN220M silicon nitride) at room temperature. This figure does not show a strong correlation between the calculated $S_{\mathrm{uts}}$ of the material and the bending component. Obviously, even though the inherent flaw size is on the order of less than the grain size, of the 31 samples, only 11 failed at the surface. Thus, the failure mechanisms are such that for these tests, percent bending of $<5.0$ does not appear to affect the strength results. Similar lack of correlation between $S_{u t s}$ and percent bending was noted for Figs. 19 and 20 in the present study.

As mentioned above, even though it is generally agreed that bending must be minimized in uniaxial tensile tests to minimize the scatter in test results for the assumed uniform stress state, there is no general agreement as to the maximum bending allowable for any one type of tensile testing (e.g., strength, stress-strain behavior, creep, etc.). $6,8,10-15,20,27,33,36-43$ Although various reports have been made of efforts to obtain and maintain percent bending in the range of less than $\sim 2.0$, the American Society for Testing and Materials (ASTM) calls for a percent bending of $<5.0$ to 10.0 for a valid tensile test, depending upon the type of test being conducted. ${ }^{33,36-40}$ The Japanese Standards Association recommends $<10.0$ percent bending ( 3.0 to 4.0 is preferred) in its standard for tensile testing ceramics at room and elevated temperatures. ${ }^{41}$ However, these values of percent bending are apparently the result of attempts to maintain a bending stress as low as possible based upon empirical observations with no formal basis for choosing the maximum allowable amount.

Recently, several proposals and studies have addressed methods to quantitatively evaluate the effect of bending on the statistical distribution of the measured tensile strengths. ${ }^{\dagger, \neq, 43}$ The most comprehensive of these proposes to perform numerical simulations of tensile strength distributions using consistent bending, randomly distributed, and Gaussian distributions of the bending with the hypothesized results as shown in

\footnotetext{
"M. Kaji, "Evaluation of Techniques of Mechanical Properties," unpublished presentation given at Kyocera Central Research Laboratory, Kokubu, Japan, July 19, 1989. †M. Kaji, "Silicon Nitride as Structural Materials," unpublished presentation given at Kyocera Central Research Laboratory, Kokubu, Japan, November 6, 1989.

łJ. Cuccio and C. Johnson, "Determination of Tensile Testing Bending Limits," unpublished presentation at ASTM Committee Meetings, San Francisco, May 1990.
} 
Fig. 24." Although the results of this proposal are yet to be achieved, two other studies have been completed that assume consistent bending. ${ }^{\dagger}, 43$ The two studies agree, in that it was quantitatively shown that up to a consistent $5.0 \%$ bending (i.e., all specimens in one series of tests receive the same percent bending) can be tolerated in tensile strength tests before the determination of the Weibull characteristic strength $\left(\mathrm{S}_{\mathrm{o}}\right)$ is affected. The Weibull modulus

(m) was not affected by the assumption of consistent bending, which is in agreement with the hypothesis shown in Fig. 24. Figure 25 shows the normalized characteristic strength $\left(S^{\prime} / S_{O}\right)$ plotted versus percent bending. In this figure, $S_{O}$ is the "true" Weibull characteristic strength and $S^{\prime}{ }_{0}$ is the Weibull characteristic strength determined from the tensile strength distributions with bending imposed. Details of the development of this figure are contained in Appendix A.

The conclusion from this limited study is that up to $5.0 \%$ bending can be consistently tolerated in fast-fracture tensile tests of brittle materials before the statistical distributions of the materials' tensile strengths are affected. Still unanswered are questions about effects of nonconsistent distributions of bending and the tensile creep behavior with initial bending.

\section{SPECIMEN DIMENSIONS AND GRINDING PROCEDURES}

As discussed previously, proper specimen dimensions and surface finishes will affect not only the interaction of the specimen and grips, but also the eccentricity introduced into the tensile testing system. Ultimately, these effects will influence the stress states in the gripped section of the specimen and in the gage section or transition region because of the induced bending. The following section discusses key aspects of specimen dimensions and grinding procedures.

\subsection{SPECIMEN DIMENSIONS}

An important point noted early in this investigation involved the need for the proper match between the machined surfaces of the specimen and the collet. Inspections of the specimens fabricated in various machining facilities revealed that none of the specimens met all the specifications of the drawings. Notable areas of discrepancy were:

*J. Cuccio and C. Johnson, "Determination of Tensile Testing Bending Limits," unpublished presentation at ASTM Committee Meetings, San Francisco, May 1990.

${ }^{\dagger}$ M. Kaji, "Silicon Nitride as Structural Materials," unpublished presentation given at Kyocera Central Research Laboratory, Kokubu, Japan, November 6, 1989. 

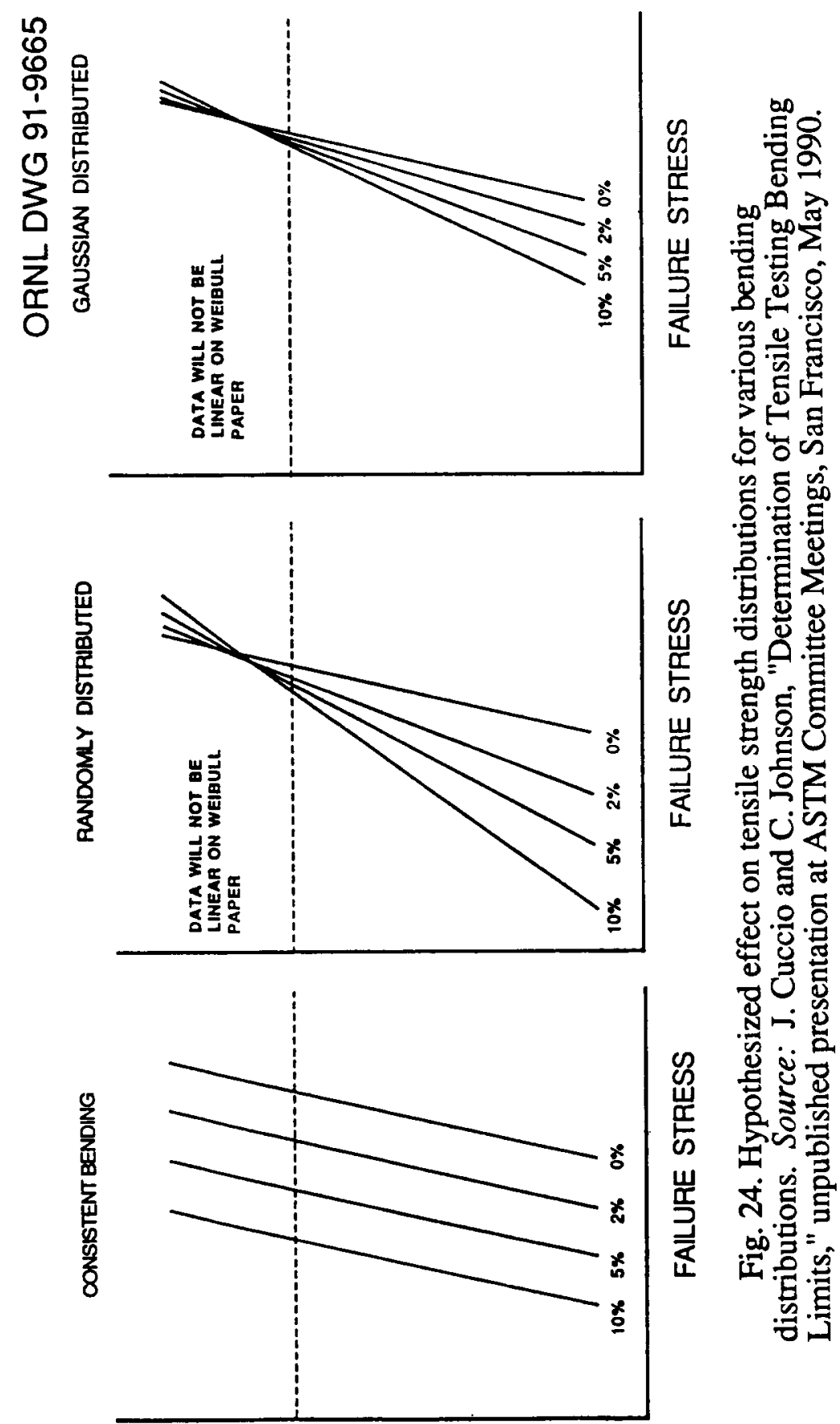

น 

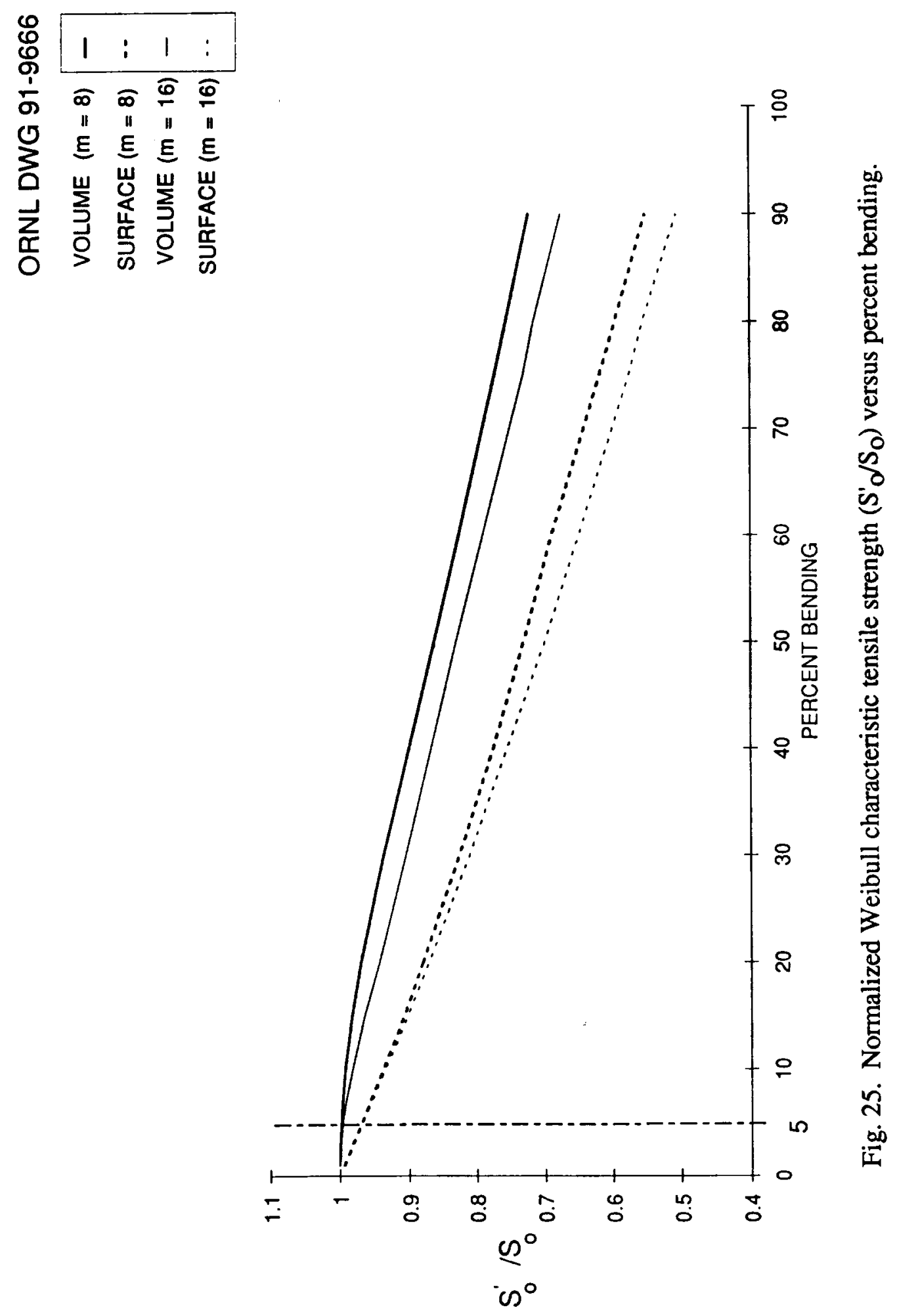
1. circumferential grinding marks in the gage sections and shanks near the button-head radii,

2. button-head radii undersized or oversized compared to the specification,

3. shanks near the buttonheads undercut or overcut,

4. shank diameters undersized or oversized compared to the specification, and

5. large radii of the gage-section transition nonuniform and undersized or oversized compared to the specification.

Some of these discrepancies can be attributed to the out-of-the-ordinary tolerances called for on the drawing $( \pm 0.005 \mathrm{~mm}$ specified with \pm 0.007 to $\pm 0.018 \mathrm{~mm}$ commonly obtainable with the required machining operations). ${ }^{44}$ However, other discrepancies are probably related to poor machining practices because of either unfamiliarity with diamond machining of ceramics or inattention to consistently meeting the drawing specifications. These poor machining practices are especially noteworthy in the button-head radius area where undercutting and overcutting, as well as inconsistent radius dimensions, can obviously be linked to the dubious technique of hand grinding this critical area.

A major effort has been expended in the present study to minimize these machining problems by (1) conducting all specimen fabrication under local, strictly controlled conditions and (2) automating the fabrication process as much as possible to minimize inconsistencies and improper practices due to human error. As discussed previously, a four-axis, CNC grinding machine with custom-designed and tailorable software was employed to this end. In addition to the numerical control, this machining operation uses formed grinding wheels ${ }^{\dagger}$ with either resinoid- or metal-bonded diamond abrasive to precisely and consistently produce correct, critical, button-head radii. The resinoid-bonded wheels are regularly dressed and trued during the machining operation to maintain the original dimensions of the form.

An accurate and reliable inspection procedure is necessary for verifying the proper execution of the machining process. In this regard, a high-resolution optical comparator with an associated numerical processor was employed to dimensionally characterize each specimen. This optical comparator system uses either projection or surface illumination

\footnotetext{
*Junger PSA 600, Grinding Technology, Inc., Hartford, Conn., 1986.

†Norton Diamond Wheel, SD320-R150BXL6145-7/32 (1/4), Norton Company, Worcester, Mass., 1990.

$\ddagger$ Nikon V-12 Profile Projector with O2L Linear Encoded Stage and DP-201 Data Processor, Nikon, Inc., Instrument Group, Garden City, New York, 1988.
} 
at magnifications from $5 \times$ to $500 \times$ to accurately determine dimensions with a resolution of $0.001 \mathrm{~mm}$, which is less than the tolerance range called for on the specimen drawings. Two important features of this system are the data processor and the optical screen sensor. The data processor automatically calculates such critical dimensions as radii and angles between intersecting surfaces with minimal operator interaction. The optical screen sensor eliminates operator guesswork by consistently determining specimen edges through the detection of the change in light intensity with a resolution of $0.001 \mathrm{~mm}$. The dimensional data are automatically recorded on a personal computer in a spreadsheet format for subsequent statistical evaluation.

Procedures for measuring specimen dimensions are contained in Appendix C. A comparison projection of a vendor-supplied specimen and one machined under the conditions described above is shown in Fig. 26. The dotted line representing the profile of the specimen machined under strictly controlled conditions matches the as-called-for drawing while the discrepancies and the vendor-supplied part are obvious.

Precise control over the various aspects of the machining operation is necessary to minimize sources of errors in producing the specimen dimensions. The verification of the specimen dimensions using high-resolution metrology such as the optical comparator is necessary not only to screen specimens with out-of-tolerance dimensions (hence, susceptible to failures outside the gage section) but also to alert the machinist to possible problems with the grinding machine, grinding wheels, or grinding procedure.

\subsection{GRINDING CONSIDERATIONS}

In addition to concerns regarding maintaining dimensions and tolerances, other salient aspects of grinding that may affect the success of tensile tests are briefly discussed below. Details of the machining "rationale" are contained in Appendix D.

CNC fabrication methods were necessary to obtain consistent specimens with the proper dimensions within the required tolerances. A necessary condition for this consistency is the complete fabrication of the specimen without removing it from the grinding apparatus, thereby avoiding building unacceptable tolerances into the finished specimen.

Formed, resinoid-bonded, diamond-impregnated wheels are necessary to both fabricate critical shapes (e.g., button-head radius) and to minimize grinding vibrations and subsurface damage in the test material. The formed, resin-bonded wheels require periodic dressing and shaping (truing), which can be done dynamically within the test machine, to maintain the cutting and dimensional integrity. 


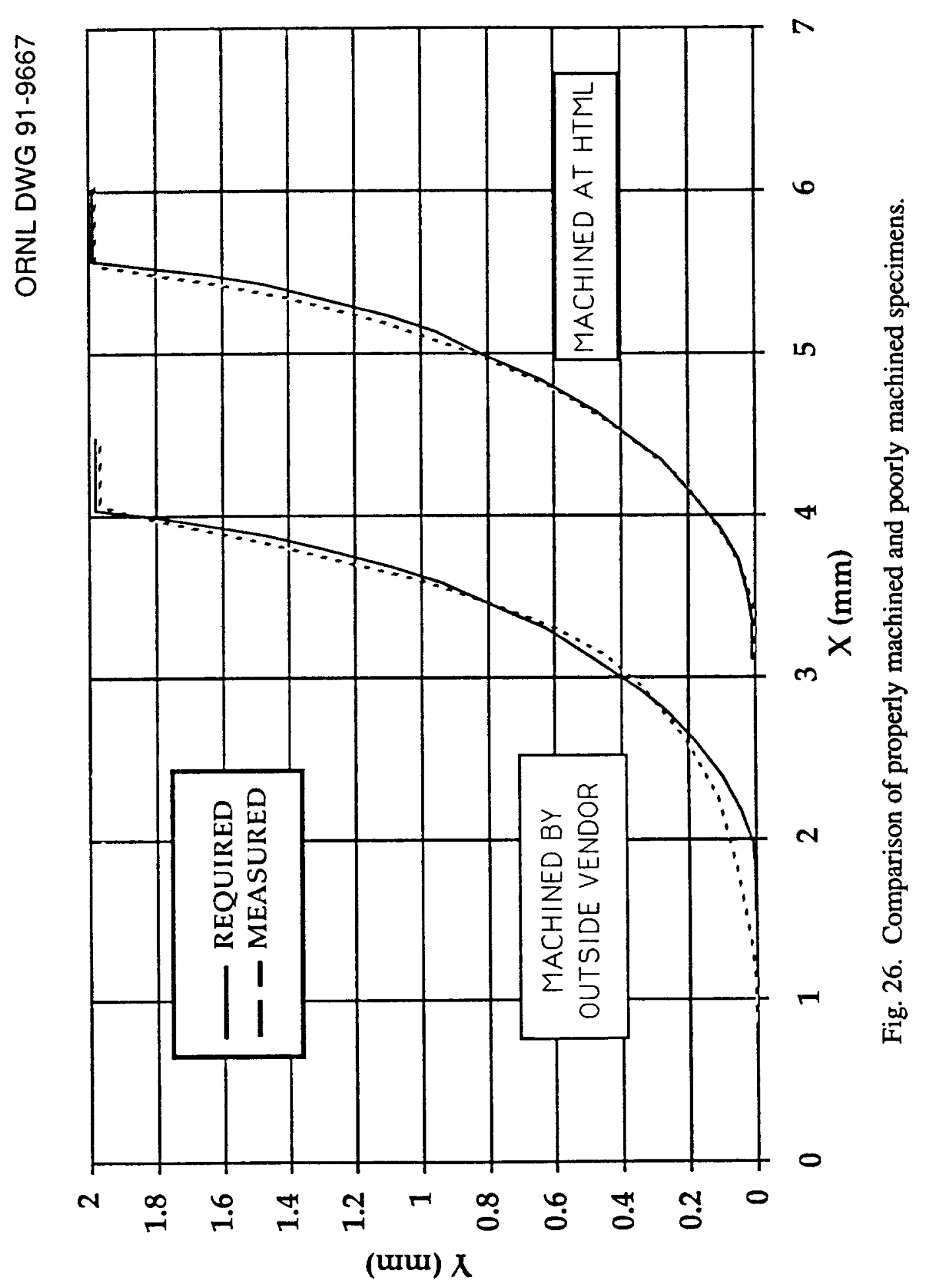


MRRs must be maintained within limits to provide acceptable productivity while minimizing subsurface damage to the test piece. The recommended grinding process can use one grit size (320 grit in a resinoid bond) for the entire operation, although a two-step process can be employed using either of two types of grinding wheels as shown in Table 2. For silicon nitride, MRR-per-unit wheel width should not exceed $645 \mathrm{~mm}^{3} /(\mathrm{mm} \cdot \mathrm{min})$ but normally should also not be less than $100 \mathrm{~mm}^{3} /(\mathrm{mm} \cdot \mathrm{min})$. This MRR should be achieved with low infeeds $(0.005$ to $0.01 \mathrm{~mm})$ and moderate crossfeeds $(0.02$ to $0.25 \mathrm{~m} / \mathrm{s})$ in conjunction with high wheel speeds ( 100 to $200 \mathrm{~m} / \mathrm{s}$ ). The most serious concern is not necessarily the surface finish (on the order of $R_{a}=0.2 \mu \mathrm{m}$ ), which is a result of the final machining steps. Instead, the subsurface damage is critically important, although this damage is not readily observed or measured and, therefore, must be inferred as the result of the grinding history. More details of this aspect are contained in Appendix D.

\section{Table 2. Recommended specifics of grinding procedure}

\begin{tabular}{|l|l|l|}
\hline Operation & Resinoid bonded $^{a}$ & Metal bonded $^{a}$ \\
\hline $\begin{array}{l}\text { 'Rough' grind to } \\
0.40 \mathrm{~mm} \text { over final } \\
\text { dimensions }\end{array}$ & $\begin{array}{l}\text { Minimum } 180 \text { grit } \\
\text { - True, dress, shape for } \\
\text { each specimen }\end{array}$ & Minimum 220 grit \\
\hline $\begin{array}{l}\text { Finish grind from } \\
0.40 \mathrm{~mm} \text { oversize to } \\
\text { final dimensions }\end{array}$ & $\begin{array}{l}\text { Minimum 320 grit } \\
\text { - True, dress, shape for } \\
\text { each specimen }\end{array}$ & Minimum 400 grit \\
\hline
\end{tabular}

$a_{75}$ to $100 \%$ concentration of diamond-per-unit volume of abrasive preferred with nickel-coated, moderate-to-high-friability diamond abrasive preferred.

Adequate coolant/lubricant flow and filtration, as well as proper coolant type, are necessary to avoid unknown and unquantifiable chip/workpiece interaction. The flow rate of the coolant should be at least as great as the MRR. In addition, care must be taken to ensure that the dynamic forces of the wheel rotation at the point of coolant entry to the interface of the wheel and workpiece do not allow the coolant to be diverted, thus "starving" the interface for adequate cooling and chip removal as discussed in Appendix D. Filtration should be on the order of the average chip size or $\sim 1.0 \mu \mathrm{m}$. The coolant type should be water based at concentrations of 25 to $50 \%$ to improve flowability as well as to increase the degree of filtration. 


\section{CONCLUSIONS AND RECOMMENDATIONS}

Nongage-section failures, particularly in the gripped section of the specimen, are related to several causes: (a) mismatch at the grip/specimen interface due to improper dimensions, (b) improper surface finish or subsurface damage due to machining practices, and (c) localized contact stresses due to mismatches of collet dimensions or materials.

In both gripping systems (straight- and tapered-collet), FEAs showed that stress ratios in the button-head region existed that were equal to 0.75 to 1.0 of the gage-section stress. In addition, a stress ratio of $\sim 1.04$ exists at the transition area near both ends of the uniformly stressed gage section. Both of these higher stressed regions can lead to failures outside the gage section.

For straight-shanked specimens tested in conjunction with self-aligning, hydraulic, load-train couplers, the tapered-collet system can sustain similar loads but with lower percent bending before gripped-section failure compared to the straight-collet system with soft copper collets. An advantage of the straight-collet system is its ease and simplicity of use.

In the comparison of the straight- and tapered-collet gripping systems, no clear-cut "best" system exists. Similar maximum loads can be achieved with either the standard, tapered- or the straight-collet system with soft, deformable collets (e.g., annealed copper). The straight-collet system shows a statistically significant greater average percent bending of all the tests than shown by the tapered-collet system, although the tapered-collet system appears to produce decreasing strengths with increasing percent bending. The straight-collet system is simpler and more straightforward to use, as well as less sensitive to slight dimensional irregularities, than is the tapered-collet system.

The authors recommend that all specimens be strain gaged with a minimum of four longitudinal strain gages equispaced around the circumference at the middle of the gage section. The strain gages will allow the monitoring of percent bending during testing to allow either a test to be stopped if percent bending is unacceptable $(>5.0 \%)$ or correlation of excessive percent bending with calculated strength.

The authors recommend that all specimens be dimensionally checked using highprecision metrology $(\sim 1.0-\mu \mathrm{m}$ resolution) to screen unacceptable specimens before testing. Dimensional tolerances of $\pm 2.5 \mu \mathrm{m}$ are required to maintain proper grip/specimen interfaces and to minimize bending influences due to nonconcentricity of the gripped areas and the gage section.

The authors recommend that the grinding history of the tensile specimen be controlled closely to minimize subsurface machining damage that may lead to undesirable failures. 
Proper dimensions within the tolerances and proper arithmetic average $\left(R_{\mathbf{a}}\right)$ surface roughness of $0.4 \mu \mathrm{m}$ are still recommended but should not be the final determination of proper machining. Resinoid-bonded, diamond-abrasive wheels of at least 320 grit, with MRRs of $\leq 645 \mathrm{~mm}^{3} /(\mathrm{mm} \cdot \mathrm{min})$ are recommended. In addition, water-based coolants and $1.0-\mu \mathrm{m}$, continuous-pass filtration are highly desirable.

The authors recommend that up to $5.0 \%$ bending can be consistently tolerated for fastfracture testing at room temperature without producing large variations in either the Weibull modulus or the Weibull characteristic strength.

The dimensions and geometry of the currently accepted button-head tensile specimen are acceptable for fast-fracture, creep, stess-relaxation, and cyclic-fatigue tensile testing at elevated temperatures. However, a possible redesign of the specimen might include a modified gripping section (conical head) with tapered collets and a straight-collet type of grip to reduce the incidences of failure of the gripped section and to facilitate the installation of the collets and grips. An elliptical type of transition from the gage section would reduce the stress raiser ${ }^{31}$ to minimize transition area failures. An example of such a specimen is shown in Fig. 27. 


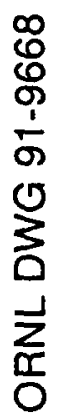
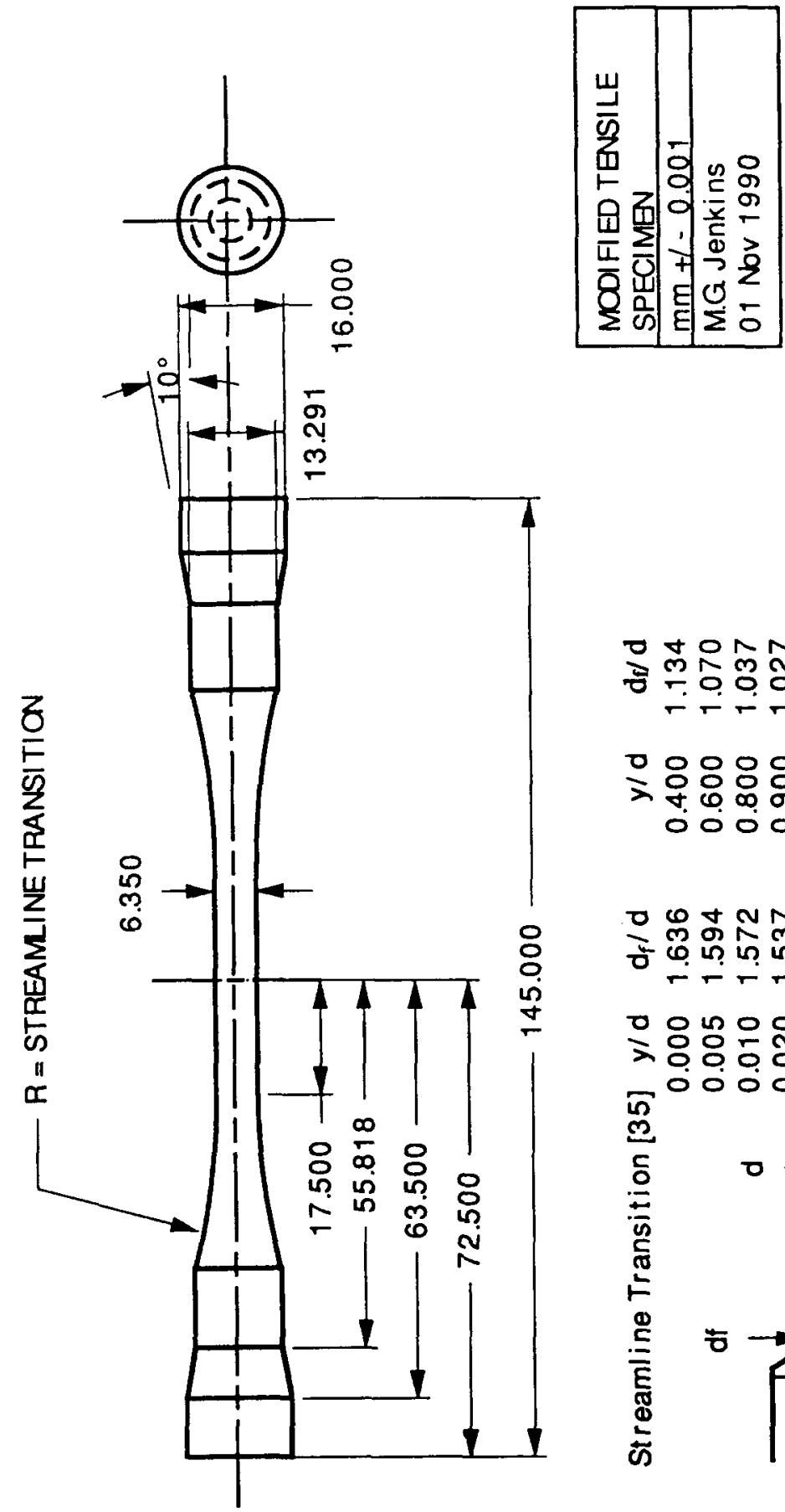

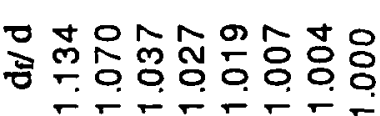

응ㅇㅇㅇㅇㅇㅇㅇㅇㅇㅇㅇ

久 $0000-\pi$

- 0 d 둥

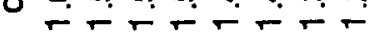

잊ㅇㅇㅇ응응융영용유

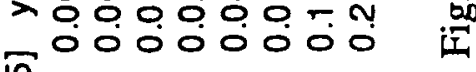

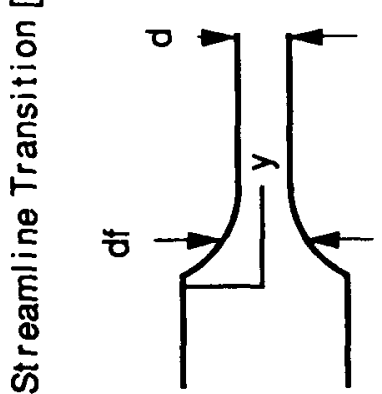




\section{ACKNOWLEDGMENTS}

The grinding and testing facilities of the Mechanical Properties User Center, High Temperature Materials Laboratory, Oak Ridge National Laboratory, were used in this study. Partial funding was supplied under the Ceramic Technology for Advanced Heat Engines Project, U.S. Department of Energy, Assistant Secretary for Conservation and Renewable Energy, Office of Transportation Technologies.

\section{REFERENCES}

1. A. Rudnick, C. W. Marschall, W. H. Duckworth, and B. R. Emrich, The Evaluation and Interpretation of Mechanical Properties of Brittle Materials, AFML-TR-67-316, Air Force Materials Laboratory, Wright Patterson Air Force Base, Ohio, 1968.

2. Instron Corporation, Instron Super Grip, PS-6-1202, Canton, Mass., 1988.

3. MTS Systems Corporation, Design Description-686.03 Grips Solve Ceramic Testing's Tough Problems, 500000-30/110.90-01, Minneapolis, Minn., 1988.

4. D. L. Vaccari and P. K. Khandelwal, "Life Prediction Methodology," WBS Element 3.2.2.2, pp. 397-401 in Ceramic Technology for Advanced Heat Engines Project Semiannual Progress Report for October 1989 through March 1990, ORNL/TM-11586, Martin Marietta Energy Systems, Inc., Oak Ridge Natl. Lab., 1990.

5. A. Comfort, J. Cuccio, and H. Fang, "Life Prediction Methodology for Ceramic Components of Advanced Engines," WBS Element 3.2.2.3, pp. 402-11 in Ibid.

6. M. H. Jones and W. F. Brown, Jr., "An Axial Loading Creep Machine," ASTM Bull. 211, 53-60 (1956).

7. C. D. Pears and M. Digesu, "Gas-Bearing Facilities for Determining Axial StressStrain and Lateral Strain of Brittle Materials to 550 F," Am. Soc. Testing Mater. Proc. 65, 855-73 (1965).

8. R. K. Penny, E. G. Ellison, and G. A. Webster, "Specimen Alignment and Strain Measurement in Axial Creep Tests," Mater. Res. Stand. 6(1), 76-89 (1966).

9. C. D. Pears and H. W. Starrett, "An Experimental Study of the Weibull Volume Theory," AFML-TR-66-228, Air Force Materials Laboratory, Wright Patterson Air Force Base, Ohio, 1967.

10. E. M. Smith, C. Grant, and J. M. Booth, "Equipment of Creep Testing at Variable Load and Temperature," J. Strain Anal. 5(2), 145-54 (1970). 
11. C. Grant, "Axiality of Loading in the Tensile Test," J. Strain Anal. 7(4), 261-65 (1972).

12. M. H. Jones and W. F. Brown, Jr., "Note on Performance of Tapered Grip Tensile Loading Devices," J. Test. Eval. 3(3), 179-81 (1975).

13. R. K. Kossowsky, D. G. Miller, and E. S. Diaz, "Tensile and Creep Rupture of Hot-Pressed Silicon Nitride," J. Mater. Sci. 10, 983-97 (1975).

14. F. F. Lange and E. S. Diaz, "Powder-Cushion Gripping to Promote Good Alignment in Tensile Testing," J. Test. Eval. 6(5), 320-23 (1978).

15. B. W. Christ and S. R. Swanson, "Alignment Problems in the Tensile Test," J. Test. Eval. 4(6), 405-17 (1979).

16. F. F. Lange, E. S. Diaz, and C. A. Anderson, "Tensile Creep Testing of Improved Silicon Nitride," J. Am. Ceram. Soc. 58, 845-48 (1979).

17. R. K. Govila, "Uniaxial Tensile and Flexural Stress Rupture Strength of HotPressed Silicon Nitride," J. Am. Ceram. Soc. 65, 15-21 (1982).

18. R. K. Govila, "High Temperature Uniaxial Tensile Stress Rupture Strength of Sintered Alpha SiC," J. Mater. Sci. 18, 1967-76 (1983).

19. T. Soma, M. Matsui, and I. Oda, "Tensile Strength of a Sintered Silicon Nitride," pp. 361-74 in Non-oxide Technical and Engineering Ceramics, ed. S. Hampshire, Elsevier Applied Science, Essex, England, 1986.

20. K. C. Liu and C. R. Brinkman, "Tensile Cyclic Fatigue of Structural Ceramics," pp. 279-84 in Proceedings of the 23rd Automotive Technology Development Contractors' Coordination Meeting, Dearborn, Michigan, October 21-24, 1985, P-165, Society of Automotive Engineers, Warrendale, Pa., 1986.

21. "Investigation of High Temperature Tensile Testing Procedures," in The Report of Research and Investigation on Standardization of High Performance Ceramics, Asahi Glass Co., Ltd.; IHI Co., Ltd.; NGK Insulator Co., Ltd., Japan, 1986.

22. H. Fujita, M. Kawai, H. Takashi, H. Abe, and J. Nakayama, "Uniaxial Tensile Fatigue Testing of Sintered Silicon Carbide under Cyclic Temperature Change," pp. 379-90 in Fracture Mechanics of Ceramics, Vol. 7, ed. R. C. Bradt, A. G. Evans, D. P. H. Hasselman, and F. F. Lange, Plenum, New York, 1987.

23. S. G. Seshadri and K-Y Chia, "Tensile Testing Ceramics," J. Am. Ceram. Soc. 70(10), C242-44 (1987).

24. T. Ohji, "Towards Routine Tensile Testing," Int. J. High Technol. Ceram. 4, 211-25 (1988). 
25. R. Vaidayanathan, J. Sankar, and V.S. Avva, "Uniaxial Tensile Characteristics of Silicon Nitride at Room Temperature," Ceram. Eng. Sci. Proc. 9 (9-10), 1383-92 (1988).

26. M. Masuda, T. Soma, M. Matsui, and I. Oda, "Cyclic Fatigue of Sintered $\mathrm{Si}_{3} \mathrm{~N}_{4}$," Ceram. Eng. Sci. Proc. 9(9-10), 13871-82 (1988).

27. D. F. Carroll, S. M. Wiederhorn, and D. E. Roberts, "Technique for Tensile Creep Testing of Ceramics," J. Am. Ceram. Soc. 72(9), 1610-14 (1989).

28. K. C. Liu and C. R. Brinkman, "Tensile Cyclic Fatigue Testing of Structural Ceramics," W.B.S. Element 3.2.1.4, pp. 359-72 in Ceramic Technology for Advanced Heat Engines Project Semiannual Progress Report for October 1989 through March 1990, ORNL/TM-11586, Martin Marietta Energy Systems, Inc., Oak Ridge Nat. Lab., 1990.

29. N. L. Hecht, "Environmental Effects in Toughened Ceramics," W.B.S. Element 3.3.1.4, pp. 379-422 in Ceramic Technology for Advanced Heat Engines Semiannual Progress Report for April 1989 through September 1989, ORNL/TM 11489, Oak Ridge Natl. Lab., Martin Marietta Energy Systems, Inc., Oak Ridge, Tenn., 1990.

30. Practical Handbook of Materials Science, ed. C. T. Lynch, CRC Press, Inc., Boca Raton, Fla., 1989.

31. R. E. Peterson, Stress Concentration Design Factors, pp. 80-107, Wiley, New York, 1953.

32. S. P. Timoshenko and J. N. Goodier, Theory of Elasticity, pp. 409-20, McGrawHill Book Co., New York, 1971.

33. "Sharp-Notch Tension Testing with Cylindrical Specimens," ASTM E 602-81, pp. 631-39 in 1989 Annual Book of ASTM Standards, Vol. 03.01, American Society for Testing and Materials, Philadelphia, 1989.

34. E. L. Crow, F. A. Davis, and M.W. Maxfield, Statistics Manual, pp. 45-6, Dover Publications, Inc., New York, 1960.

35. R. B. Abernethy, J. E. Breneman, C. H. Medlin, and G. L. Reinman, Weibull Analysis Handbook, AFWAL-TR-83-2079, Aero Propulsion Laboratory, Wright-Patterson Air Force Base, Ohio, 1983.

36. "Standard Practice Elevated Temperature Tension Tests of Metallic Materials," ASTM E 21-79, pp. 191-97 in 1989 Annual Book of ASTM Standards, Vol. 03.01, American Society for Testing and Materials, Philadelphia, 1989.

37. "Standard Practice for Conducting Creep, Creep-Rupture, and Stress-Rupture Tests of Metallic Materials," ASTM E 139-83, pp. 313-23 in 1989 Annual Book of ASTM Standards, Vol. 03.01, American Society for Testing and Materials, Philadelphia, 1989. 
38. "Standard Practice for Conducting Time-for-Rupture Notch Tension Tests of Materials," ASTM E292-83, pp. 418-26 in 1989 Annual Book of ASTM Standards, Vol. 03.01, American Society for Testing and Materials, Philadelphia, 1989.

39. "Standard Practice for Conducting Constant-Amplitude Axial Fatigue Tests of Metallic Materials,"ASTM E 466-82, pp. 539-43 in 1989 Annual Book of ASTM Standards, Vol. 03.01, American Society for Testing and Materials, Philadelphia, 1989.

40. "Standard Practice for Conducting Constant-Amplitude Low-Cycle Fatigue Testing," ASTM E 606-80, pp. 601-13 in 1989 Annual Book of ASTM Standards, Vol. 03.01, American Society for Testing and Materials, Philadelphia, 1989.

41. Japanese Standards Association, "Testing Methods for Tensile Strength of High Performance Ceramics at Room and Elevated Temperatures," JIS R1606, 1990.

42. T. J. Vasko and B. N. Cassenti, The Statistical Prediction of Failure Location in Brittle Test Specimens, United Technologies Research Center, United Technologies Corporation, East Hartford, Conn., 1986.

43. M. G. Jenkins, M. K. Ferber, and R. L. Martin, "Evaluation of the Stress State in a Button-Head, Tensile Specimen for Ceramics," Ceram. Eng. Sci. Proc. 11(9), 1346-63 (1990).

44. E. Oberg, F. D. Jones, and H. L Horton, pp. 1528-78 in Machinery's Handbook 21st Edition, Industrial Press, New York, 1981. 


\section{APPENDIX A. STRAIGHT- AND TAPERED-COLLET GRIPPING SYSTEMS}

The following pages contain engineering drawings for the straight- and tapered-collet gripping systems and procedures for conducting tensile tests with each gripping system. Applicable dimensions from these drawings were used for the finite element analysis (FEA) studies. The complete drawings were used to construct the grips used in the empirical tests.

\section{A.1 STRAIGHT-COLLET GRIPPING SYSTEM}

The straight-collet gripping system consists of the following components:

- two grip holders (Fig. A.1), one for the upper and one for the lower end of the specimen;

- two sets of grip cover plates (Fig. A.2), one set for the upper grip and one set for the lower grip (each cover plate set is held in place for six M6- $6 \mathrm{H} \times 8$ flathead screws); and

- two sets of collets (Figs. A.3 and .4), one set for the upper grip and one set for the lower grip.

The procedure for conducting a tensile test using the straight-collet system is as follows (refer to Fig. A.5):

1. Holding the specimen with the longitudinal axis vertical, place a set of freshly annealed copper collets around the upper shank of the specimen near the button head. Ensure that the radii of the collets are in contact with the radius of the button head.

2. Insert the "colleted" end of the specimen into the opening of the upper grip holder until the ends of the collets are flush with the surface of the grip holder.

3. Place both halves of the cover plate set in position on the grip holder so as to cover the collets while encircling the shank of the specimen. Insert and snugly tighten the six screws required to hold the cover plate set in place.

4. Ensuring that the specimen is hanging freely from the upper grip holder, attach the strain-gage wires to the strain-gage conditioner. It is important to balance the strain gage at this point with no axial or eccentric loads applied to the specimen. 


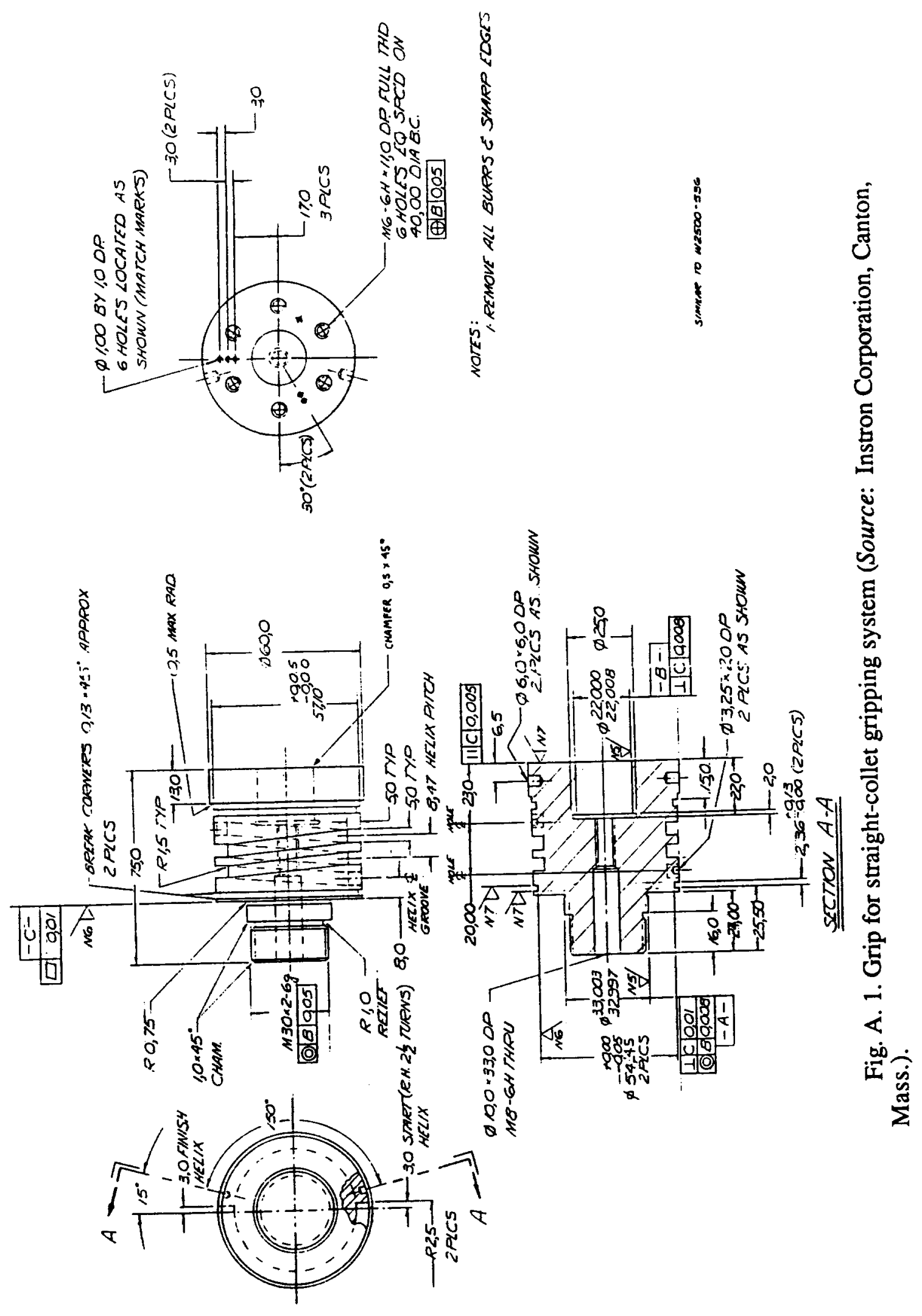




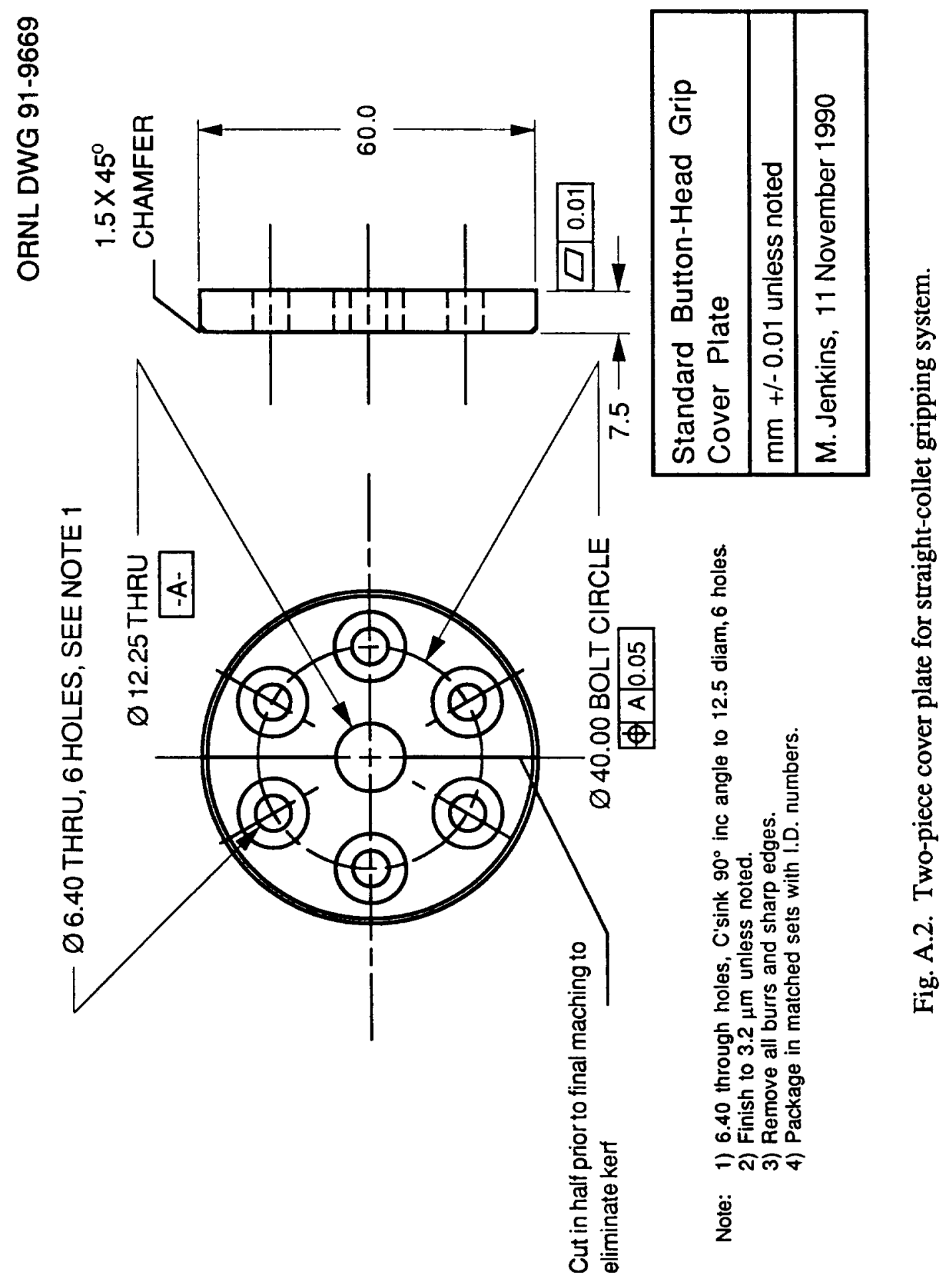


0
0
1
$\frac{1}{0}$
0
0
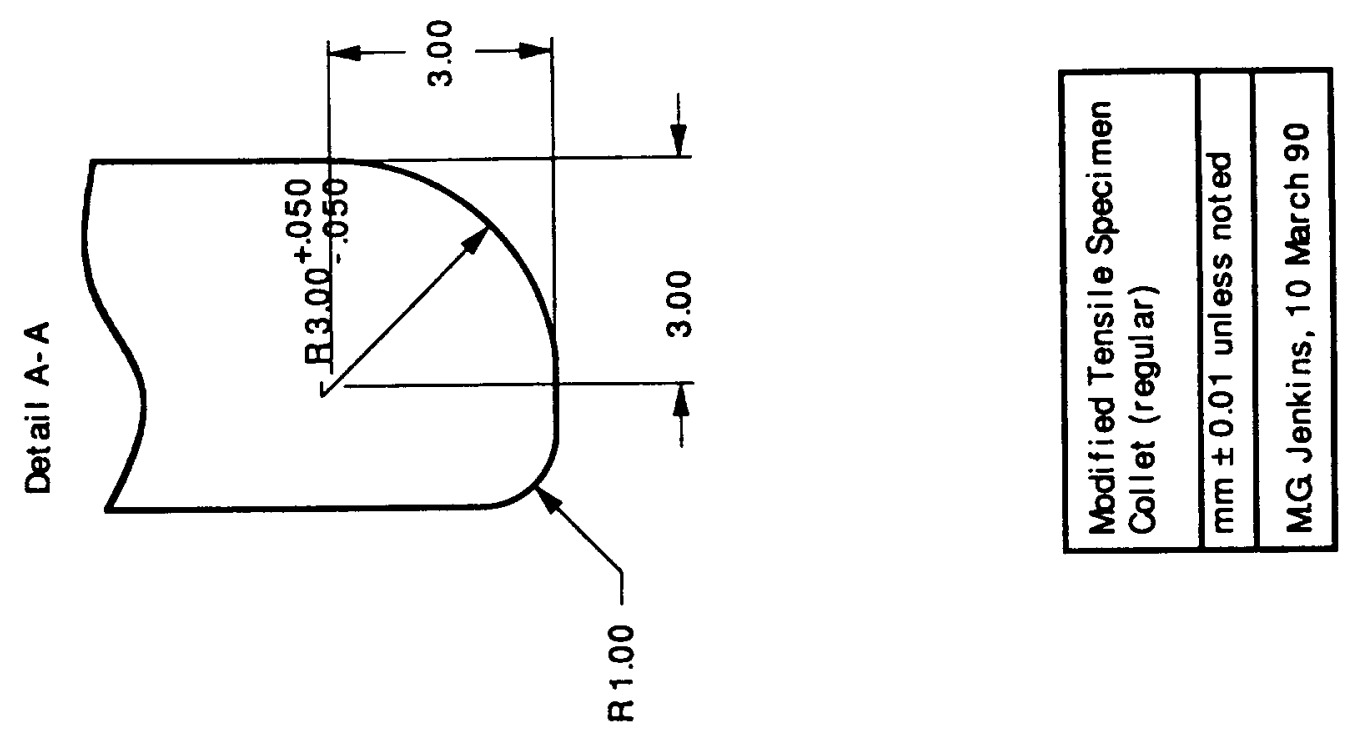

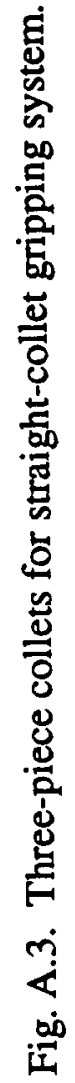
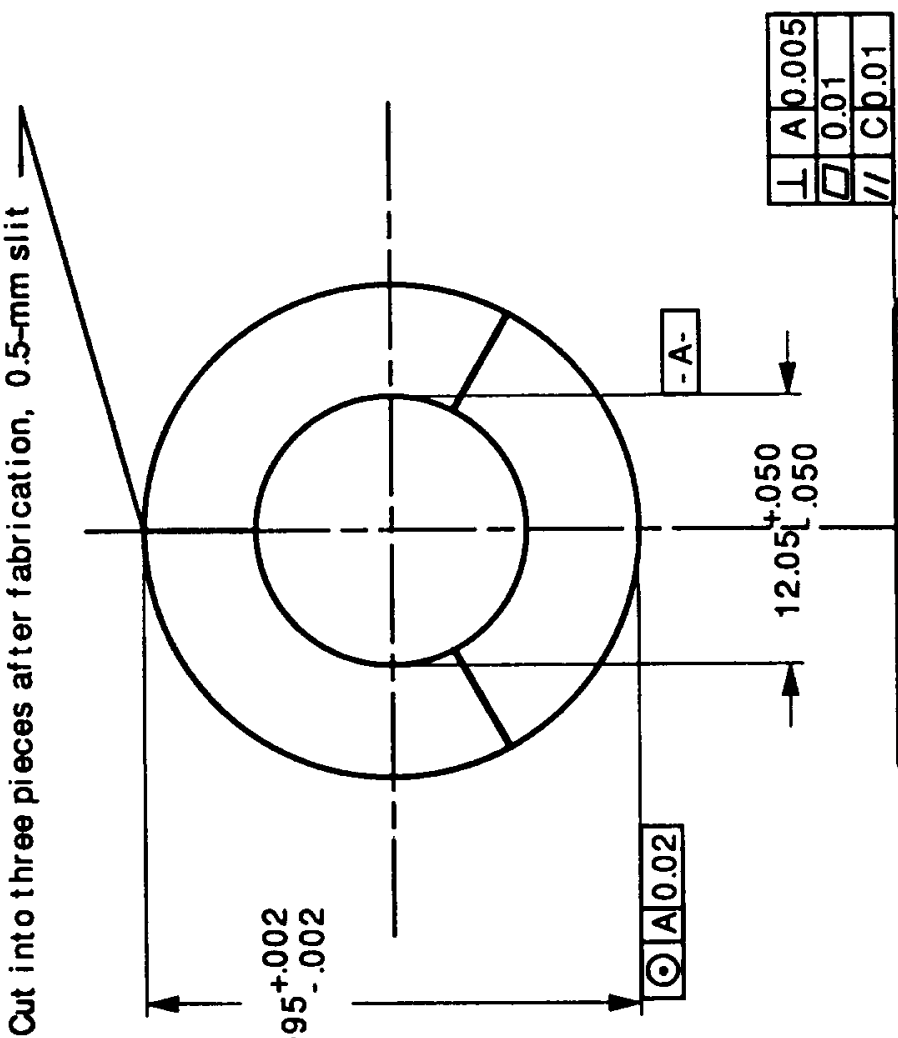

4

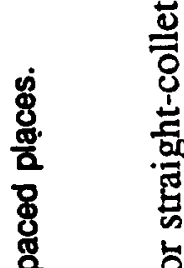



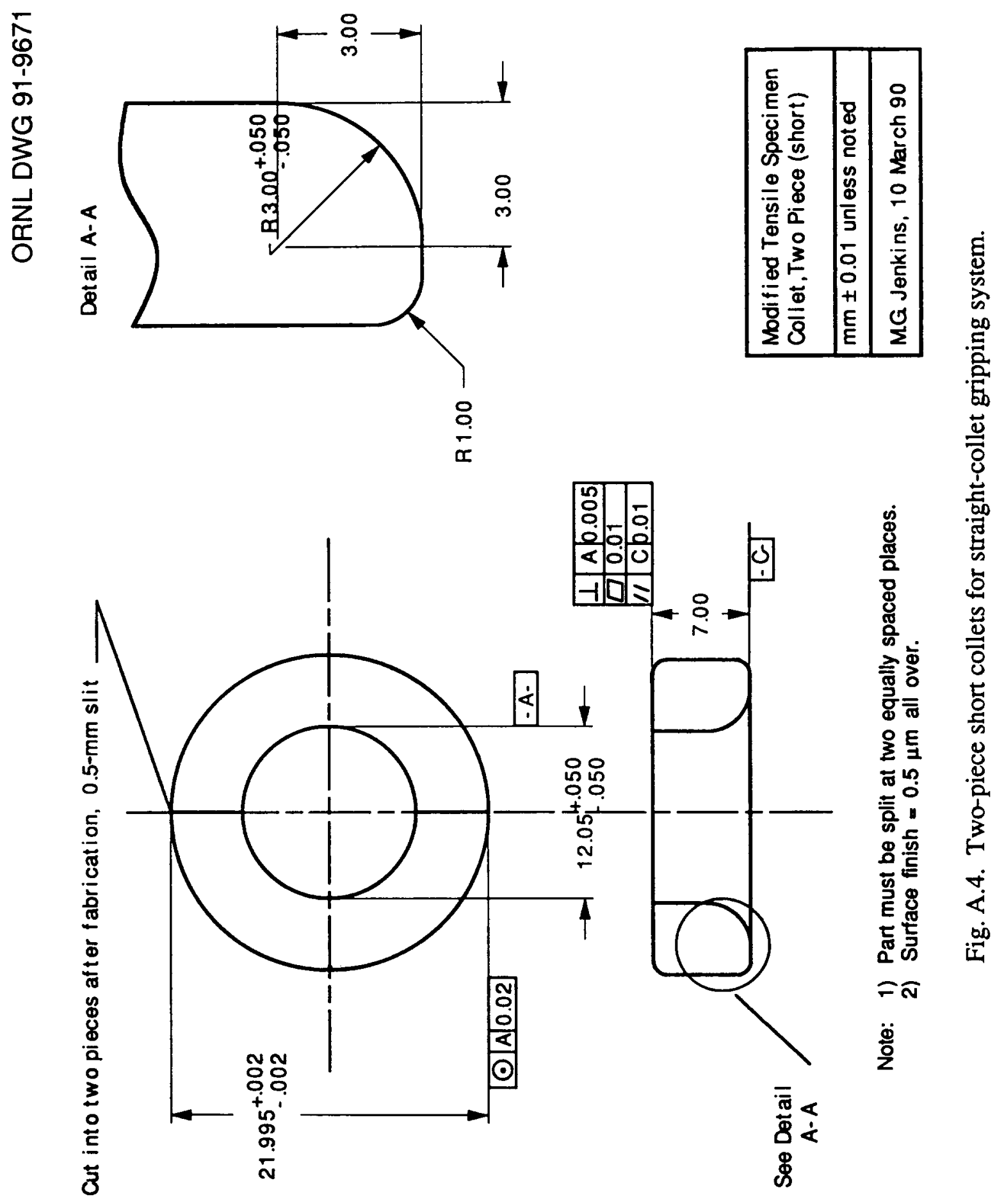
ORNL DWG 91-9672

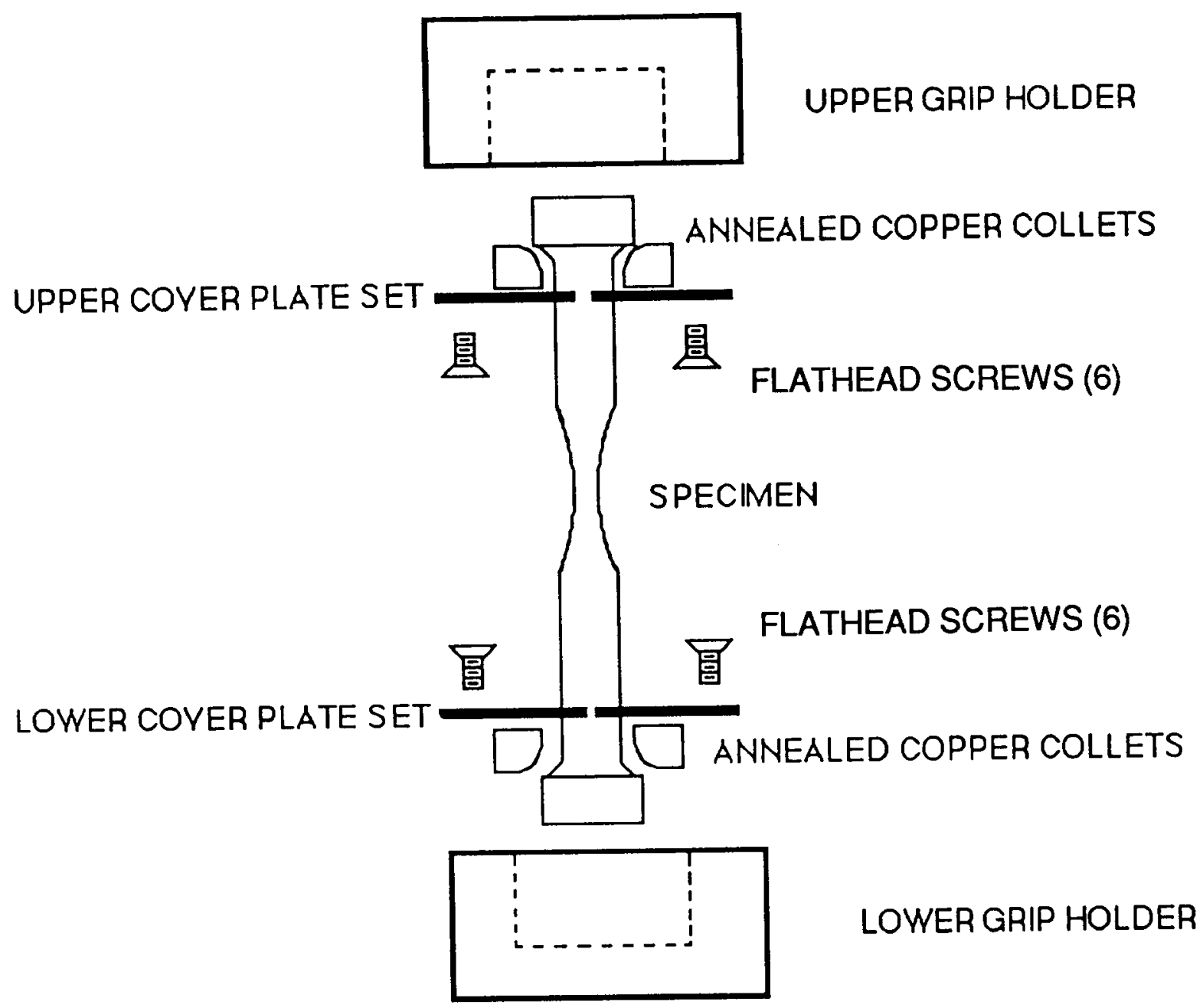

Fig. A.5. Procedure for using straight-collet gripping system. 
5. Place a set of freshly annealed copper collets around the lower shank of the specimen near the button head. Ensure that the radii of the collets are in contact with the radius of the button head.

6. Insert the "colleted" end of the specimen into the opening of the lower grip holder until the ends of the collets are flush with the surface of the grip holder by raising or lowering the cross head of the test machine depending upon the testing configuration.

7. Place both halves of the cover plate set in position on the grip holder so as to cover the collets while encircling the shank of the specimen. Insert and snugly tighten the six screws required to hold the cover plate set in place.

8. Slowly apply a preload of 150 to $200 \mathrm{~N}$ to the load train to take the "slack" out of the system.

9. After switching to load control, apply a stressing rate of $\sim 0.2 \mathrm{MPa} / \mathrm{s}$ from the preload to $6,500 \mathrm{~N}(\sim 1,000 \mathrm{~s})$. Strain-gage readings and percent bending should be noted during this slow loading to monitor the deformation of the copper collets as they conform to the specimen.

10. At a load of $6,500 \mathrm{~N}$ the percent bending in the specimen should be on the order of 5.0 to 10.0 . If the value is $>10.0$, the load should be reduced to about $200 \mathrm{~N}$ and the rotational alignment of the grips changed to minimize the bending. Reapply a load of $6,500 \mathrm{~N}$ and check the percent bending again. Repeat this process until 5.0 to $10.0 \%$ bending is achieved.

11. Begin recording the strain-gage information continuously while applying a stressing rate of $\sim 30 \mathrm{MPa} / \mathrm{s}$ from $6,500 \mathrm{~N}$ to failure $(\sim 30 \mathrm{~s}$ to load to $35,000 \mathrm{~N})$.

12. After the specimen fails, save the data file with the strain-gage and load information into it for later data reduction. Remove the specimen in reverse order of the installation. The collets should not be reused but should instead be annealed in a vacuum $\left(\sim 10^{-4} \mathrm{~Pa}\right)$ for $1 \mathrm{~h}$ at 800 to $850^{\circ} \mathrm{C}$.

\section{A.2 TAPERED-COLLET GRIPPING SYSTEM}

The tapered-collet gripping system consists of the following components:

- two modified grip adaptors (Figs. A.6 and/or A.7), one for the upper and one for the lower end of the specimen;

- two grip holders (Fig. A.8), one set for the upper grip and one set for the lower grip (each grip holder is threaded into its matching grip adaptor); and 
0
1
0
1
0
0
$\vdots$
0
$\vdots$
$\vdots$
0
0

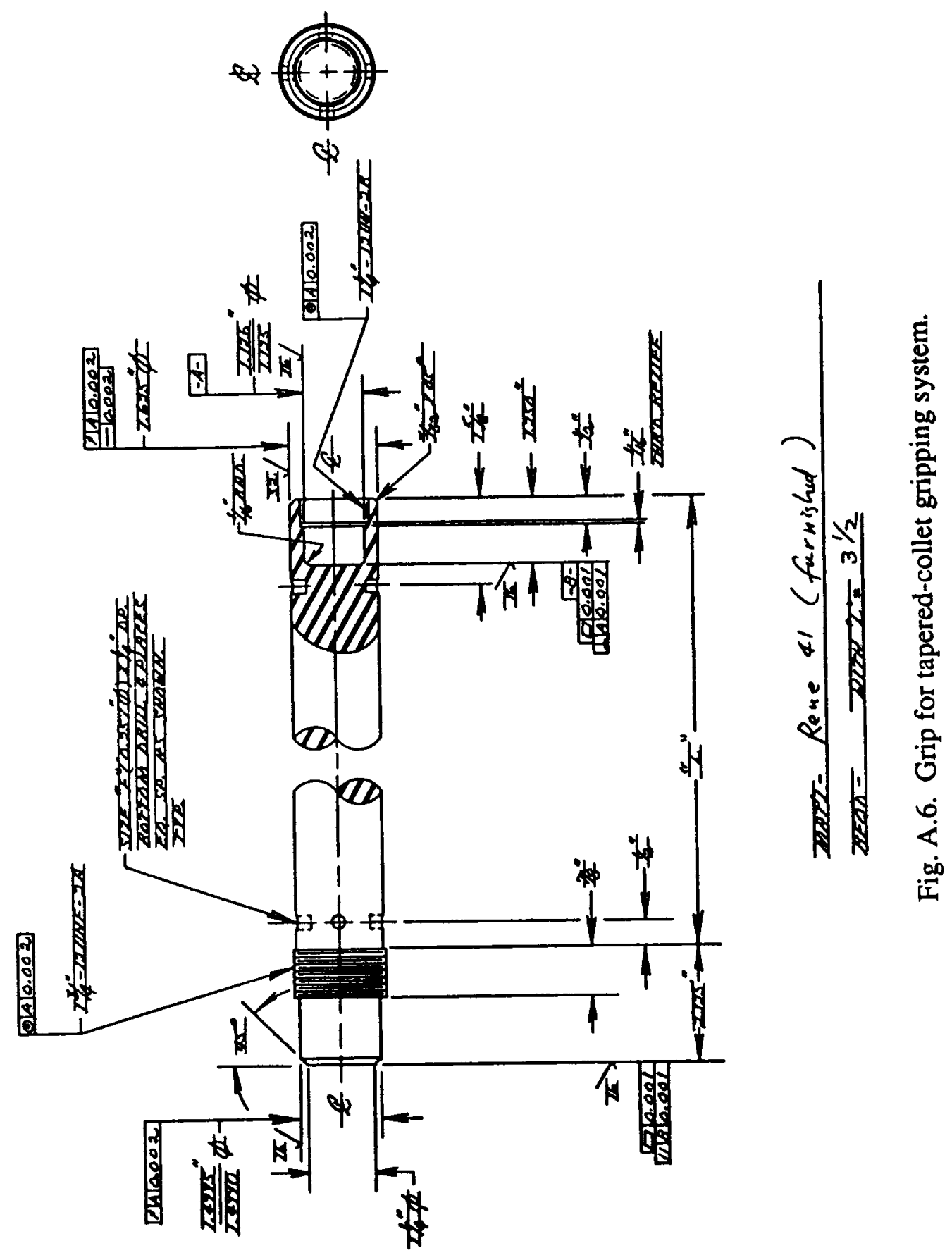




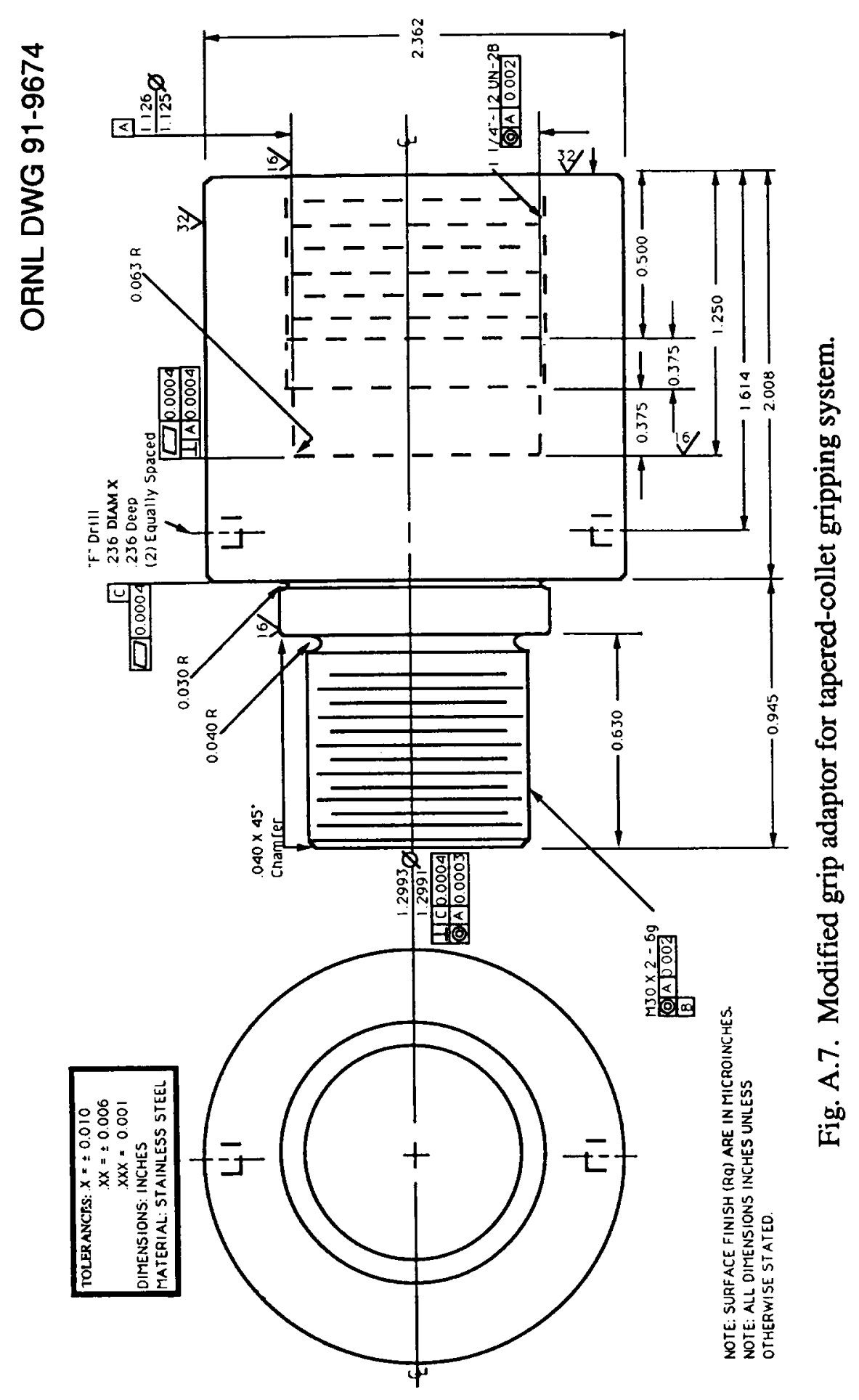


66

0
0
0
1
$\sigma$
0
$\vdots$
$\vdots$
$\vdots$
$\vdots$
0
0

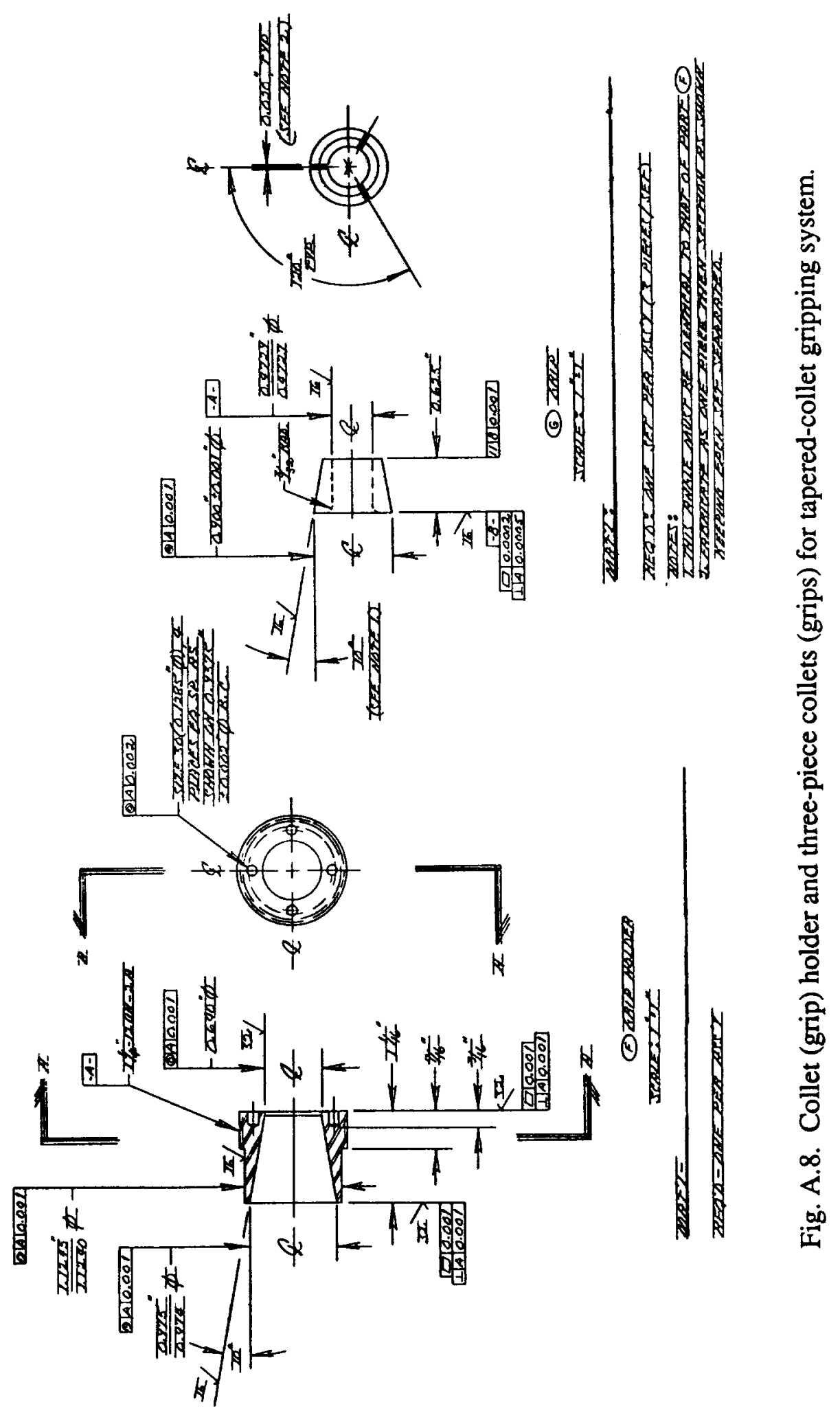


- two sets of tapered collets (Figs. A.8 and A.9), one set for the upper grip and one set for the lower grip.

The criticality of the match between the angles of the tapered collets and the grip holders required the development of the following fabrication procedure:

\section{A.2.1. Fabrication Procedure for Tapered-Collet Gripping System} The following parts are required:

1. two modified grip adaptors from 304 stainless steel (SS), Drawing 90RLM0327-T1 (Fig. A.7);

2. two grip collets from 304 SS, Drawing SK-52B-6, part "G" (Fig. A.8);

3. two grip collets from titanium (Ti6Al4V), Drawing SK-52B-6, part "G" (Fig. A.8); and

4. four grip holders from maraging steel 300, Drawing SK-52B-6, part "F" (Fig. A.8).

Fabricate items 2, 3, and 4 to the following procedure:

1. Machine the two 304 SS grip collets and the two titanium grip collets as shown in the preliminary drawing, Fig. A.9.

2. Fabricate the four grip holders as specified in Drawing SK-52B-6, part "F" (Fig. A.8).

3. All parts then require heat treatment as appropriate for the particular material (see notes).

4. At this point, grip collets and grip holders are placed in matched sets, one grip collet to one grip holder, and identified as a set as follows:

one titanium grip to one holder: 1-Ti-T,

one titanium grip to one holder: 1-Ti-B,

one 304 SS grip to one holder: 1-SS-T, and

one 304 SS grip to one holder: 1-SS-B.

5. Grip collet and grip holder are then lapped together to mate the $10^{\circ}$ surfaces. 

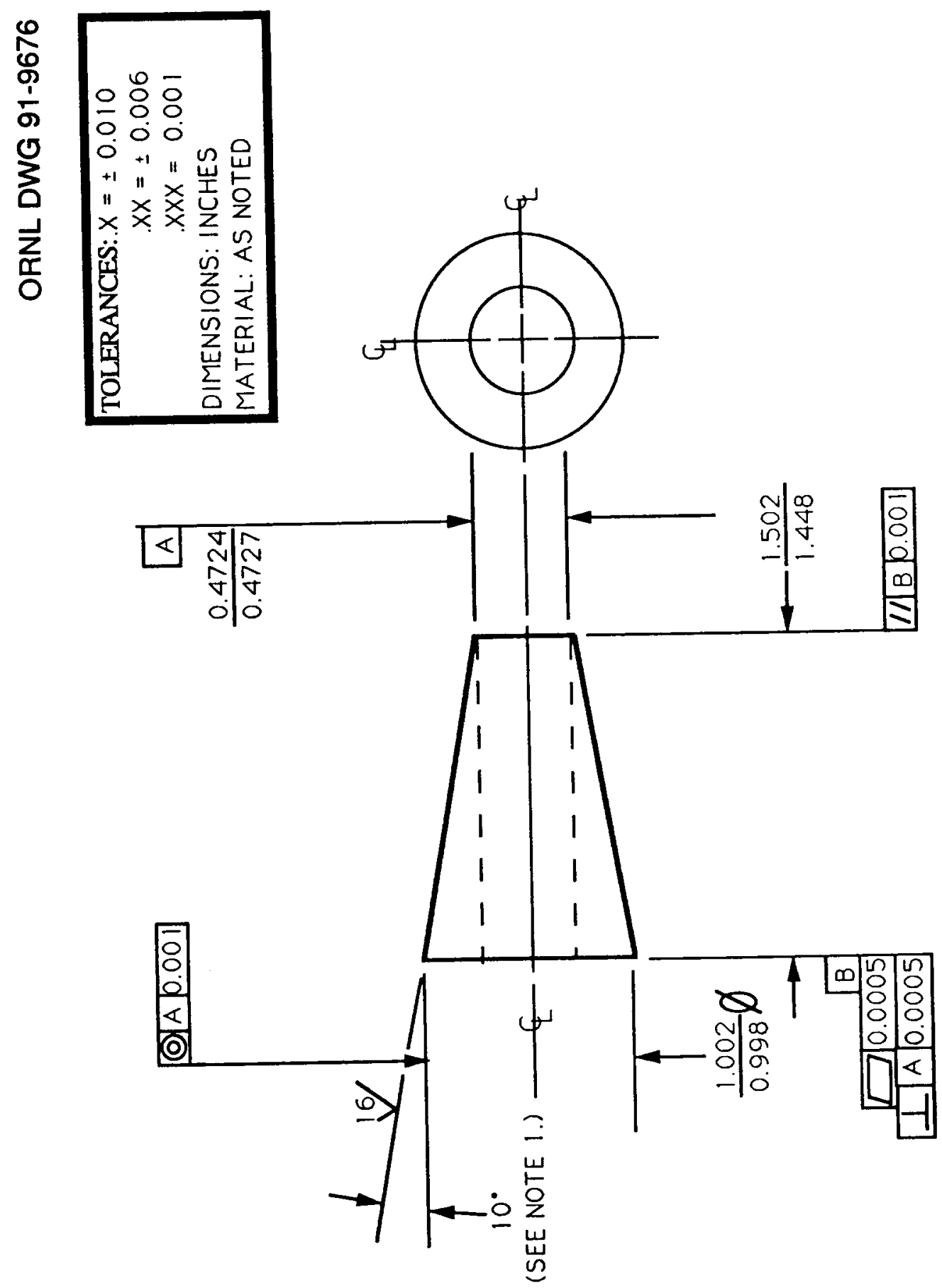

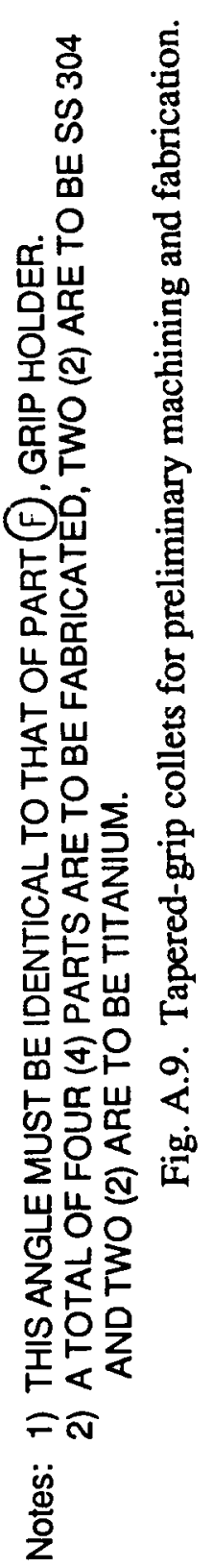


6. Grip collets are then to be cut by electron discharge machining (EDM) to specifications in Drawing SK-52B-6, part "G" (Fig. A.7), and round all sharp edges in contact with center to 1.5 -mm radius. Identify each of the three grip collet pieces as 1-Ti-T-A, 1-Ti-T-B, and 1-Ti-T-C, etc., so as to identify the grip collets and the positions in the grip holder (See Fig. A.10).

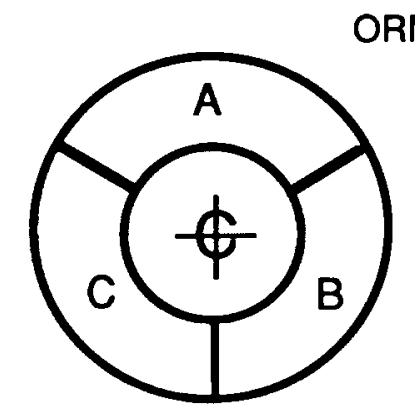

ORNL DWG 91-9677

Fig. A.10. Illustration

of the identification marks

on each collet.

Note: Maraging steel 300 heat treatment is at $485^{\circ} \mathrm{C}$ for $4 \mathrm{~h}$ in vacuum $\left(\sim 10^{-4} \mathrm{~Pa}\right)$.

Titanium (Ti6Al4V) heat treatment is at $705^{\circ} \mathrm{C}$ for $2 \mathrm{~h}$ in vacuum $\left(\sim 10^{-4} \mathrm{~Pa}\right)$.

$304 \mathrm{SS}$ heat treatment is at $705^{\circ} \mathrm{C}$ for $2 \mathrm{~h}$ in vacuum $\left(\sim 10^{-4} \mathrm{~Pa}\right)$.

\section{A.2.2 Testing Procedure using the Tapered-Collet Gripping System}

The procedure for conducting a tensile test using the tapered-collet system is as follows (refer to Fig. A.11):

1. Each grip holder and set of collets (grips) must be thoroughly cleaned with acetone and wiped dry with a clean cloth to remove all traces of grease and ceramic debris from previous tests. In addition, the shank of each specimen should be rubbed with a cloth dampened in acetone to remove traces of grease, which may cause the collets to slip on the shank.

2. Using a cotton-tipped applicator, apply a light, uniform coating of anti-seize grease to the polished, tapered surface of each grip holder. Apply a similar coating of grease to the threads and pilot surfaces of the grip adaptors.

3. Holding the specimen with the longitudinal axis vertical, place a grip holder over the upper button head of the specimen with the pilot of the holder facing toward the button head and the threads toward the gage section. Hold the grip holder away from the 
ORNL DWG 91-9678

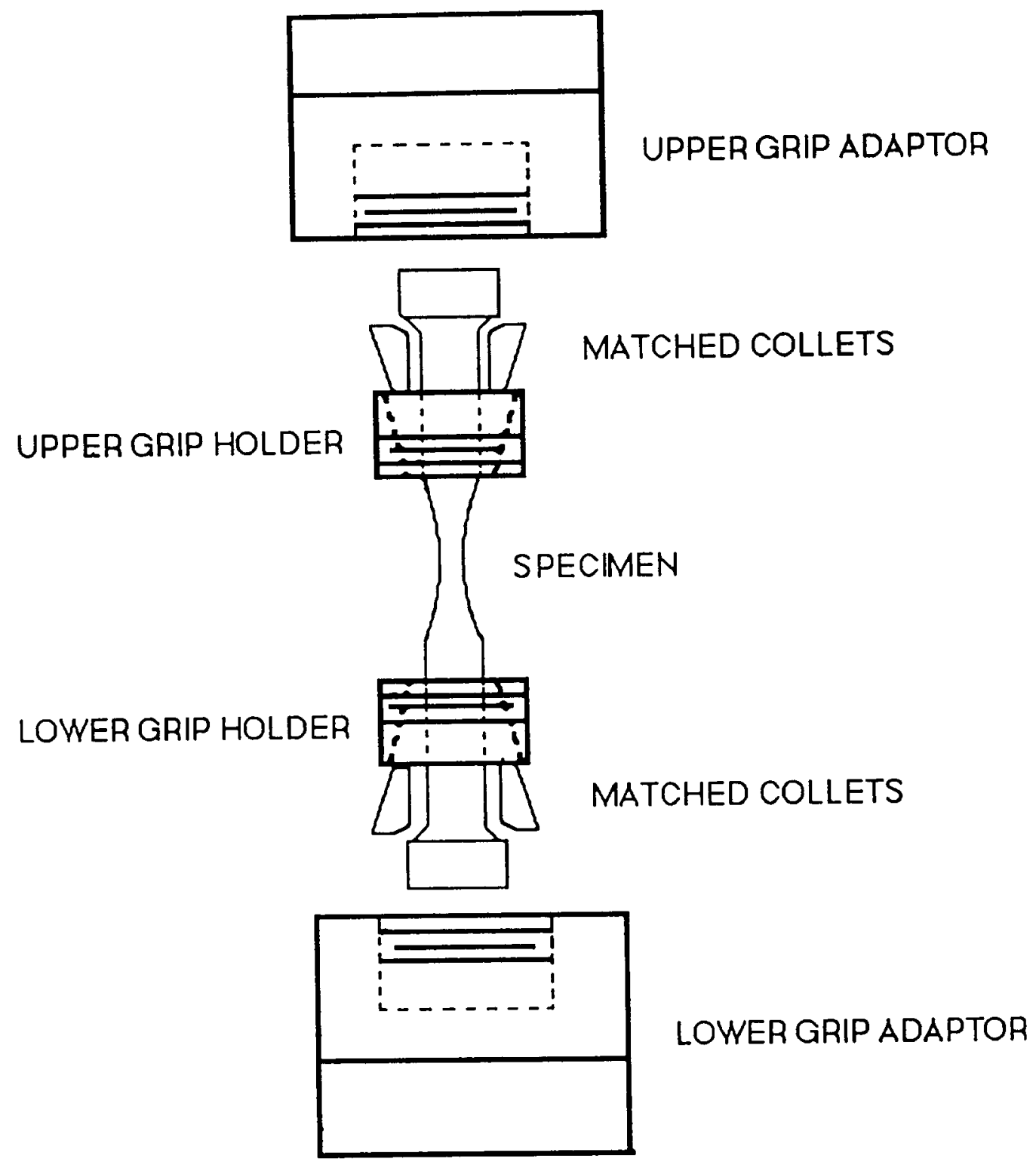

Fig. A.11. Procedure for using tapered-collet gripping system. 
specimen and position it about midway along the shank. Ensure that the grease coating on the inside of the grip holder does not touch the shank of the specimen.

4. Insert each piece of the collet set matched to the grip holder into the space between the grip holder and the shank of the specimen. Insert each piece separately and ensure that the radii of the collet pieces are toward the radius of the button head.

5. When all the collet pieces are inserted between the grip holder and the specimen, allow the specimen to hang freely from the grip holder supported by the collets. At this point, ensure that the collets are uniformly aligned in the grip holder for equal and uniform contact with the edge of the button head.

6. Insert the grip holder with the "colleted" end of the specimen into the opening of the upper grip adaptor, and slowly rotate the grip holder until the threads engage. Tighten the grip holder snugly into the tapered pilot with a spanner wrench placed in the appropriate holes in the grip holder.

7. Ensuring that the specimen is hanging freely from the upper grip holder, attach the strain-gage wires to the strain-gage conditioner. It is important to balance the strain gages at this point with no axial or eccentric loads applied to the specimen.

8. Place a grip holder over the lower button head of the specimen with the pilot of the holder facing toward the button head and the threads toward the gage section. Hold the grip holder away from the specimen and position it about midway along the shank. Ensure that the grease coating on the inside of the grip holder does not touch the shank of the specimen.

9. Insert each piece of the collet set matched to the grip holder into the space between the grip holder and the shank of the specimen. Insert each piece separately, and ensure that the radii of the collet pieces are toward the radius of the button head.

10. When all the collet pieces are inserted between the grip holder and the specimen, allow the grip holder to hang freely from the specimen supported by the collets. At this point ensure that the collets are uniformly aligned in the grip holder for equal and uniform contact with the edge of the button head.

11. Insert the grip holder with the "colleted" end of the specimen into the opening of the lower grip adaptor by raising or lowering the cross head of the test machine depending upon the testing configuration. Slowly rotate the grip holder until the threads engage. Tighten the grip holder snugly into the tapered pilot with a spanner wrench placed in the appropriate holes of the grip holder.

12. Slowly apply a preload of 150 to $200 \mathrm{~N}$ to the load train to take the "slack" out of the system. 
13. After switching to load control, apply any reasonable stressing rate from the preload to $6,500 \mathrm{~N}$. Strain-gage readings and percent bending should be noted during this loading process to monitor any irregularities as the tapered collets are pulled into position against the specimen.

14. At a load of $6,500 \mathrm{~N}$, the percent bending in the specimen should be on the order of 5.0 to 10.0. If the value is $>10.0$, the load should be reduced to about $200 \mathrm{~N}$ and the rotational alignment of the grips changed to minimize the bending. Reapply a load of $6,500 \mathrm{~N}$ and check the percent bending again. Repeat this process until 5.0 to $10.0 \%$ bending is achieved.

15. Begin recording the strain-gage information continuously while applying a stressing rate of $\sim 30 \mathrm{MPa} / \mathrm{s}$ from $6,500 \mathrm{~N}$ to failure $(\sim 30 \mathrm{~s}$ to load to $35,000 \mathrm{~N})$.

16. After the specimen fails, save the data file with the strain gage and load information into it for later data reduction. Remove the specimen in reverse order of the installation. The collets and grip holders can be reused many times but must be cleaned thoroughly between each use to remove ceramic particles and grease from previous tests. 


\section{APPENDIX B. ALLOWABLE BENDING (ECCENTRICITY)}

It is generally agreed that bending must be minimized in uniaxial tensile tests to minimize the scatter in test results for the assumed uniform stress state. ${ }^{*}+,+\neq, * *, 1-19$ However, there is no general agreement as to the maximum bending allowable for any one type (e.g., fast fracture, creep, stress-relaxation) of tensile testing. In an attempt to quantify the maximum allowable percent bending, a limited numerical/statistical study was undertaken to evaluate the effect of bending on the determination of a material's Weibull characteristic tensile strength. This study was conducted along similar lines as previous studies. ${ }^{\dagger, 18}$ The starting values of the Weibull statistical parameters were approximately those of the NT-154 silicon nitride at room temperature (Weibull characteristic tensile strength, $\mathrm{S}_{\mathrm{O}}=774 \mathrm{MPa}$ and Weibull modulus, $m,=7$ to 8 ) [Ref. 20]. In general, the Weibull distributions for the cumulative probability of failure are

$$
P f=1-\exp \left[-\int\left(\sigma / S_{o}\right)^{m} d V / V_{o}\right]
$$

for the distribution of stresses through the volume, and

$$
\mathrm{Pf}=1-\exp \left[-\int\left(\sigma / \mathrm{S}_{\mathrm{O}}\right)^{\mathrm{m}} \mathrm{dA}_{\mathrm{S}} / \mathrm{A}_{\mathrm{SO}}\right]
$$

for the distribution of stresses over the surface of the volume, where $\sigma$ is the applied stress within the volume or on the surface, $S_{O}$ is the Weibull characteristic tensile strength, $m$ is the Weibull modulus, and $\mathrm{V}_{\mathrm{O}}$ and $\mathrm{A}_{\mathrm{so}}$ are normalizing constants for volume and surface area, respectively. The effect of the percent bending is assumed to make $\sigma$ a linear function of position, $x$, across the cross section of the volume or at the surface as shown in Fig. B.1. Thus, this function includes terms that must be incorporated in the volume or surface integrand, such that

$$
\sigma=\sigma_{\mathrm{a}}(1+\mathrm{bx} / \mathrm{R}),
$$

"M. Kaji, "Evaluation of Techniques of Mechanical Properties, "unpublished presentation given at Kyocera Central Research Laboratory, Kokubu, Japan, July 19, 1989.

†M. Kaji, "Silicon Nitride as Structural Materials," unpublished presentation given at Kyocera Central Research Laboratory, Kokubu, Japan, November 6, 1989.

$\ddagger \mathrm{J}$. Cuccio and C. Johnson, "Determination of Tensile Testing Bending Limits," unpublished presentation at ASTM Committee Meetings, San Francisco, May 1990.

** M. Kaji, "Silicon Nitride as Structural Materials," unpublished presentation given at Kyocera Central Research Laboratory, Kokubu, Japan, November 6, 1989. 


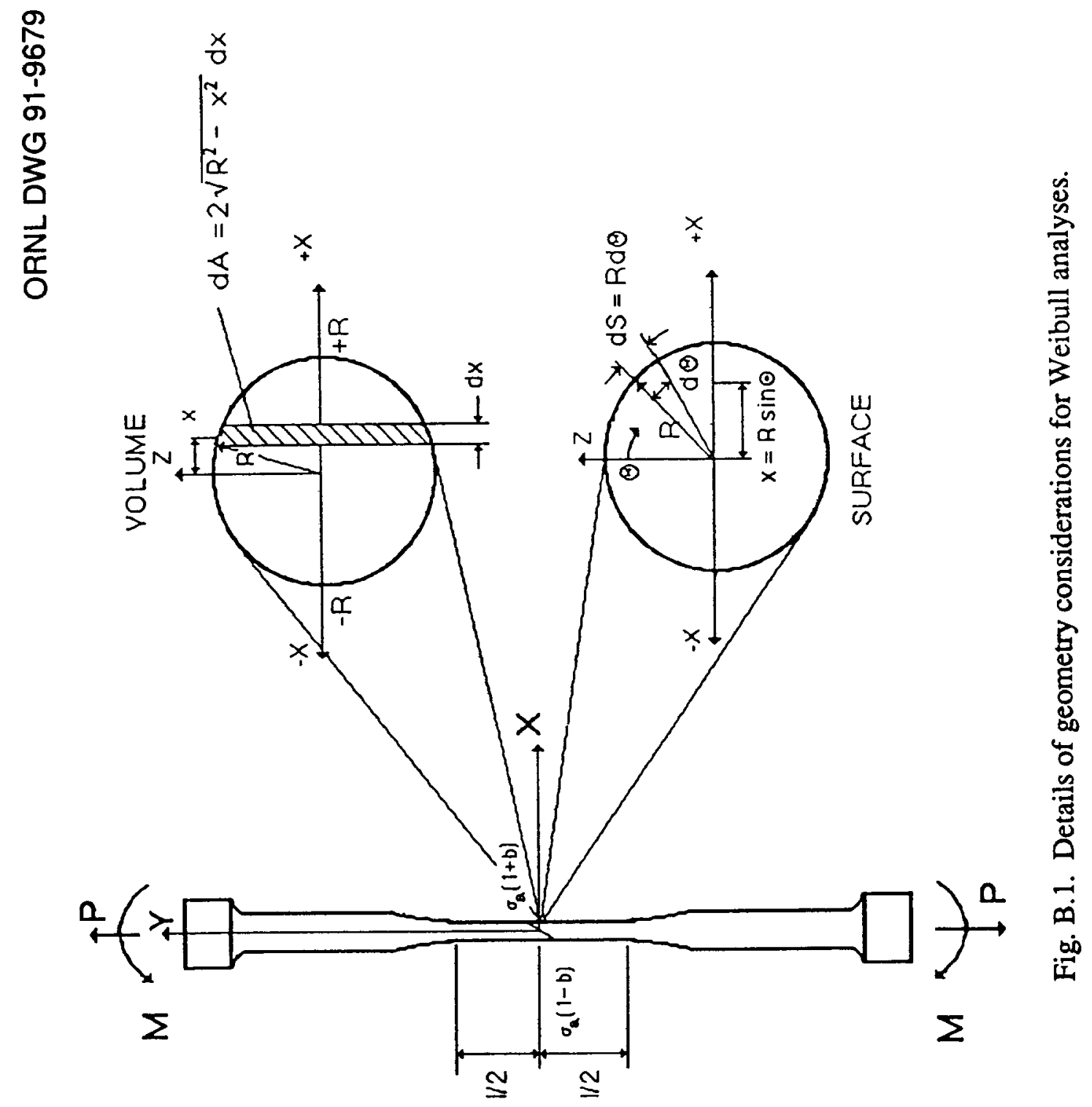


where $\sigma_{\mathrm{a}}$ is the nominal applied stress, $\mathrm{b}$ is the bending component (percent bending divided by 100 ), $x$ is the variable of the position across the cross section, and $\mathrm{R}$ is the radius of the gage section. The functions for the volume and surface are

$$
d V=d A d y=2 \sqrt{R^{2}-x^{2}} d x d y
$$

and

$$
d A_{S}=d S d y=R d \Theta d y,
$$

where $y$ is the longitudinal axis, $A$ is the cross-sectional area, $S$ is the circumferential length, and $\Theta$ is the angle about the longitudinal axis in cylindrical coordinates (Fig. B.1). R can be written in terms of Cartesian coordinates where $R=x / \sin \Theta$.

Combining Eqs. (B1) through (B5) yields:

$$
\begin{aligned}
\mathrm{Pf}=1-\exp \left[-1 / \mathrm{Vo}_{\mathrm{o}} \int\left(\sigma_{\mathrm{a}}(1+\mathrm{bx} / \mathrm{R}) / \mathrm{S}_{\mathrm{o}}\right)^{\mathrm{m}} 2 \sqrt{\mathrm{R}^{2}-\mathrm{x}^{2}} \mathrm{dx} d y\right] & \text { for }-\mathrm{R} \leq \mathrm{x} \leq+\mathrm{R} \\
& \text { for }-1 / 2 \leq \mathrm{y} \leq+1 / 2
\end{aligned}
$$

for the distribution of stresses through the volume and

$$
\begin{aligned}
& \mathrm{Pf}=1-\exp \left[-1 / \mathrm{A}_{\mathrm{SO}} \int\left(\sigma_{\mathrm{a}}(1+\mathrm{b} \sin \Theta) / \mathrm{S}_{\mathrm{o}}\right)^{\mathrm{m}} 2 \mathrm{R} d \Theta \mathrm{dy}\right] \quad \text { for }-\pi / 2 \leq \Theta \leq+\pi / 2 \\
& \text { for }-1 / 2 \leq y \leq+1 / 2
\end{aligned}
$$

for the distribution of stresses over the surface area, where 1 is the length of the gage section. A numerical integration scheme was used to solve for Eqs. (B6) and (B7) for the probabilities of failure as functions of failure stress, assuming constant bending in every specimen. Figure B. 2 shows such a distribution for $5.0 \%$ bending. These results were then evaluated for the effect of percent bending on the Weibull characteristic tensile strength, $S_{0}$, (strength at $\mathrm{P}_{\mathrm{f}}=0.632$ ) and the Weibull modulus, $\mathrm{m}$.

The Weibull modulus was essentially unchanged from starting values of 8.0 and 16.0 regardless of percent bending. However, the Weibull characteristic tensile strength, normalized to the starting value of the Weibull characteristic tensile strength, showed large decreases for increasing percent bending as shown in Fig. B.3. The effects of Weibull modulus on these curves are also shown in Fig. B.3, where it is seen that for increasing Weibull modulus, the decreasing strength effect due to percent bending is more pronounced.

Note that the decreasing strength effect is also more pronounced for surface failures. However, it has been recently reported that volume failures accounted for the majority 


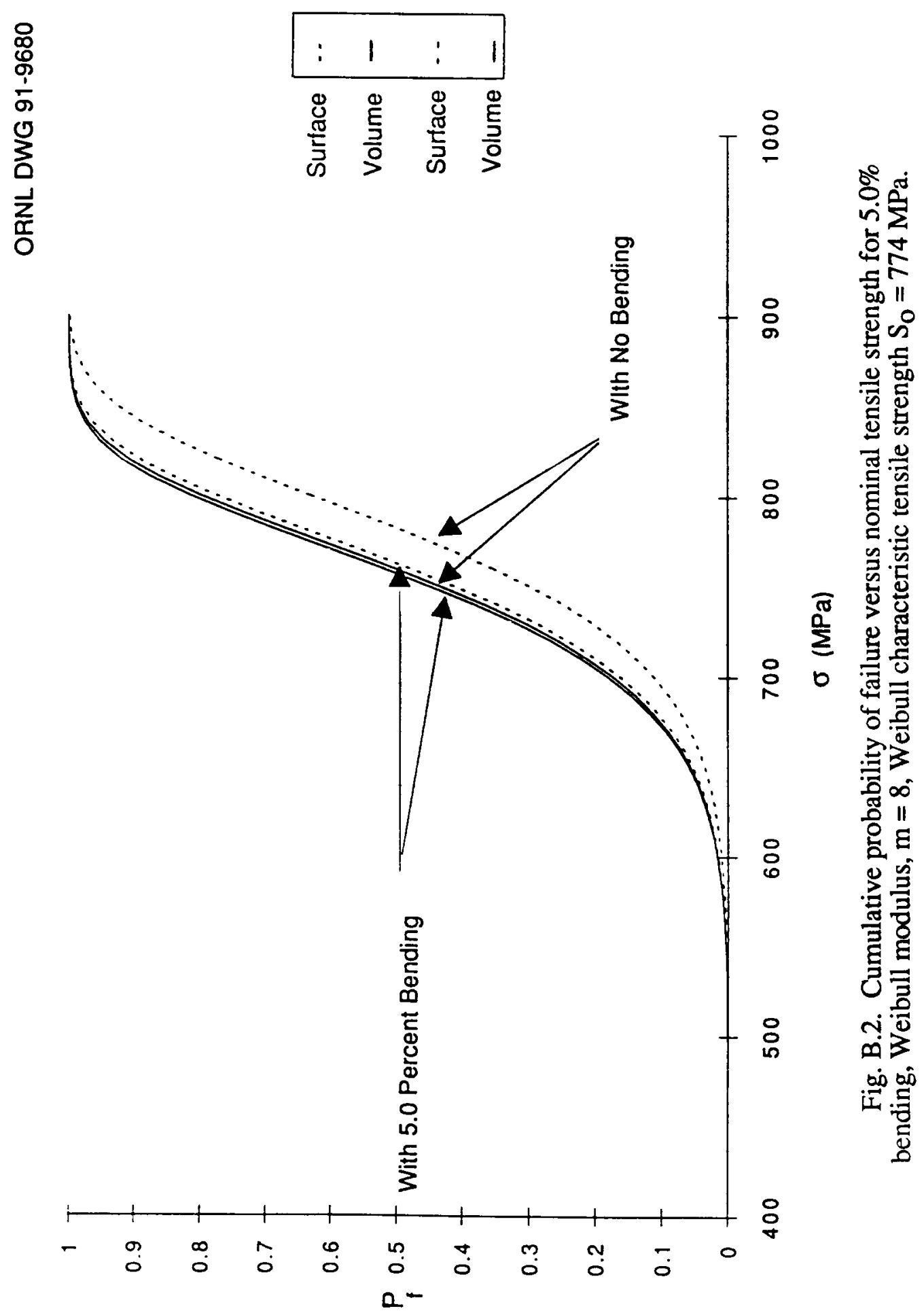



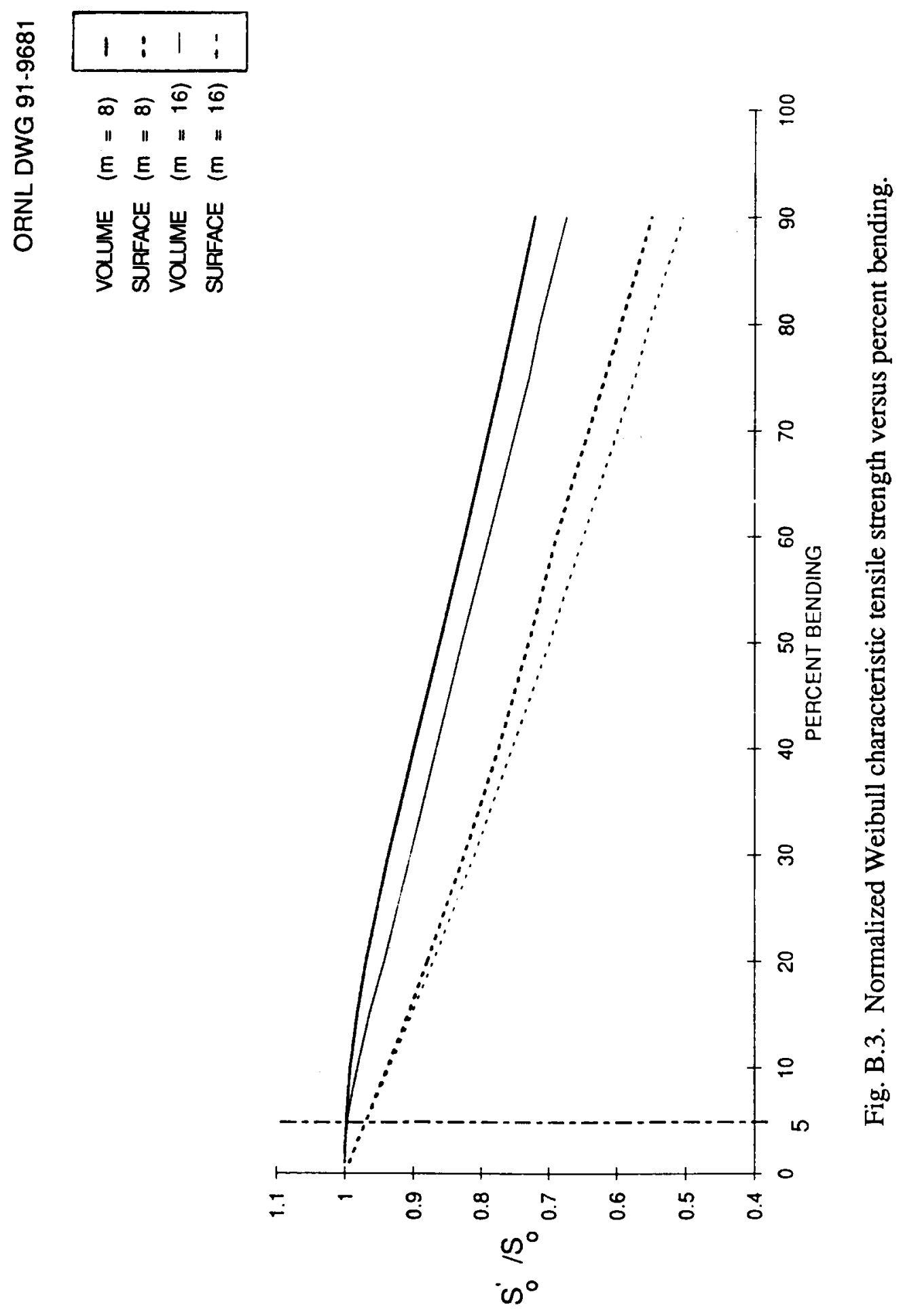
Note that the decreasing strength effect is also more pronounced for surface failures. However, it has been recently reported that volume failures accounted for the majority $(\sim 66 \%)$ of the tensile test failures in a high-performance silicon nitride at room temperature." Additionally, in that study, no correlation was found between percent bending and either calculated tensile strength or failure origin (i.e., volume or surface). In a related study, similar statistically based analyses were conducted, and it was concluded that 5.0 was an acceptable maximum percent bending for tensile strength tests. ${ }^{\dagger}$

The present study supports the acceptance of $5.0 \%$ bending as a maximum upper limit for tensile strength tests. However, the issue is more clouded for tensile stress rupture or creep tests where the effects of temperature, stress state, and creep rate may severely affect not only the material behavior but also the experimentally measured displacements or times to failure. Thus, at this time, no upper limit for percent bending for tensile creep or stress rupture can be recommended.

\section{REFERENCES}

1. M. H. Jones and W. F. Brown, Jr., "An Axial Loading Creep Machine," ASTM Bull. 211, 53-60 (1956).

2. R. K. Penny, E. G. Ellison, and G. A. Webster, "Specimen Alignment and Strain Measurement in Axial Creep Tests," Mater. Res. Stand. 6(1), 76-89 (1966).

3. E. M. Smith, C. Grant, and J. M. Booth, "Equipment of Creep Testing at Variable Load and Temperature," J. Strain Anal. 5(2), 145-54 (1970).

4. C. Grant, "Axiality of Loading in the Tensile Test," J. Strain Anal. 7(4), 261-65 (1972).

5. M. H. Jones and W. F. Brown, Jr., "Note on Performance of Tapered Grip Tensile Loading Devices," J. Test. Eval. 3(3), 179-81 (1975).

6. R. K. Kossowsky, D. G. Miller, and E. S. Diaz, "Tensile and Creep Rupture of Hot-Pressed Silicon Nitride," J. Mater. Sci. 10, 983-97 (1975).

7. F. F. Lange and E. S. Diaz, "Powder-Cushion Gripping to Promote Good Alignment in Tensile Testing," J. Test. Eval 6(5), 320-23 (1978).

8. B. W. Christ and S. R. Swanson, "Alignment Problems in the Tensile Test," J. Test. Eval. 4(6), 405-17 (1979).

"M. Kaji, "Evaluation of Techniques of Mechanical Properties," unpublished presentation given at Kyocera Central Research Laboratory, Kokuba, Japan, July 19, 1989.

†M. Kaji, "Silicon Nitride as Structural Materials," unpublished presentation given at Kyocera Central Research Laboratory, Kokubu, Japan, November 6, 1989. 
9. K. C. Liu and C. R. Brinkman, "Tensile Cyclic Fatigue of Structural Ceramics," pp. 279-84 in Proceedings of the 23rd Automotive Technology Development Contractors' Coordination Meeting, Dearborn, Michigan, October 21-24, 1985, P-165, Society of Automotive Engineers, Warrendale, Pa., 1986.

10. D. F. Carroll, S. M. Wiederhorn, and D. E. Roberts, "Technique for Tensile Creep Testing of Ceramics," J. Am. Ceram. Soc. 72 (9), 1610-14 (1989).

11. "Sharp-Notch Tension Testing with Cylindrical Specimens," ASTM E 602-81, pp. 631-39 in 1989 Annual Book of ASTM Standards, Vol. 03.01, American Society for Testing and Materials, Philadelphia, 1989.

12. "Standard Practice Elevated Temperature Tension Tests of Metallic Materials, "ASTM E 21-79, pp. 191-97, 1989 Annual Book of ASTM Standards, Vol. 03.01, American Society for Testing and Materials, Philadelphia, 1989.

13. "Standard Practice for Conducting Creep, Creep-Rupture, and Stress-Rupture Tests of Metallic Materials,"ASTM E 139-83, pp. 313-23 in 1989 Annual Book of ASTM Standards, Vol. 03.01, American Society for Testing and Materials, Philadelphia, 1989.

14. "Standard Practice for Conducting Time-for-Rupture Notch Tension Tests of Materials," ASTM E 292-83, pp. 418-26 in 1989 Annual Book of ASTM Standards, Vol. 03.01, American Society for Testing and Materials, Philadelphia, 1989.

15. "Standard Practice for Conducting Constant-Amplitude Axial Fatigue Tests of Metallic Materials,"ASTM E 466-82, pp. 539-43 in 1989 Annual Book of ASTM Standards, Vol. 03.01, American Society for Testing and Materials, Philadelphia, 1989.

16. "Standard Practice for Conducting Constant-Amplitude Low-Cycle Fatigue Testing," ASTM E 606-80, pp. 601-13, 1989 Annual Book of ASTM Standards, Vol. 03.01, American Society for Testing and Materials, Philadelphia, 1989.

17. "Testing Methods for Tensile Strength of High Performance Ceramics at Room and Elevated Temperatures," JIS R1606, Japanese Standards Association, 1990.

18. T. J. Vasko and B. N. Cassenti, The Statistical Prediction of Failure Location in Brittle Test Specimens, United Technologies Research Center, United Technologies Corporation, East Hartford, Conn. (1986).

19. M. G. Jenkins, M. K. Ferber, and R. L. Martin, "Evaluation of the Stress State in a Button-Head, Tensile Specimen for Ceramics," Ceram. Eng. Sci. Proc. 11(9), 1346-63 (1990).

20. N. L. Hecht, "Environmental Effects in Toughened Ceramics," W.B.S. Element 3.3.1.4, pp. $382-90$ in Ibid. 


\section{APPENDIX C. INSPECTION PROCEDURE OF TENSILE SPECIMENS}

The following pages contain the steps used to verify the dimensions of tensile specimens using an optical comparator with digital processor." The first section provides detailed instructions for inspecting the shank and button-head regions only. The second section (including Table C.1) provides steps necessary for the complete inspection on a finished tensile specimen.

\section{C.1 TENSILE SPECIMEN INSPECTION PROCEDURE (SHANK AND BUTTON HEAD ONLY)}

1. Mount specimen in " $V$ " block with chamfered end under lens.

2. Set dimension coordinates by choosing " $B$ " coordinate system on data processor.

3. Ready computer to receive data.

4. Using the $50 \times$ magnification, measure radius of button head three times on side farther from operator (bottom of specimen on screen) as shown in Fig. C.1. These values represent measurements 1,2 , and 3 on inspection sheet.

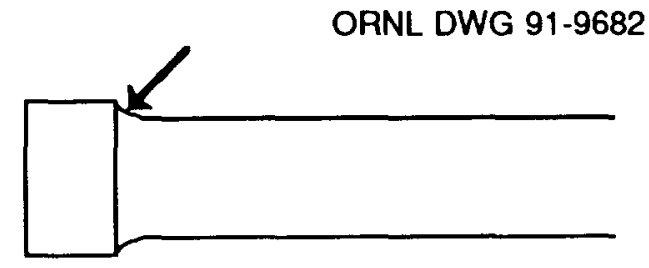

Fig. C.1. Close-up view of inspection point farther from operator on button-head radius.

5. Repeat step 2 on radius of button head nearer to operator (top of specimen on screen) as shown in Fig. C.2. These values represent measurements 4, 5, and 6 on inspection sheet.

*Nikon V-12 Profile Projector with O2L Linear Encoded Stage and DP-201 Data Processor, Nikon, Inc., Instrument Group, Garden City, New York, 1988. 
ORNL DWG 91-9683

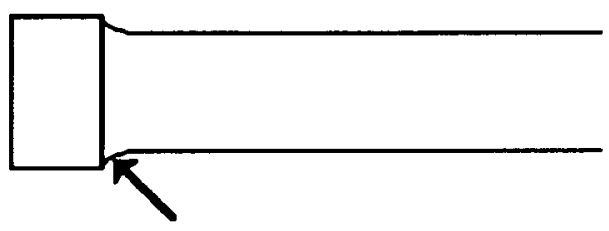

Fig. C.2. Close-up view of inspection point nearer to operator on button-head radius.

6. Using high point of radius as zero reference, measure across specimen at five points: $0,2.9,6,11$, and $16 \mathrm{~mm}$ as shown in Fig. C.3. These values represent measurements $7,8,9,10$, and 11 on inspection sheet.

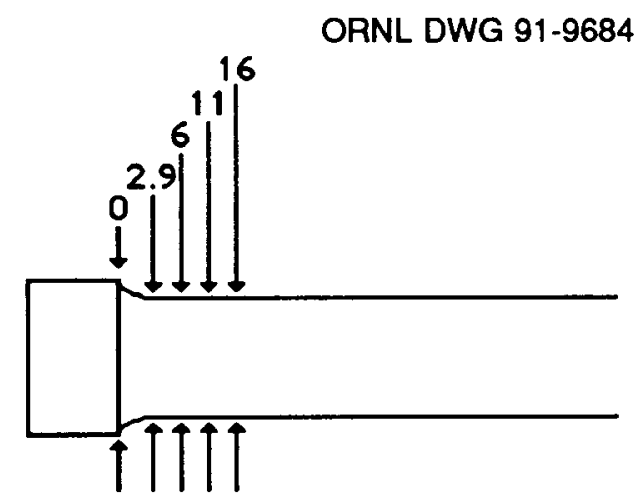

Fig. C.3. Inspection points in button-head radius and immediate shank region ( $\mathrm{mm}$ from 0 reference).

7. Rotate specimen $90^{\circ}$ and repeat steps $1,2,3$, and 5. These values represent measurements 12 through 22 on inspection sheet.

8. Remove specimen from "V" block, turn end for end, and repeat steps 2 through 6 on unchamfered end. These values represent measurements 23 through 44 on inspection sheet. 


\section{C.2 TENSILE SPECIMEN INSPECTION PROCEDURE (COMPLETE SPECIMEN)}

Table C1. Detailed steps for dimensional checking of complete tensile specimen in optical comparator

\begin{tabular}{|c|c|}
\hline Step & Measurement \\
\hline 1 & Radius, identified end at screen bottom \\
\hline 2 & Radius, identified end at screen bottom \\
\hline 3 & Radius, identified end at screen bottom \\
\hline 4 & Radius, identified end at screen top \\
\hline 5 & Radius, identified end at screen top \\
\hline 6 & Radius, identified end at screen top \\
\hline 7 & Identified end $0 \mathrm{~mm} \times$ reference button-head diameter at screen bottom \\
\hline 8 & Identified end $0 \mathrm{~mm} \times$ reference button-head diameter at screen top \\
\hline 9 & Identified end $2.900 \mathrm{~mm} \times$ reference shank diameter at screen top \\
\hline 10 & Identified end $2.900 \mathrm{~mm} \times$ reference shank diameter at screen bottom \\
\hline 11 & Identified end $6.000 \mathrm{~mm} \times$ reference shank diameter at screen bottom \\
\hline 12 & Identified end $6.000 \mathrm{~mm} \times$ reference shank diameter at screen top \\
\hline 13 & Identified end $11.000 \mathrm{~mm} \times$ reference shank diameter at screen top \\
\hline 14 & Identified end $11.000 \mathrm{~mm} \times$ reference shank diameter at screen bottom \\
\hline 15 & Identified end $16.000 \mathrm{~mm} \times$ reference shank diameter at screen bottom \\
\hline 16 & Identified end $16.000 \mathrm{~mm} \times$ reference shank diameter at screen top \\
\hline 17 & Identified end $58.500 \mathrm{~mm} \times$ reference gage diameter at screen top \\
\hline 18 & Identified end $58.500 \mathrm{~mm} \times$ reference gage diameter at screen bottom \\
\hline 19 & Identified end $63.500 \mathrm{~mm} \times$ reference gage diameter at screen bottom \\
\hline 20 & Identified end $63.500 \mathrm{~mm} \times$ reference gage diameter at screen top \\
\hline 21 & Identified end $68.500 \mathrm{~mm} \times$ reference gage diameter at screen top \\
\hline 22 & Identified end $68.500 \mathrm{~mm} \times$ reference gage diameter at screen bottom \\
\hline 23 & Identified end $73.500 \mathrm{~mm} \times$ reference gage diameter at screen bottom \\
\hline 24 & Identified end $73.500 \mathrm{~mm} \times$ reference gage diameter at screen top \\
\hline 25 & Identified end $78.500 \mathrm{~mm} \times$ reference gage diameter at screen top \\
\hline 26 & Identified end $78.500 \mathrm{~mm} \times$ reference gage diameter at screen bottom \\
\hline
\end{tabular}


Table C.1 (continued)

\begin{tabular}{|l|l|}
\hline Step & \multicolumn{1}{|c|}{ Reasurement } \\
\hline & \multicolumn{1}{|c|}{ Rote specimen $90^{\circ}$} \\
\hline 27 & Radius, identified end at screen bottom \\
\hline 28 & Radius, identified end at screen bottom \\
\hline 29 & Radius, identified end at screen bottom \\
\hline 30 & Radius, identified end at screen top \\
\hline 31 & Radius, identified end at screen top \\
\hline 32 & Radius, identified end at screen top \\
\hline 33 & Identified end $0 \mathrm{~mm} \times$ reference button-head diameter at screen bottom \\
\hline 34 & Identified end $0 \mathrm{~mm} \times$ reference button-head diameter at screen top \\
\hline 35 & Identified end $2.900 \mathrm{~mm} \times$ reference shank diameter at screen top \\
\hline 36 & Identified end $2.900 \mathrm{~mm} \times$ reference shank diameter at screen bottom \\
\hline 37 & Identified end $6.000 \mathrm{~mm} \times$ reference shank diameter at screen bottom \\
\hline 38 & Identified end $6.000 \mathrm{~mm} \times$ reference shank diameter at screen top \\
\hline 39 & Identified end $11.000 \mathrm{~mm} \times$ reference shank diameter at screen top \\
\hline 40 & Identified end $11.000 \mathrm{~mm} \times$ reference shank diameter at screen bottom \\
\hline 41 & Identified end $16.000 \mathrm{~mm} \times$ reference shank diameter at screen bottom \\
\hline 42 & Identified end $16.000 \mathrm{~mm} \times$ reference shank diameter at screen top \\
\hline 43 & Identified end $58.500 \mathrm{~mm} \times$ reference gage diameter at screen top \\
\hline 44 & Identified end $58.500 \mathrm{~mm} \times$ reference gage diameter at screen bottom \\
\hline 45 & Identified end $63.500 \mathrm{~mm} \times$ reference gage diameter at screen bottom \\
\hline 46 & Identified end $63.500 \mathrm{~mm} \times$ reference gage diameter at screen top \\
\hline 47 & Identified end $68.500 \mathrm{~mm} \times$ reference gage diameter at screen top \\
\hline 48 & Identified end $68.500 \mathrm{~mm} \times$ reference gage diameter at screen bottom \\
\hline 49 & Identified end $73.500 \mathrm{~mm} \times$ reference gage diameter at screen bottom \\
\hline 50 & Identified end $73.500 \mathrm{~mm} \times$ reference gage diameter at screen top \\
\hline 51 & Identified end $78.500 \mathrm{~mm} \times$ reference gage diameter at screen top \\
\hline 52 & Identified end $78.500 \mathrm{~mm} \times$ reference gage diameter at screen bottom \\
\hline
\end{tabular}


Table C.1 (continued)

\begin{tabular}{|c|c|}
\hline Step & Measurement \\
\hline & Flip specimen end to end \\
\hline 53 & Radius, unidentified end at screen bottom \\
\hline 54 & Radius, unidentified end at screen bottom \\
\hline 55 & Radius, unidentified end at screen bottom \\
\hline 56 & Radius, unidentified end at screen top \\
\hline 57 & Radius, unidentified end at screen top \\
\hline 58 & Radius, unidentified end at screen top \\
\hline 59 & Unidentified end $0 \mathrm{~mm} \times$ reference button-head diameter at screen bottom \\
\hline 60 & Unidentified end $0 \mathrm{~mm} \times$ reference button-head diameter at screen top \\
\hline 61 & Unidentified end $2.900 \mathrm{~mm} \times$ reference shank diameter at screen top \\
\hline 62 & Unidentified end $2.900 \mathrm{~mm} \times$ reference shank diameter at screen bottom \\
\hline 63 & Unidentified end $6.000 \mathrm{~mm} \times$ reference shank diameter at screen bottom \\
\hline 64 & Unidentified end $6.000 \mathrm{~mm} \times$ reference shank diameter at screen top \\
\hline 65 & Unidentified end $11.000 \mathrm{~mm} \times$ reference shank diameter at screen top \\
\hline 66 & Unidentified end $11.000 \mathrm{~mm} \times$ reference shank diameter at screen bottom \\
\hline 67 & Unidentified end $16.000 \mathrm{~mm} \times$ reference shank diameter at screen bottom \\
\hline 68 & Unidentified end $16.000 \mathrm{~mm} \times$ reference shank diameter at screen top \\
\hline 69 & Unidentified end $58.500 \mathrm{~mm} \times$ reference gage diameter at screen top \\
\hline 70 & Unidentified end $58.500 \mathrm{~mm} \times$ reference gage diameter at screen bottom \\
\hline 71 & Unidentified end $63.500 \mathrm{~mm} \times$ reference gage diameter at screen bottom \\
\hline 72 & Unidentified end $63.500 \mathrm{~mm} \times$ reference gage diameter at screen top \\
\hline 73 & Unidentified end $68.500 \mathrm{~mm} \times$ reference gage diameter at screen top \\
\hline 74 & Unidentified end $68.500 \mathrm{~mm} \times$ reference gage diameter at screen bottom \\
\hline 75 & Unidentified end $73.500 \mathrm{~mm} \times$ reference gage diameter at screen bottom \\
\hline 76 & Unidentified end $73.500 \mathrm{~mm} \times$ reference gage diameter at screen top \\
\hline 77 & Unidentified end $78.500 \mathrm{~mm} \times$ reference gage diameter at screen top \\
\hline 78 & Unidentified end $78.500 \mathrm{~mm} \times$ reference gage diameter at screen bottom \\
\hline
\end{tabular}


Table C.1 (continued)

\begin{tabular}{|c|l|}
\hline Step & \multicolumn{1}{|c|}{ Measurement } \\
\hline & \multicolumn{1}{|c|}{ Rotate specimen $90^{\circ}$} \\
\hline 79 & Radius, unidentified end at screen bottom \\
\hline 80 & Radius, unidentified end at screen bottom \\
\hline 81 & Radius, unidentified end at screen bottom \\
\hline 82 & Radius, unidentified end at screen top \\
\hline 83 & Radius, unidentified end at screen top \\
\hline 84 & Radius, unidentified end at screen top \\
\hline 85 & Unidentified end $0 \mathrm{~mm} \times$ reference button-head diameter at screen bottom \\
\hline 86 & Unidentified end $0 \mathrm{~mm} \times$ reference button-head diameter at screen top \\
\hline 87 & Unidentified end $2.900 \mathrm{~mm} \times$ reference shank diameter at screen top \\
\hline 88 & Unidentified end $2.900 \mathrm{~mm} \times$ reference shank diameter at screen bottom \\
\hline 89 & Unidentified end $6.000 \mathrm{~mm} \times$ reference shank diameter at screen bottom \\
\hline 90 & Unidentified end $6.000 \mathrm{~mm} \times$ reference shank diameter at screen top \\
\hline 91 & Unidentified end $11.000 \mathrm{~mm} \times$ reference shank diameter at screen top \\
\hline 92 & Unidentified end $11.000 \mathrm{~mm} \times$ reference shank diameter at screen bottom \\
\hline 93 & Unidentified end $16.000 \mathrm{~mm} \times$ reference shank diameter at screen bottom \\
\hline 94 & Unidentified end $16.000 \mathrm{~mm} \times$ reference shank diameter at screen top \\
\hline 95 & Unidentified end $58.500 \mathrm{~mm} \times$ reference gage diameter at screen top \\
\hline 96 & Unidentified end $58.500 \mathrm{~mm} \times$ reference gage diameter at screen bottom \\
\hline 97 & Unidentified end $63.500 \mathrm{~mm} \times$ reference gage diameter at screen bottom \\
\hline 98 & Unidentified end $63.500 \mathrm{~mm} \times$ reference gage diameter at screen top \\
\hline 99 & Unidentified end $68.500 \mathrm{~mm} \times$ reference gage diameter at screen top \\
\hline 100 & Unidentified end $68.500 \mathrm{~mm} \times$ reference gage diameter at screen bottom \\
\hline 101 & Unidentified end $73.500 \mathrm{~mm} \times$ reference gage diameter at screen bottom \\
\hline 102 & Unidentified end $73.500 \mathrm{~mm} \times$ reference gage diameter at screen top \\
\hline 103 & Unidentified end $63.500 \mathrm{~mm} \times$ reference gage diameter at screen top \\
\hline 104 & Unidentified end $78.500 \mathrm{~mm} \times$ reference gage diameter at screen bottom \\
\hline & \\
\hline 9 & \\
\hline 93 &
\end{tabular}




\section{APPENDIX D. GRINDING EFFECTS (SUBSURFACE DAMAGE)}

During the fabrication of ceramic tensile specimens, the generation of surfaces of the required geometry, tolerances, and surface quality are key elements leading to successful tensile tests. While a number of nonabrasive methods (e.g., laser cutting, electron beam cutting, electro-chemical cutting, etc.) exist for fabricating ceramic components, abrasive machining processes have been the most successful in grinding advanced ceramics. ${ }^{1}$ Of the abrasive methods, the most extensively employed process is the hard machining of fully densified ceramics using diamond-impregnated wheels.

This appendix focuses on the use and effects of diamond-abrasive wheels since this process appears to produce the most consistent and satisfactory results. ${ }^{1}$ Accordingly, much experience has been gained in successfully grinding ceramics with diamond-abrasive wheels including the present study. ${ }^{1-9}$

\section{D.1. KEY ASPECTS OF THE GRINDING PROCESS}

Figure D.1 shows the salient factors that influence the grinding process and ultimately result in a measure of "grindability." ${ }^{*}, 1$ Key specific factors are detailed as follows:

1. Machine tool requirements that contribute to minimized vibration include (a) high degrees of static and dynamic stiffness in machine components (spindle, bearing, work support); (b) on-machine balancing of grinding wheels to minimize vibrations caused by wheel vibrations; and (c) hydraulic controls that minimize pulsations. In addition, fine filtration of the coolant/lubricant is needed to minimize chip/work piece interaction.

2. Wheel selection is a key area of concern. Selection of grinding wheels will be determined by the diamond abrasive used (diamond type, particle size, concentration of the particles). For the wheel, Table D.1 lists factors influencing the selection of abrasive and bond types. Generally, resin-bonded wheels offer resilience and vibration-absorbing characteristics, which minimize chatter at the grinding face but with shorter useful lives and less form-holding ability than stiffer, metal-bonded wheels.

"J. W. Picone, "Ceramics Market Development Program," unpublished presentation at Oak Ridge Natl. Lab., Oak Ridge, Tenn., May 6, 1990 
ORNL DWG 91-9685

\section{FACTORS INFLUENCING GRINDABILITY}

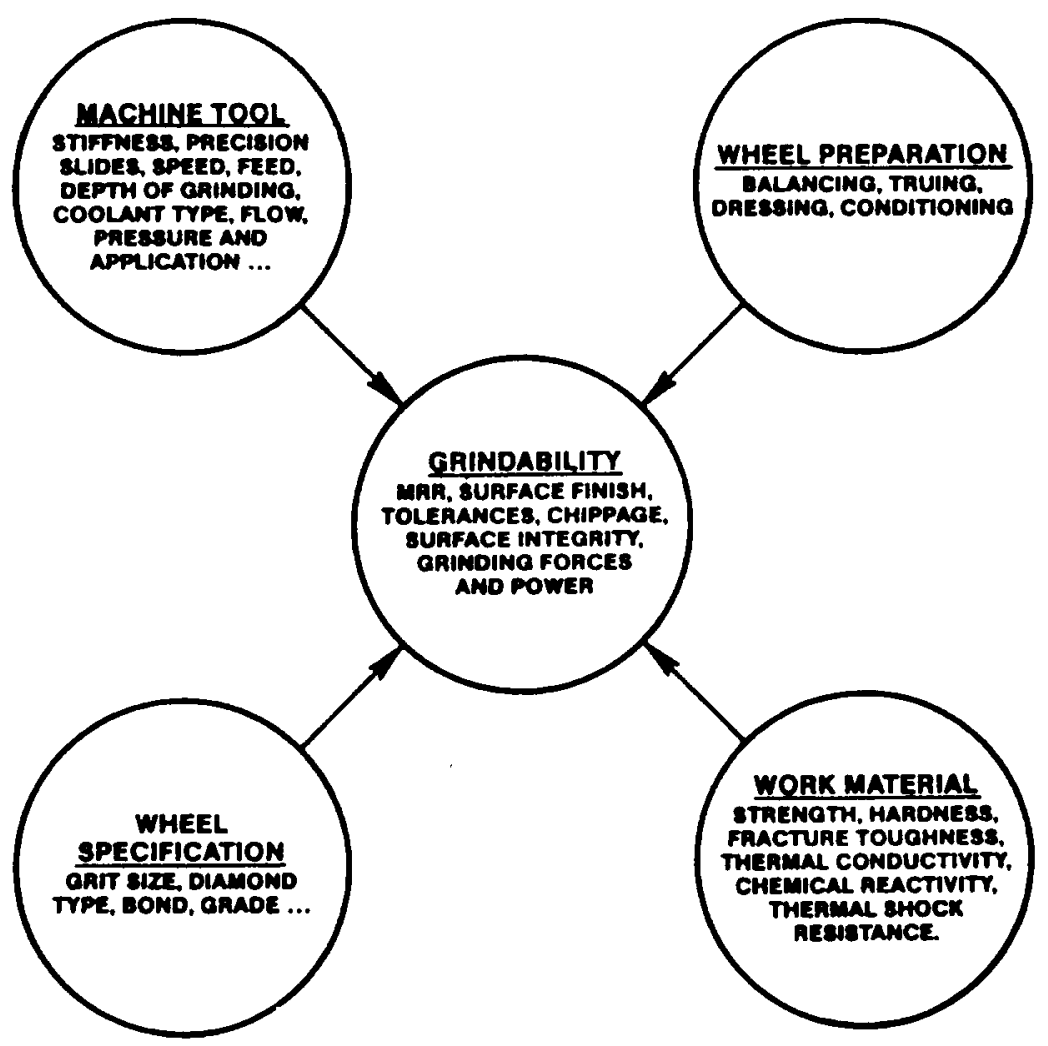

Fig. D.1. Salient features that influence the grinding process.

Source: K. Subramanian, "Advanced Ceramic Components:

Current Methods and Future Needs for Generation of Surfaces,"

pp. 10-32 in Intersociety Symposium on Machining of Advanced

Ceramic Materials and Components, ed. R. E. Barks, K. Subramanian, and K. E. Ball, American Ceramic Society, Westerville, Ohio, 1987. 
Table D.1. Factors influencing selection of abrasive and bond type $\mathrm{e}^{a}$

\begin{tabular}{|l|l|}
\hline \multicolumn{1}{|c|}{ Diamond abrasive } & \multicolumn{1}{c|}{ Influence on grinding process } \\
\hline Type: & \\
- Strong or weak (friable) & - Sharpness of abrasive grit \\
- Monocrystalline or polycrystalline & - Self-sharpening characteristics \\
- Coated or uncoated & - Grit retention strength \\
\hline Particle size: & \\
- Coarse & - High material removal rate, poor finish \\
- Fine & - Low material removal rate, improved finish \\
- Micron powders & - Extremely fine for polishing operations \\
\hline Particle size distribution: & \\
- Inconsistent & - Nonuniform grinding results \\
- Uniform/consistent & - Reliable grinding at low chippage \\
\hline Content/concentration: & \\
- Low & - Free cutting action, low life \\
- High & - Long life, higher grinding forces or power \\
\hline & \multicolumn{1}{|c|}{ Influence on grinding process } \\
\hline Property: & Bond \\
- Hardness/grade & - Freeness of cut \\
- Stiff/resilient & - Dampening characteristics \\
- Porosity & - Freeness of cut, coolant entrainment \\
- Thermal conductivity & - Heat removal from grinding zone \\
\hline
\end{tabular}

$a_{\mathrm{K}}$. Subramanian, "Advanced Ceramic Components: Current Methods and Future Needs for Generation of Surfaces," pp. 10-32 in Intersociety Symposium on Machining of Advanced Ceramic Materials and Components, ed. R. E. Barks, K. Subramanian, and K. E. Ball, American Ceramic Society, Westerville, Ohio, 1987.

3. Wheel preparation is a critical element in successful diamond-wheel grinding. Wheels balanced on the machine spindles are imperative to achieving low vibration, thus minimizing chipping of the work piece. In addition, truing is necessary for achieving concentricity and geometrically accurate form of the wheel face. Periodic dressing is required to clear the grit area and to expose the abrasive grits for efficient grinding action. 
4. Work material plays a major role in the ultimate grinding success. Hardness, strength, fracture resistance, thermal conductivity, and microstructure (e.g., porosity, grain size, secondary phase) all drastically influence the final outcome of the grinding process. Generally, greater hardness of material requires higher normal grinding forces, while greater strengths require higher grinding powers. In addition, low fracture resistances and low thermal conductivity increase the importance of adequate cooling to minimize thermal shock and subsequent cracking in the grinding zone.

\section{D.2. SURFACE QUALITY}

As previously mentioned, key elements in the successful fabrication of ceramic tensile specimens are the generation of proper dimensions and tolerances with the proper surface quality. Proper dimensions within the required tolerances $(\sim 2.5 \mu \mathrm{m})$ can be achieved consistently by using formed, diamond-abrasive wheels, computer numerical control (CNC) grinding machines, and attention to the grinding procedure (e.g., complete machining of the specimen without removal from the original setup).

However, the proper surface quality is not so easily achieved. Proper surface quality can be described as three aspects: (a) surface finish (or roughness), (b) surface residual stress, and (c) subsurface damage. The proper surface finish can be achieved during the machining process by using fine-grit wheels or during a post-machining operation by using diamond-paste lapping. With the proper surface finish, the calculated fracture strength can be independent of grinding direction as shown in Fig. D.2. In addition, surface finish can be related to the proper intended fit of the components.

Surface residual stresses have been measured and calculated to be compressive as shown in Fig. D.3 (Ref. 9). In a study of machining effects on silicon nitride, X-ray diffraction measurements indicated surface residual stresses, $\sigma_{\mathrm{r}}$, for various grinding conditions ranging from $-94 \mathrm{MPa}$ to $-590 \mathrm{MPa} .{ }^{8}$ Compressive residual stresses at the component surface are considered beneficial in metals undergoing cyclic loading because fatigue cracks tend to initiate in free surfaces in tension. However, in ceramic materials that are sensitive to the tensile principal stress state, the subsurface tensile residual stress state (required to equilibrate the compressive residual stresses at the surface) may superpose on the applied tensile stress field to produce fracture initiating at subsurface origins.

Subsurface machining damage can be directly related to the grinding history of the ceramic. Therefore, simply achieving the desired surface finish may not be enough to prevent detrimental subsurface damage as shown in Fig. D.4. In particular, it has been shown that median cracks may form, which can be related to the size of the diamond grit 


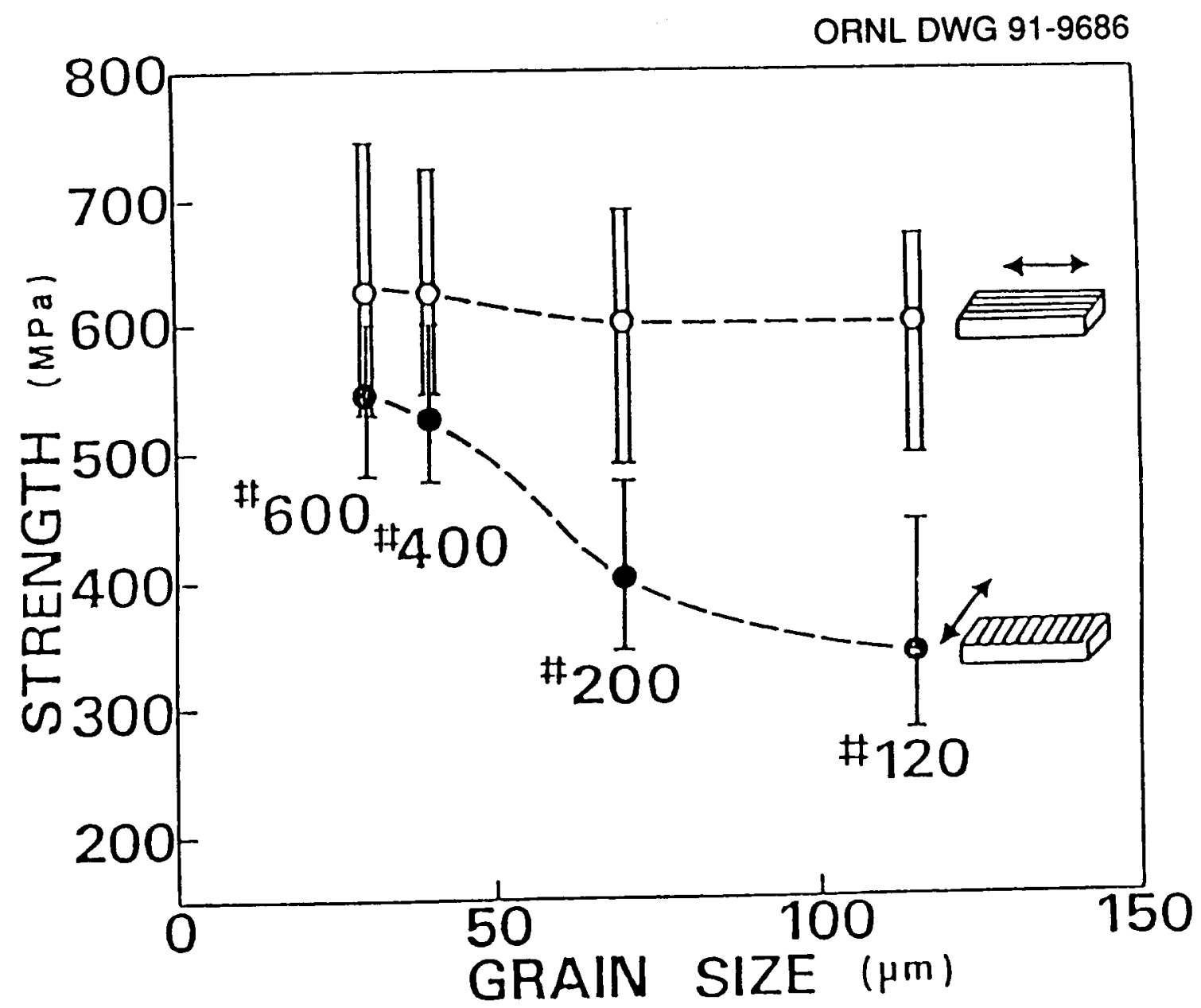

Fig. D.2. Measured fracture strength as a function of grit size. Source: J. W. Picone, "Ceramics Market Development Program," unpublished presentation at Oak Ridge Natl. Lab., Oak Ridge, Tenn., May 6, 1990. 

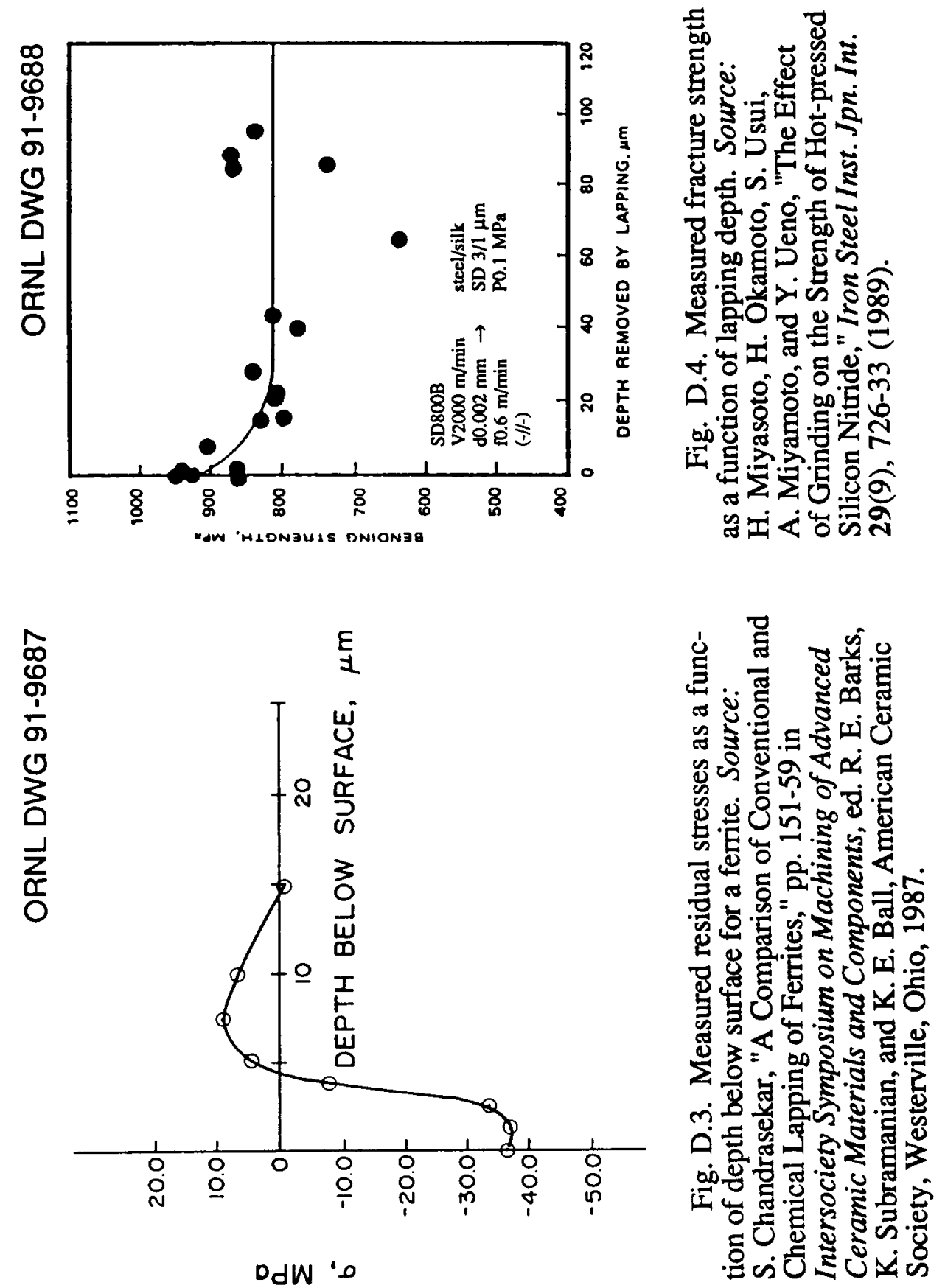
used in the machining process. ${ }^{*}, 1-3$ A rule of thumb recommended to minimize this subsurface damage is to remove a depth of material to achieve the final dimensions equal to twice the grit size of the coarsest wheel used in the grinding process. It is believed that this final depth of material contains median cracks at least as long as the coarsest grit. Figure D.5 shows the effect of this subsurface damage to a silicon nitride due to previous grinding history. ${ }^{8}$ The use of a metal-bonded, 200-grit, diamond-abrasive wheel at a very high material removal rate (MRR) of $\sim 1500 \mathrm{~mm}^{3} /(\mathrm{mm} \cdot \mathrm{min})$ produced damage to a depth of $40 \mu \mathrm{m}$ from the surface with a subsequent decrease in measured bend strength. The bending strength of the material was subsequently restored by removal of the damaged $40-\mu \mathrm{m}$ layer of material by using a resinoid-bonded, 800 -grit, diamond-abrasive wheel at a MRR of $<100 \mathrm{~mm}^{3} /(\mathrm{mm} \cdot \mathrm{min})$.

In summarizing the previous discussion, it is necessary to emphasize that the mechanisms of abrasively grinding structural ceramics have not been quantitatively determined. What appears to work for one type of ceramic is not generally applicable to all ceramics. ${ }^{10}$ However, the following guidelines might be employed: (a) reduce vibration in the grinder and work piece by employing stiff machines and highly damped grinding wheels (resinoid bonded); (b) reduce work piece chipping by employing a friable diamond and a resilient bond matrix (resin); (c) lower grinding forces and local heating, hence subsurface damage, by decreasing MRR and reducing concentrations of exposed diamond (bonded in resin); and (d) reduce localized heating and remove chip/work piece interactions by directing a clear stream of coolant precisely into the interface of the wheel/workpiece, as shown in Fig. D.6.*

\section{D.3 REFERENCES}

1. K. Subramanian, "Advanced Ceramic Components: Current Methods and Future Needs for Generation of Surfaces," pp. 10-32 in Intersociety Symposium on Machining of Advanced Ceramic Materials and Components, ed. R. E. Barks, K. Subramanian, and K. E. Ball, American Ceramic Society, Westerville, Ohio, 1987.

2. R. W. Rice and J. J. Mecholsky, Jr., "The Nature of Strength Controlling Machining Flaws in Ceramics," pp. 351-78 in The Science of Ceramic Machining and Surface Finishing II, ed. B. J. Hockey and R. W. Rice, Special Publication 562, National Bureau of Standards, U.S. Government Printing Office, Washington, D.C., 1979.

"J. W. Picone, "Ceramics Market Development Program," unpublished presentation at Oak Ridge Natl. Lab., Oak Ridge, Tenn., May 6, 1990. 
ORNL DWG 91-9689

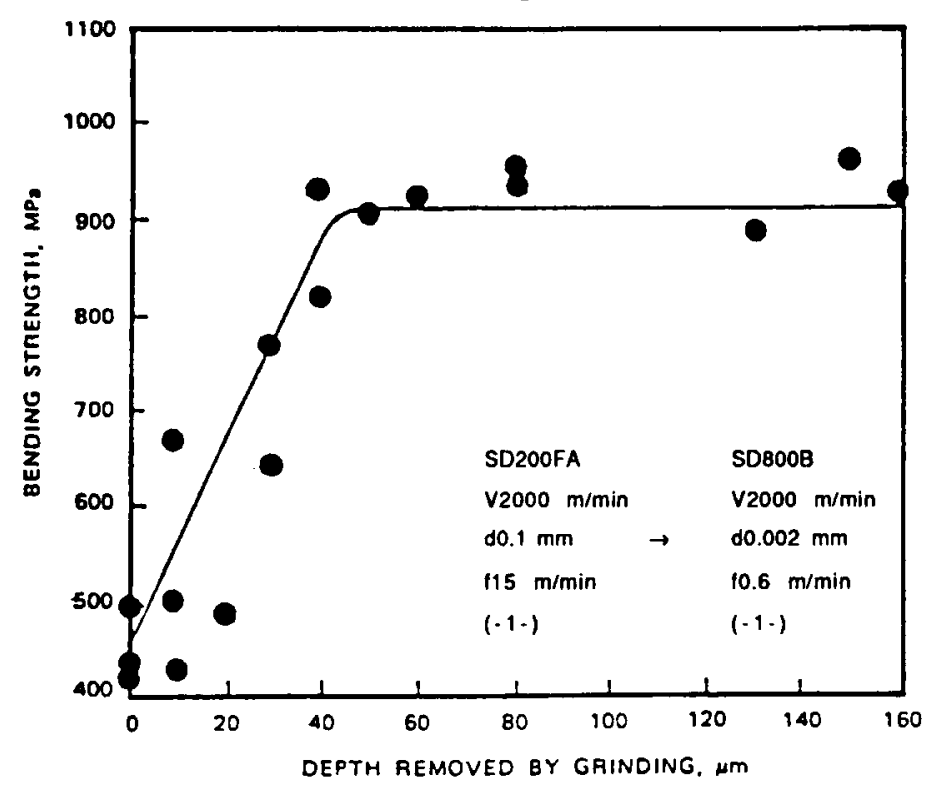

Fig. D.5. Measured fracture strengths as a function of the removed, damaged material. Source: H. Miyasoto, H. Okamoto, S. Usui, A. Miyamoto, and Y. Ueno,"The Effect of Grinding on the Strength of Hot-pressed Silicon Nitride," Iron Steel Inst. Jpn.

Int. 29(9), 726-33 (1989).

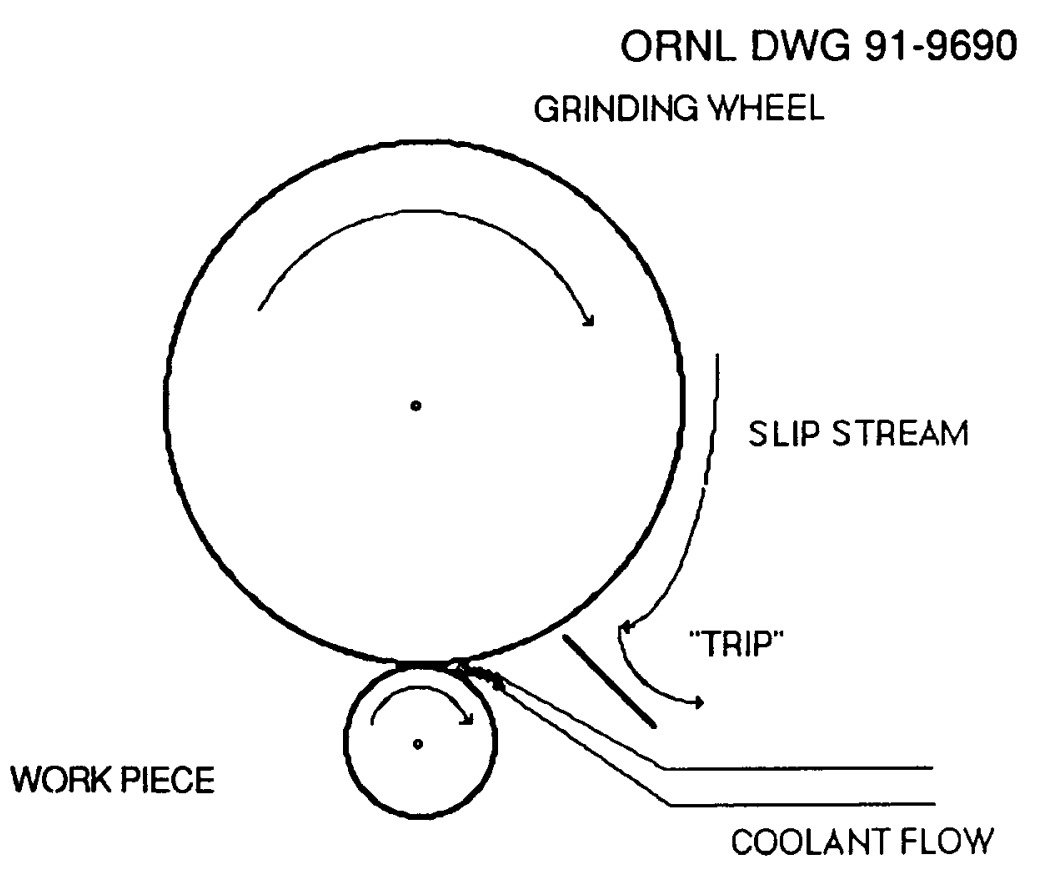

Fig. D.6. Method of tripping the air flow of rotating wheel to feed coolant directly to the wheel/specimen interface. 
3. C. C. Wu and K. R. McKinney, "The Effect of Surface Finishing on the Strength of Commercial Hot Pressed $\mathrm{Si}_{3} \mathrm{~N}_{4}$," pp. 447-81 in The Science of Ceramic Machining and Surface Finishing II, ed. B. J. Hockey and R. W. Rice, Special Publication 562, National Bureau of Standards, U.S. Government Printing Office, Washington, D.C., 1979.

4. C. A. Andersson and R. J. Bratton, "Effect of Surface Finish on the Strength of Hot Pressed Silicon Nitride," pp 463-76 in The Science of Ceramic Machining and Surface Finishing II, ed. B. J. Hockey and R. W. Rice, Special Publication 562, National Bureau of Standards, U.S. Government Printing Office, Washington, D.C., 1979.

5. H. Tominori, "Grinding of Fine Ceramics," FC Report - Bull. Fine Ceram. Soc. 1(8), (1983).

6. M. B. Thomas, R. D. West, and W. E. West, Jr., Grinding Hot Pressed Silicon Nitride For Optimum Surface Finish and Strength," THERM Incorporated Internal Publication, Ithaca, New York, 1986.

7. T. Imai, "Performance of Diamond Wheel in Grinding Silicon Nitride Ceramics," pp. 138-60 in Intersociety Symposium on Machining of Advanced Ceramic Materials and Components, ed. R. E. Barks, K. Subramanian, and K. E. Ball, American Ceramic Society, Westerville, Ohio, 1987.

8. H. Miyasoto, H. Okamoto, S. Usui, A. Miyamoto, and Y. Ueno, "The Effect of Grinding on the Strength of Hot-pressed Silicon Nitride," Iron Steel Inst. Jpn. Int. 29(9), 726-33 (1989).

9. S. Chandrasekar, "A Comparison of Conventional and Chemical Lapping of Ferrites," pp. 151-59 in Intersociety Symposium on Machining of Advanced Ceramic Materials and Components, ed. R. E. Barks, K. Subramanian, and K. E. Ball, American Ceramic Society, Westerville, Ohio, 1987.

10. E. Salje' and H. Möhlen, "Advanced Techniques in Grinding High Strength Ceramic Materials," pp. 33-49 in Intersociety Symposium on Machining of Advanced Ceramic Materials and Components, ed. R. E. Barks, K. Subramanian, and K. E. Ball, American Ceramic Society, Westerville, Ohio, 1987. 
ORNL/TM-11767

\section{INTERNAL DISTRIBUTION}

1-2. Central Research Library

3. Document Reference Section

4-5. Laboratory Records Department

6. Laboratory Records, ORNL-RC

7. ORNL Patent Section

8-10. M\&C Records Office

11. R. L. Beatty

12. P. F. Becher

13. K. W. Bowling

14. C. R. Brinkman

15. R. S. Carlsmith

16. D. F. Craig

17-21. M. F. Ferber

22. R. L. Freeny

23. B. G. Gieseke

24. M. L. Grossbeck

25. F. M. Haggag

26. L. L. Horton

27. C. R. Hubbard

28-32. M. G. Jenkins

33-37. V. T. Jenkins

38. D. R. Johnson
39. R. R. Judkins

40. J. R. Keiser

41. H. E. Kim

42. K. C. Liu

43. H. E. McCoy, Jr.

44-48. R. L. Martin

49. J. R. Mayotte

50. O. O. Omatete

51. G. M. Slaughter

52. C. O. Stevens

53. D. P. Stinton

54. R. A. Strehlow

55-59. V. J. Tennery

60. L. J. Turner

61. R. K. Williams

62. A. D. Brailsford (Consultant)

63. Y. A. Chang (Consultant)

64. H. W. Foglesong (Consultant)

65. J. J. Hren (Consultant)

66. M. L. Savitz (Consultant)

67. J. B. Wachtman, Jr. (Consultant)

\section{EXTERNAL DISTRIBUTION}

68. FRAUNHOFER-INSTITUT FUR WERKSTOFFMECHANIK IWM, Wohlerstrasse 11, D-7800 Freiburg, Germany

T. Hollstein

69. GARRETT AUXILIARY POWER DIVISION, 2739 East Washington Street, Box 5227, MS 93-772/1302-2P, Phoenix, AZ 85010

H. Fang

70. GARRETT ENGINE DIVISION, 111 S. 34th Street, P.O. Box 5217, MS 93-392/302-1, Phoenix, AZ 85010

\section{J. Hartman}

71. GTE LABORATORIES, INC., 40 Sylvan Road, Waltham, MA 02254
A. Pasto 
72. INSTRON CORPORATION, 100 Royall Street, Canton, MA 02021

D. Scanlon

73. JAPAN FINE CERAMICS CENTRE, Engineering and Mechanical Ceramics Division, 2-4-1 Mutsuno, Atsuka-ku, Nagoya 456, Japan

H. Awaji

74. LAWRENCE LIVERMORE NATIONAL LABORATORY, P.O. Box 808, MS L-338, Livermore, CA 94550

R. Lyon

75. NASA LEWIS RESEARCH CENTER, MS 49-7, 21000 Brookpark Road, Cleveland, $\mathrm{OH} 44135$

J. A. Salem

76. NEW MEXICO INSTITUTE OF MINING AND TECHNOLOGY, Department of Materials Science and Metallurgical Engineering, Socorro, NM 87801

K. K. Chawla

77. NORTON COMPANY, Advanced Ceramics, Goddard Road, Northboro, MA 01532-2527

M. Foley

78. SIEMENS AG, Dept. AFE ME AMF 23, Otto-Hahn-Ring 6, P.O. Box 830952 D-8000 Munich 83, Germany

U. Bast

79. UNIVERSITY OF DAYTON RESEARCH INSTITUTE, 300 College Park, Dayton, OH 45469-0001

N. Hecht

80-86. U. S. DOE, OFFICE OF ASSISTANT SECRETARY FOR CONSERVATION AND RENEWABLE ENERGY, Office of Transportation Technologies, Building, CE-151, 1000 Independence Avenue, Washington DC 20585

A. A. Chesnes

87. U. S. DOE, OAK RIDGE FIELD OFFICE, P. O. Box 2001, Oak Ridge, TN 37831-8600

Assistant Manager for Energy Research and Development 
88. U. S. DOE, OAK RIDGE FIELD OFFICE, OAK RIDGE NATIONAL LABORATORY, P. O. Box 2008, Oak Ridge, TN 37831-6269

E. E. Hoffman

89-98. DOE, OFFICE OF SCIENTIFIC AND TECHNICAL INFORMATION, P.O. Box 62, Oak Ridge, TN 37831

For distribution by microfiche as shown in DOE/OSTI-4500, Distribution Categories UC-332 (Ceramics/Advanced Materials) and UC-365 (High Temperature Materials). 